US Army Corps

of Engineers ${ }_{\circledast}$

Engineer Research and

Development Center
INNOVATIVE SOLUTIONS

for a safer, better world

Operational Energy Capabilities Improvement

\title{
Energy Performance Measurement and Simulation Modeling of Tactical Soft-Wall Shelters
}

Michael Deru, Eric Bonnema, Greg Barker, Ed Hancock, and Ashok Kumar
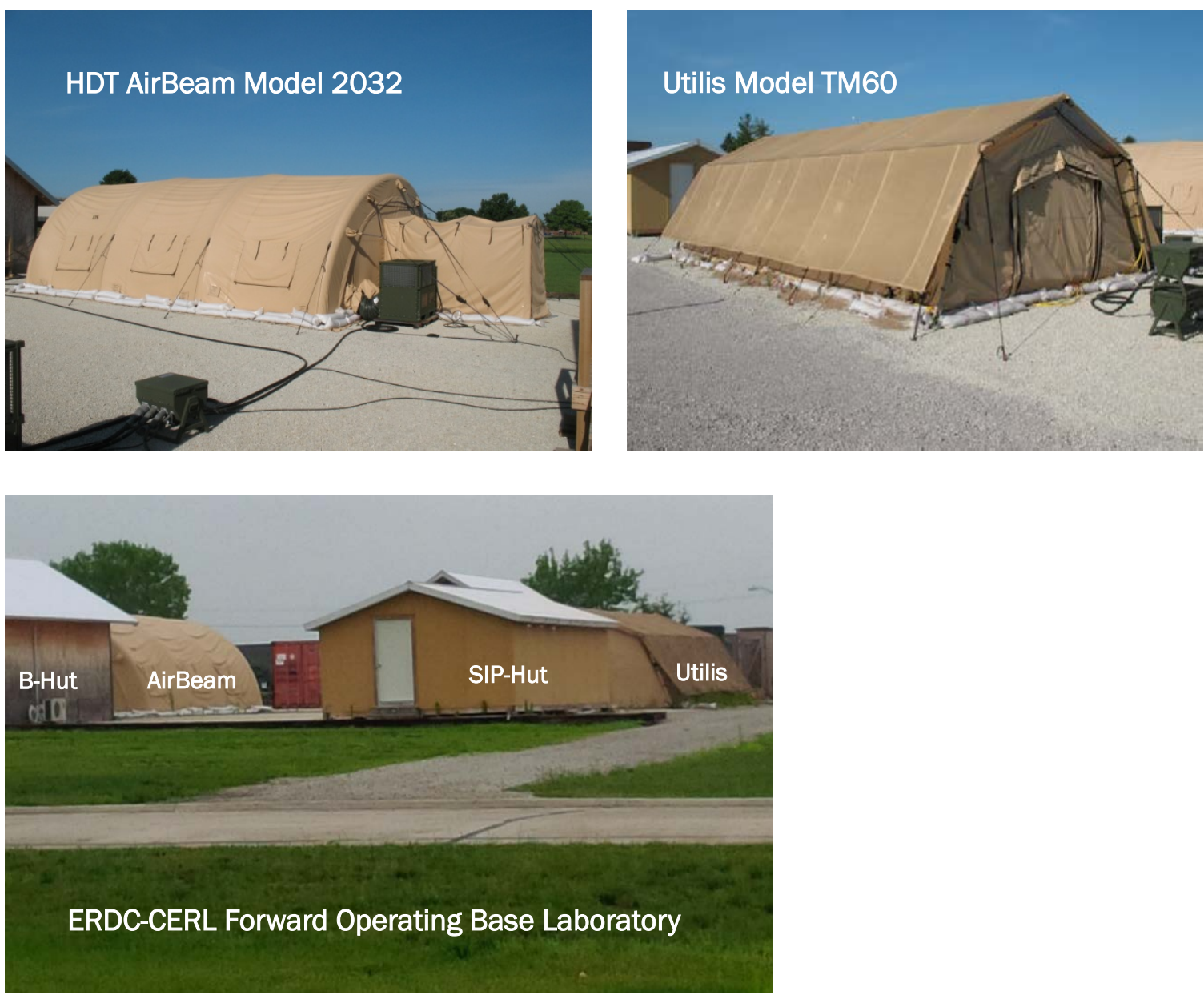

Approved for public release; distribution is unlimited. 
The U.S. Army Engineer Research and Development Center (ERDC) solves the nation's toughest engineering and environmental challenges. ERDC develops innovative solutions in civil and military engineering, geospatial sciences, water resources, and environmental sciences for the Army, the Department of Defense, civilian agencies, and our nation's public good. Find out more at www.erdc.usace.army.mil.

To search for other technical reports published by ERDC, visit the ERDC online library at http:// acwc.sdp.sirsi.net/ client/ default. 


\title{
Energy Performance Measurement and
} Simulation Modeling of Tactical Soft-Wall Shelters

\author{
Ashok Kumar \\ Construction Engineering Research Laboratory \\ U.S. Army Engineer Research and Development Center \\ 2902 Newmark Drive \\ Champaign, IL 61822 \\ Michael Deru and Eric Bonnema \\ National Renewable Energy Laboratory \\ 15013 Denver West Parkway \\ Golden, CO 80401 \\ Greg Barker and Ed Hancock \\ Mountain Energy Partnership \\ 13900 North 87th St \\ Longmont, CO 80503
}

Final report

Approved for public release; distribution is unlimited.

\footnotetext{
Prepared for Office of the Assistant Secretary of Defense 3700 Defense Pentagon Washington, DC 20301-3700

Under Project P2 5D390F, “Advanced Energy Efficient Shelter Systems for Contingency Basing and Other Applications"
} 


\section{Abstract}

Two soft-wall tactical shelters, Airbeam Series 32 and Utilis TM 60, were set up at an outdoor test facility in Champaign, IL. Each was instrumented to record energy-loss measurements during a heating and cooling season, and a standard tracer-gas technique was used to measure infiltration. These data, and thermal load assumptions for a command-operations shelter, were used as inputs to develop and calibrate shelter simulation models using the Department of Energy's EnergyPlus modeling platform. Simulations were run to validate the calibrated models, and then a series of other simulations was run using climate data from eight U.S. climate zones and a locale in Kuwait. These simulations included the application of energy-conservation accessories such as shade flies and radiant heat barriers materials.

Simulation results indicate that using either type of radiant barrier provided the best performance in cold climates; and the combination of both barriers provided the best performance in the hot climates. The shade fly provided the least savings in all simulated climates except for Panama City, FL, where it provided the highest savings. With limitations explained in the report, the models provide a useful technology for identifying energy performance trends and making comparisons between the two modeled shelters. 


\section{Contents}

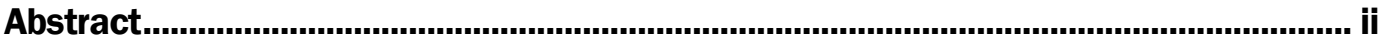

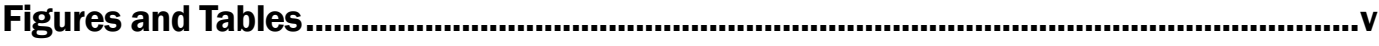

Preface

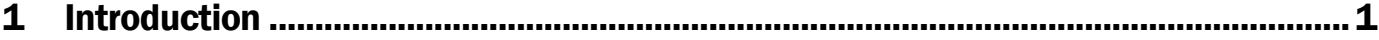

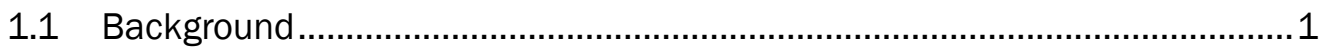

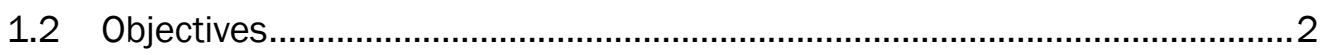

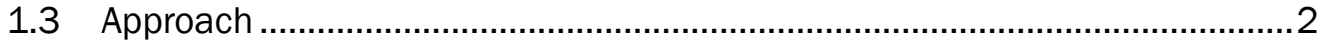

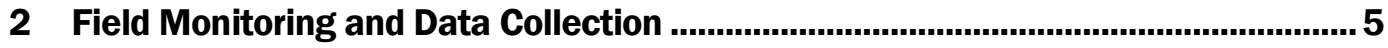

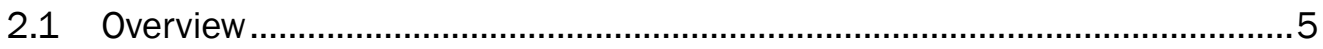

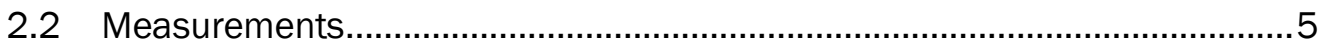

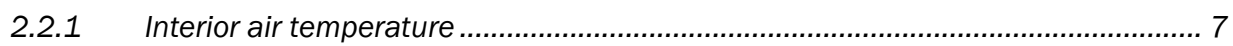

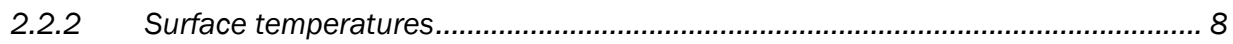

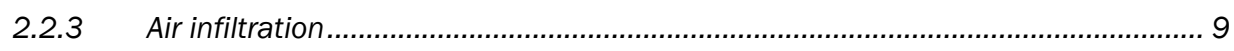

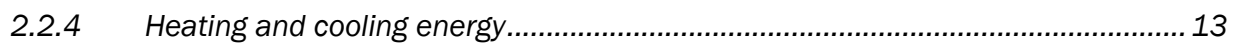

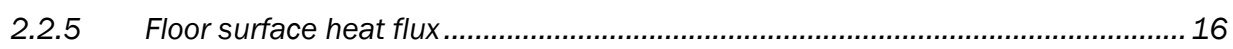

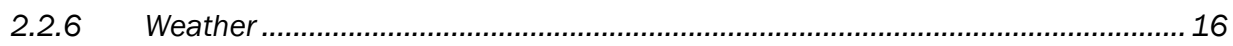

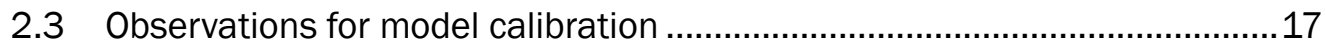

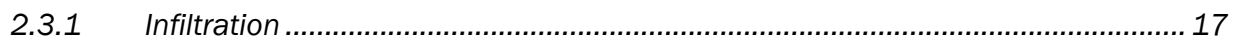

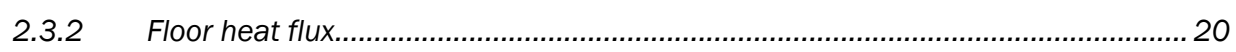

2.3.3 Observations from thermography ..................................................................... 23

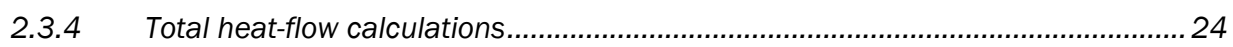

3 Model Development and Calibration .......................................................................31

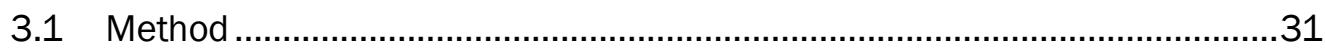

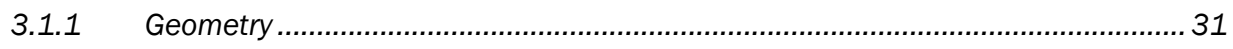

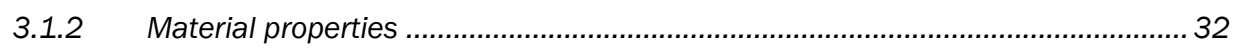

3.1.3 Shade fly thermal performance ....................................................................... 33

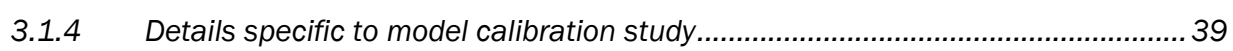

3.2 Calibration study........................................................................... 41

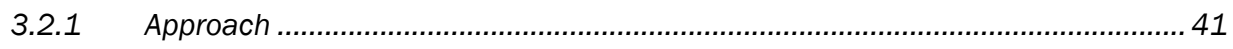

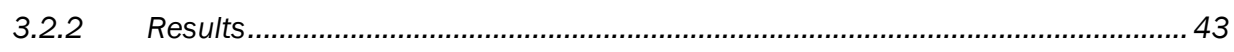

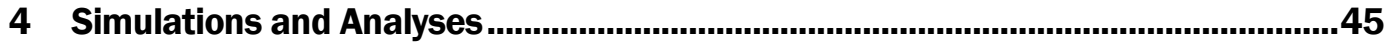

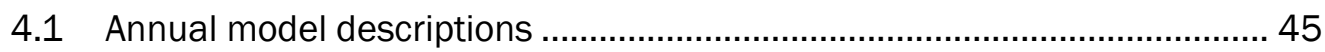

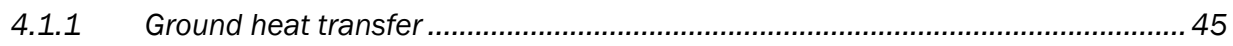

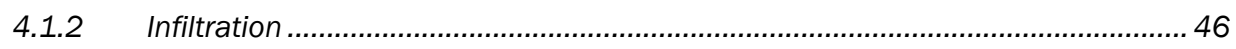

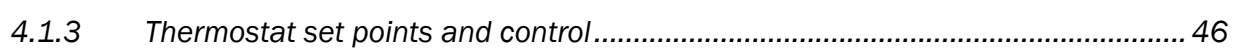

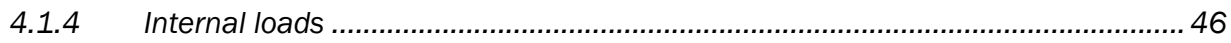




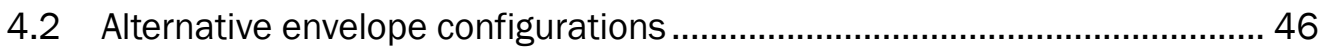

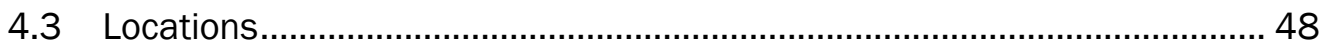

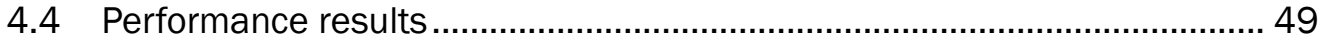

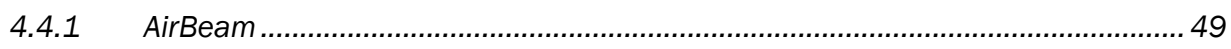

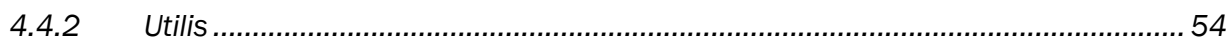

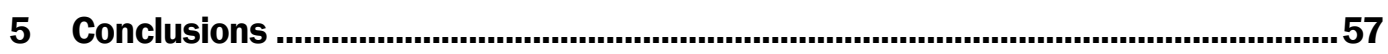

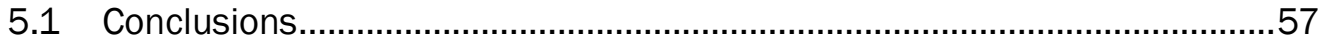

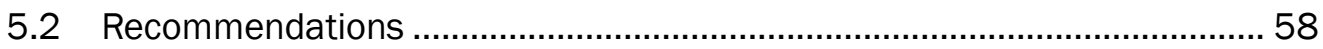

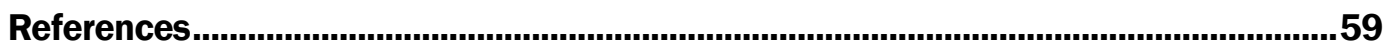

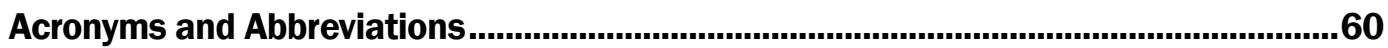

Report Documentation Page 


\section{Figures and Tables}

\section{Figures}

Figure 1. Site plan, June 2014 .....................................................................................

Figure 2. Utilis TM60 shelter. ............................................................................................... 4

Figure 3. HDT AirBeam shelter........................................................................................ 4

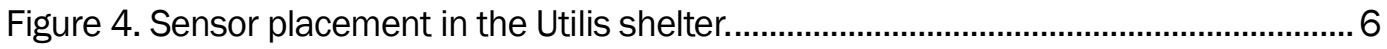

Figure 5. Sensor placement in the AirBeam shelter. ........................................................... 7

Figure 6. Aspirated temperature shield......................................................................... 8

Figure 7. IR temperature sensors, with two facing the east and west walls and two facing the floor. .................................................................................................... 9

Figure 8. Thermocouple measuring outside surface temperature, covered with a

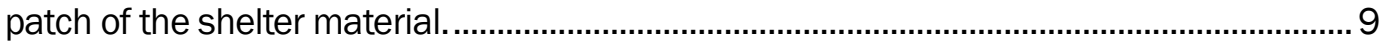

Figure 9. Utilis shelter blower-door test results. ...............................................................11

Figure 10. Blower door installed on the Utilis shelter. ........................................................1

Figure 11. Blower-door fan installed in the AirBeam shelter. .............................................12

Figure 12. AirBeam shelter blower-door test results......................................................12

Figure 13. The floor of the AirBeam shelter gradually rising during the depressurization test.

Figure 14. Temporary installation of the TrueFlow Plate for a one-time measurement of ECU air flow..............................................................................................15

Figure 15. Measurement point for return air temperature and humidity. ...........................15

Figure 16. Goodness of fit of air-change rates as a function of wind speed, wind direction, and inside/outside temperature difference for the Utilis shelter in the heating season

Figure 17. Goodness of fit of air-change rates as a function of wind speed, wind direction, and inside/outside temperature difference for the AirBeam shelter in the heating season

Figure 18. Floor heat flux for each shelter in the heating season.

Figure 19. Floor heat flux measurements in each shelter (positive value indicates

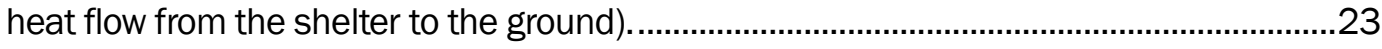

Figure 20. Infrared images of the Utilis shelter door, walls, and floor. ................................24

Figure 21. Infrared images of the AirBeam shelter door, walls, and window. ....................24

Figure 22. AirBeam floor area weighting for heat flux measurements. ................................25

Figure 23. Utilis floor area weighting for heat flux measurements....................................25

Figure 24. AirBeam winter heat flows. ..................................................................................28

Figure 25. Utilis winter heat flows. ...........................................................................29

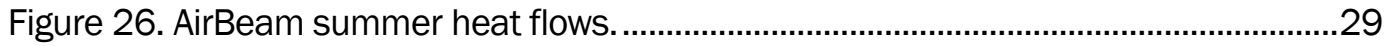

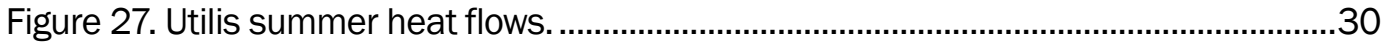




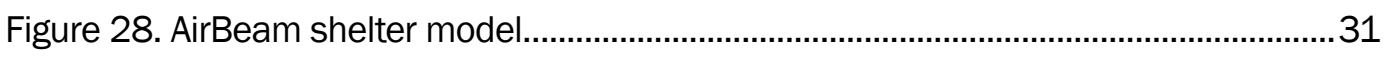

Figure 29. Utilis shelter model. ...................................................................................32

Figure 30. Thermal models for heat transfer through the shading fabric. .........................34

Figure 31. Solar transmittance as a function of beam incidence angle for the Utilis shading fabric.

Figure 32. Solar transmittance as a function of beam incidence angle for the AirBeam shading fabric.

Figure 33. Simplified thermal network showing resistances to heat flow through various paths.

Figure 34. Annual ECU energy consumption and savings for the AirBeam shelter.

Figure 35. Monthly ECU energy performance for the AirBeam shelter in Champaign, IL for the baseline (left bar) and radiant barrier (right bar) cases.

Figure 36. Monthly ECU energy performance for the AirBeam shelter in Champaign, IL for the baseline (left bar) and Thinsulate (right bar) liner cases.

Figure 37. Monthly ECU energy performance for the AirBeam shelter in Champaign, IL for the baseline (left bar) and radiant barrier and Thinsulate liner (right bar) cases.

Figure 38. Monthly ECU energy performance for the AirBeam shelter for in

Champaign, IL the baseline (left bar) and the shade fly (right bar) cases. 52

Figure 39. Annual ECU energy consumption and savings for the AirBeam shelter with the PCM liner. 54

Figure 40. Annual ECU energy consumption and savings for the Utilis shelter. .56

\section{Tables}

Table 1. Measurement points on each shelter.

Table 2. One-time measurements on each shelter (cooling season).................................... 6

Table 3. AirBeam shelter material properties for model calibration.......................................32

Table 4. Utilis shelter material properties for model calibration. .......................................33

Table 5. Coefficients for solar fraction correlations. ........................................................39

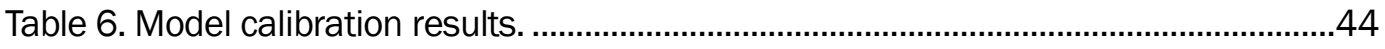

Table 7. Convection heat-transfer coefficient scaling factors ...............................................44

Table 8. Floor material properties. ...................................................................................45

Table 9. Infiltration ELA and leakage rates......................................................................46

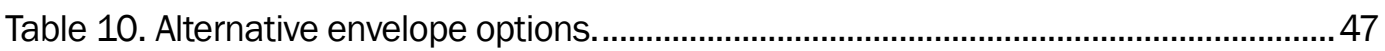

Table 11. Envelope material properties....................................................................... 47

Table 12. Temperature vs enthalpy of commercial PCM......................................................48

Table 13. U.S. climate zones for PCM modeling in AirBeam shelter..................................48

Table 14. AirBeam results for Champaign, IL.........................................................................49

Table 15. AirBeam results for Fort Devens, MA..............................................................50

Table 16. AirBeam results for Ali Al Salem, Kuwait. ............................................................50

Table 17. AirBeam ECU energy consumption......................................................................5 


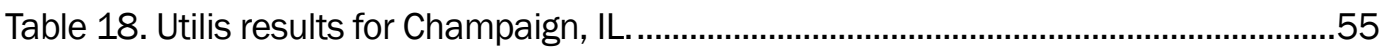

Table 19. Utilis results for Fort Devens, MA. .................................................................55

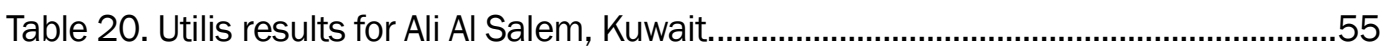




\section{Preface}

This research was conducted for the Office of the Assistant Secretary of Defense for Energy, Installations and Environment, Operational Energy Plans and Programs (OEPP) under Research, Development, Test \& Evaluation, Defense-Wide Budget Activity BA3, "Advanced Technology Development”; Program Element PE 0604055D8Z, "Operational Energy Capabilities Improvement"; Project P2 5D390F, "Advanced EnergyEfficient Shelter Systems for Contingency Basing and Other Applications (AEES)." The lead technical monitor was Clinton McAdams (Natick Soldier Research, Development and Engineering Center), and J ohn J ennings (ASD/OEPP) was the Director for Innovation in the OEPP. The ERDC Program Manager for this work was Dr. Ashok Kumar.

This investigation was led by the Materials and Structures Branch (CFM) of the Infrastructure Division (CF), U.S. Army Engineer Research and Development Center, Construction Engineering Research Laboratory (ERDCCERL). Portions of the work were performed under contract by the Department of Energy National Renewable Energy Laboratory (NREL), Golden, CO; and Mountain Energy Partnership (MEP), Longmont, CO. At the time of publication, Vicki L. Van Blaricum was Chief, CEERD-CFM; Michelle J . Hanson was Acting Chief, CEERD-CF; and Kurt Kinnevan, CEERD-CZT, was the Technical Director for Adaptive and Resilient Installations. The Deputy Director of ERDC-CERL was Dr. Kirankumar Topudurti and the Director was Dr. Ilker Adiguzel.

Lesley Herrmann, NREL, is acknowledged for providing the infrared thermography images on page 24 .

The Acting Commander of ERDC was LTCJ ohn T. Tucker III and the Director was Dr. J effery P. Holland. 


\section{Introduction}

\subsection{Background}

Current battlefield shelter systems, including tents, are not energy efficient, and often require powerful, energy-intensive heating and air conditioning units to compensate for air leakage. Expeditionary base camps consume excessive amounts of fuel that must continually be resupplied, which increases security convoy demand and diverts warfighter efforts. A 5 ton Environmental Control Unit (ECU) must be transported to the site of each small shelter. There is an urgent need to address the energy demand of forward operating bases (FOBs): for every gallon of generator fuel consumed for sheltering soldiers, seven gallons are needed to transport it there. Heating, ventilating, and air conditioning (HVAC) service comprises $75 \%$ of the electrical demand, and $50 \%$ of that energy is lost because softwalled shelters are inefficient at retaining conditioned air.

FOBs are typically powered by electric generators operating on diesel or J et Propulsion 8 (JP8) fuel. These fuels are expensive and dangerous to deliver in high-risk, hostile areas (Hartranft 2008). A large portion of the fuel requirement is used to condition the shelters, which provide little protection against extreme environmental conditions in many areas of operation. Therefore, there is a strong interest in finding materials and methods that will substantially reduce energy consumption and improve soldier comfort inside shelters.

The Engineer Research and Development Center (ERDC) is a partner in a J oint Service research program supported by the Department of Defense (DoD) Operational Energy Capital Improvement Fund (OECIF), which also includes the Air Force Civil Engineering Center (AFCEC) and is led by the U.S. Army Natick Soldier Research, Development, and Engineering Center (NSRDEC). The program supports initial demonstrations and evaluations; development projects to advance the state of the art to reduce logistics impacts and energy costs; follow-on demonstrations to optimize initial results and validate cost savings; and transition efforts to field shelters that significantly reduce battlefield fuel consumption and manpower requirements. 
The demonstration project reported here, led by the ERDC Construction Engineering Research Laboratory (ERDC-CERL), investigated the energy consumption of two soft-sided shelter systems using an outdoor ERDCCERL FOB research facility and a Department of Energy (DOE) simulation modeling technology.

\subsection{Objectives}

The objectives of this project were to develop calibrated computer models of two soft-walled military shelters using the EnergyPlus simulation modeling package, and then analyze those models to investigate the energyconsumption impacts of adding insulated liners, radiant barriers, or shading to these shelters in different climates.

\subsection{Approach}

Researchers applied data collection and monitoring methods developed from research on conventional buildings to use in calibrating energy-use models for two types of soft-sided military shelters: the HDT AirBeam 2032 (HDT Global, Solon, OH) and the Utilis TM60 (Utilis USA, Fort Watson Beach, FL). This report describes the process of instrumenting and monitoring one shelter of each type set up at the ERDC-CERL Forward Operating Base Laboratory (EFOB-L), Champaign, IL, to collect data for input to calibrated baseline shelter models developed with the energysimulation model EnergyPlus, Version 8.0 (DOE 2014a).

The baseline EnergyPlus models were modified and analyzed to investigate how energy performance would be affected upon application of various energy-enhancing accessories such as an interior liner, a radiant-heattransfer barrier, or a shade fly. These modifications were modeled in four different climates. Also, the baseline energy model for the Airbeam shelter was modified to investigate the performance of a phase-change material (PCM) liner in DOE climate zones 1-8.

The two shelters were set up at the ERDC-CERL Forward Operating Base Laboratory (EFOB-L) facilities in Champaign, IL. (The facility also includes three hard-sided shelters that are the subjects of a separate study.) Field monitoring of the shelters was performed in March and J une of 2014 for cold- and hot-weather testing, respectively. The layout of the shelters is shown in 
Figure 1. The shading impact of the B-huts was included in the energy modeling of the soft-sided shelters.

Figure 1. Site plan, June 2014.

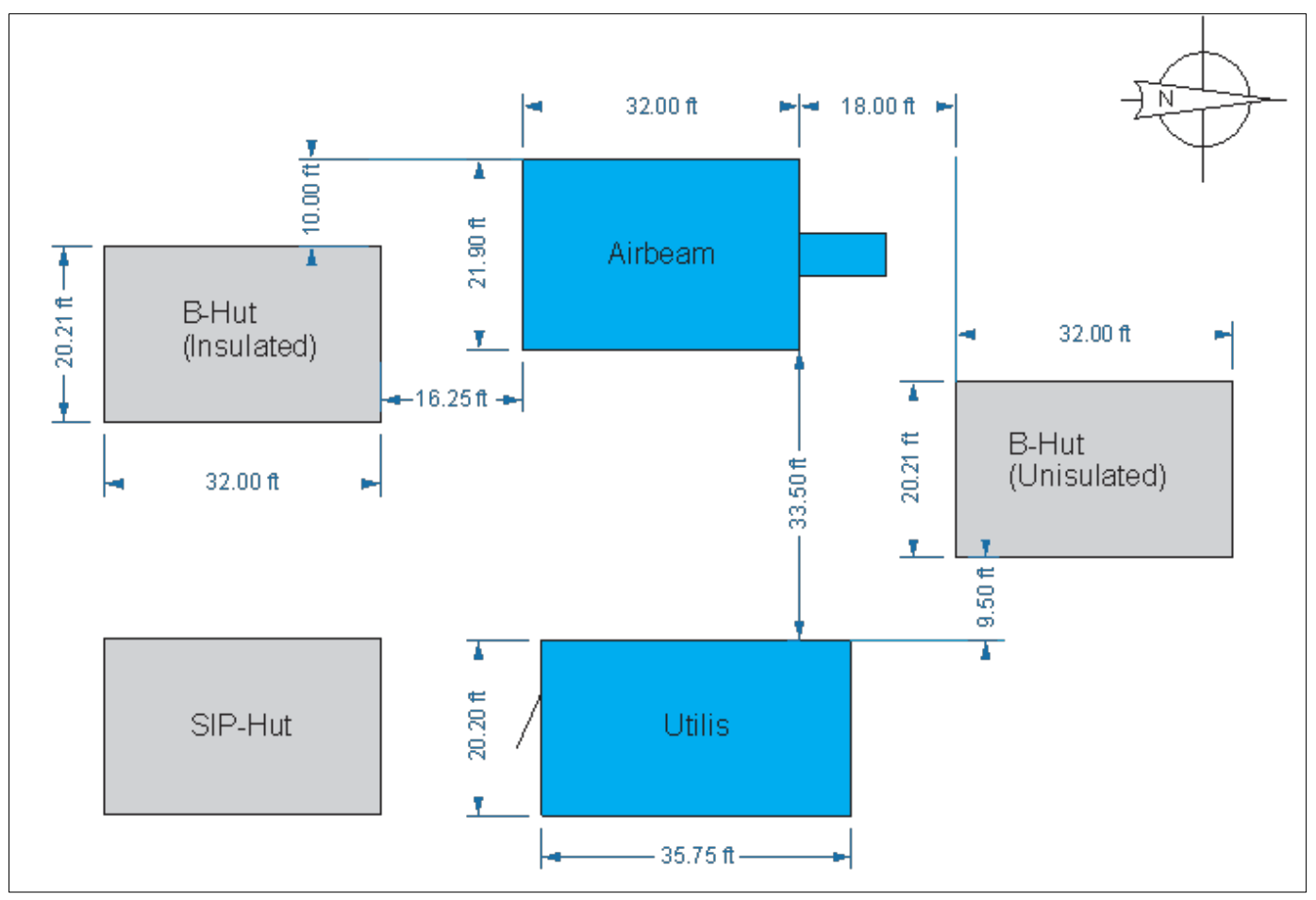

Note: the Structurally Insulated Panel Hut (SIP-Hut) was not in place during the March 2014 tests.

The Utilis TM60 is $34 \mathrm{ft}$ by $19 \mathrm{ft}$ ( $10.4 \mathrm{~m}$ by $5.8 \mathrm{~m})$ by $9 \mathrm{ft}$ high $(2.7 \mathrm{~m})$, with area of $650 \mathrm{ft}^{2}\left(60 \mathrm{~m}^{2}\right)$. It is designed for extreme conditions, and can be used for various purposes such as command and control centers, billeting, and medical (Utilis 2014). The shelter, as tested, had a Thinsulate ${ }^{\mathrm{TM}^{*}}$ liner and a mesh shade fly. Pictures of the TM60 shelter with the mesh shade fly set up at the EFOB-L are shown in Figure 2.

* Thinsulate is a trademark of 3M, Maplewood, MN. 
Figure 2. Utilis TM60 shelter.
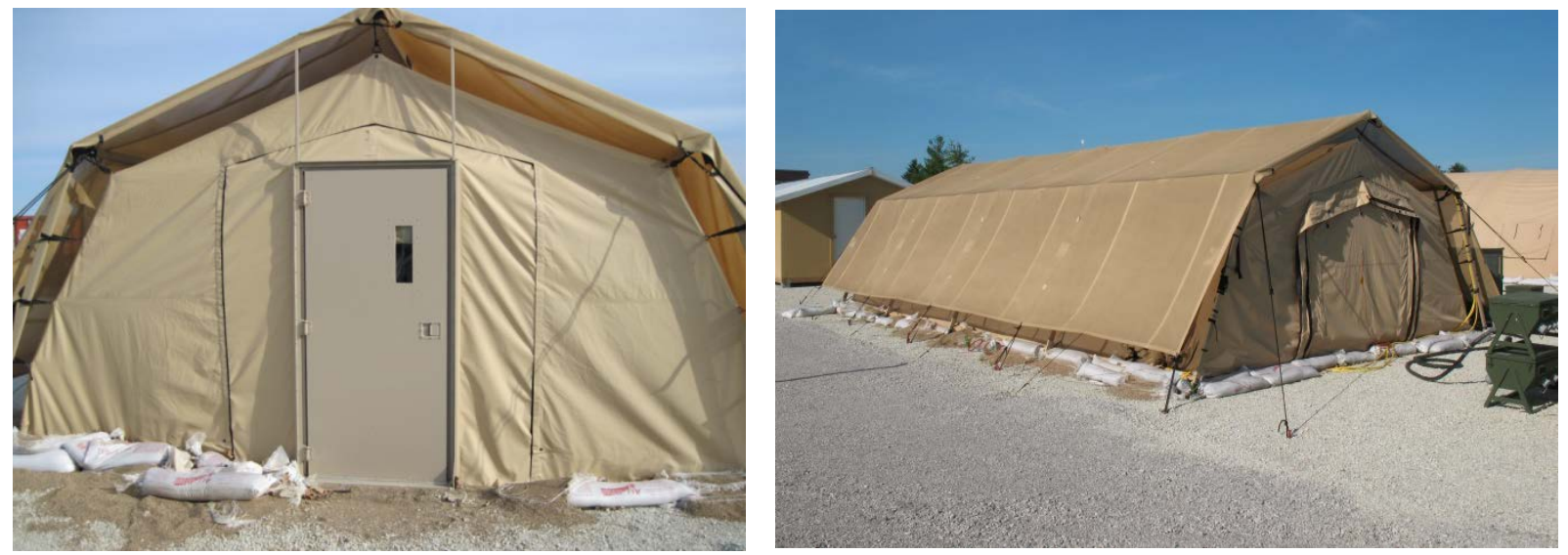

The HDT AirBeam 2032 shelter measures $20 \mathrm{ft}$ by $32 \mathrm{ft}(6.1 \mathrm{~m}$ by $9.8 \mathrm{~m})$ by $11 \mathrm{ft}$ high (3.35 m), with a usable area of $640 \mathrm{ft}^{2}\left(59.5 \mathrm{~m}^{2}\right)$ (HDT 2010). The pressurized "air beam" in this shelter provides a wide, unobstructed space that can be used for command and control space, maintenance activities, or other purposes. The shelter, as tested, had a standard interior liner and no energy-efficiency features except a vestibule. Images of the AirBeam shelter with vestibule at ERDC-CERL are shown in Figure 3.

Figure 3. HDT AirBeam shelter.
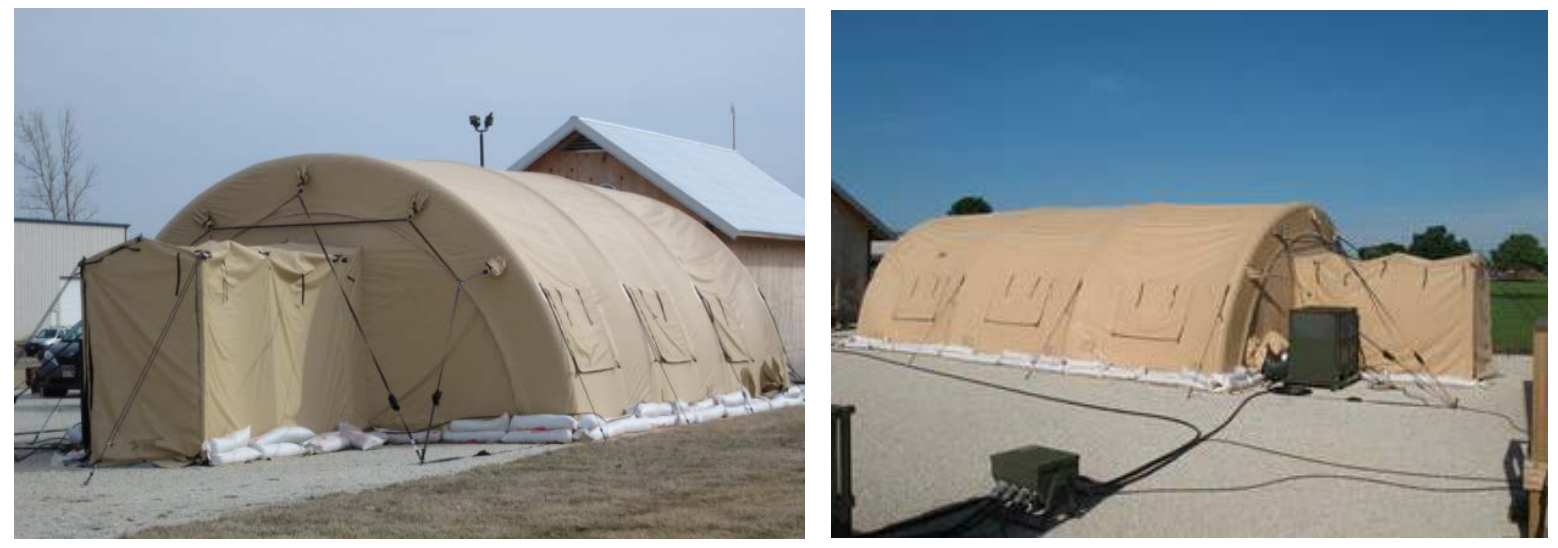

Each shelter was conditioned with a 60,000 Btu Improved Environmental Control Unit (IECU) from DRS Technologies, Florence, KY. This unit is rated at $60,000 \mathrm{Btu} / \mathrm{h}$ cooling capacity and 30,000 Btu/h heating capacity at $125^{\circ} \mathrm{F}\left(52^{\circ} \mathrm{C}\right)$ dry bulb (DB) ambient and $90^{\circ} \mathrm{F}\left(32^{\circ} \mathrm{C}\right) \mathrm{DB}$, and $75^{\circ} \mathrm{F}$ $\left(24^{\circ} \mathrm{C}\right)$ wet bulb indoor temperatures. It is rated at a 5.8 energy-efficiency ratio at these conditions. The IECUs were only used in the summer cooling testing. Electric resistance heaters were used during the winter testing. 


\section{Field Monitoring and Data Collection}

\subsection{Overview}

The general approach to making measurements for the purpose of calibrating a simulation model is to simplify the system to be calibrated and force that system to experience a large but realistic range of conditions that affect the behavior of the system. In this case the system is a softwalled shelter, excluding the ground upon which it sits. In order to test the shelters over a wide range of operating conditions each shelter was tested in a heating and a cooling season (March and J une, respectively). The tests consisted simply of controlling the interior air temperature of each shelter to a nearly constant value by adding heat (heating season) or removing heat (cooling season) for a minimum of 24 hours, continuously measuring the total amount of heat added to or removed from the shelter. These energy-flow measurements were then used along with weather, an extensive temperature network, and other measurements to calibrate the energy simulation models for the heating and cooling modes of operation.

Infiltration and ground heat-transfer energy flows are particularly difficult to simulate accurately in buildings, and even more so in soft-walled shelters. For calibration purposes, these heat flows were measured directly and served as known inputs to the calibration process. Detailed measurements were then used to inform accepted models for infiltration and ground heat transfer for annual energy simulations. This approach allows for the most accurate calibration feasible given the constraints of the problem and the need for a reasonably accurate simulation model If more precise predictions of energy consumption and comfort for soft-walled shelters were required, additional research on infiltration and ground heat transfer from these shelters would be needed for model development.

\subsection{Measurements}

Monitoring plans were developed for the heating season and cooling season tests. The measurement points on each shelter are specified in Table 1 and Table 2. The layout of the sensors in the shelters for the cooling season test is shown in Figure 4 and Figure 5. The sensor placement for the heating season tests was the same except for the heat flux transducers (HFTs) on the floor (which can be seen in sec 2.3.4.1, Figure 22 and Figure 23). 
Table 1. Measurement points on each shelter.

\begin{tabular}{|l|l|c|}
\hline Measurement & Instrument & Quantity \\
\hline Outside fabric surface temperature & Type T Thermocouple & 6 \\
\hline Inside fabric surface temperature & Type T Thermocouple & 6 \\
& Omega IR Temperature Sensor & 4 \\
\hline Inside floor surface temperature & Type T Thermocouple & 2 \\
& Omega IR Temperature Sensor & 2 \\
\hline Heat flux at floor & Hukseflux HFP03 heat flux transducer & 3 \\
\hline Total electrical energy to interior of shelter & Continental Controls Watt Node & 1 \\
\hline Total electrical energy to ECU * & Continental Controls Watt Node & 1 \\
\hline ECU supply air temperature \& humidity * & Vaisala HMP 50 & 1 \\
\hline ECU return air temperature \& humidity * & Vaisala HMP 50 & 1 \\
\hline
\end{tabular}

*Cooling-season tests only

Table 2. One-time measurements on each shelter (cooling season).

\begin{tabular}{|l|c|c|c|c|}
\hline \multirow{2}{*}{ Description } & Shelter & Symbol & \multicolumn{2}{|c|}{ Measurement } \\
\hline \multirow{2}{*}{ ECU air volume flow rate } & Utilis & $F_{\mathrm{v}}$ & $42.04 \mathrm{~m}^{3} / \mathrm{min}$ & $1484.7 \mathrm{cfm}$ \\
\cline { 2 - 5 } & AirBeam & $F_{\mathrm{v}}$ & $40.43 \mathrm{~m}^{3} / \mathrm{min}$ & $1427.7 \mathrm{cfm}$ \\
\hline \multirow{2}{*}{$\begin{array}{l}\text { Equivalent Leakage } \\
\text { Area }\end{array}$} & Utilis & ELA & $264 \mathrm{~cm}^{2}$ & $41 \mathrm{in}^{2}$ \\
\cline { 2 - 5 } & AirBeam & ELA & $466 \mathrm{~cm}^{2}$ & $72 \mathrm{in}^{2}$ \\
\hline
\end{tabular}

Figure 4. Sensor placement in the Utilis shelter.

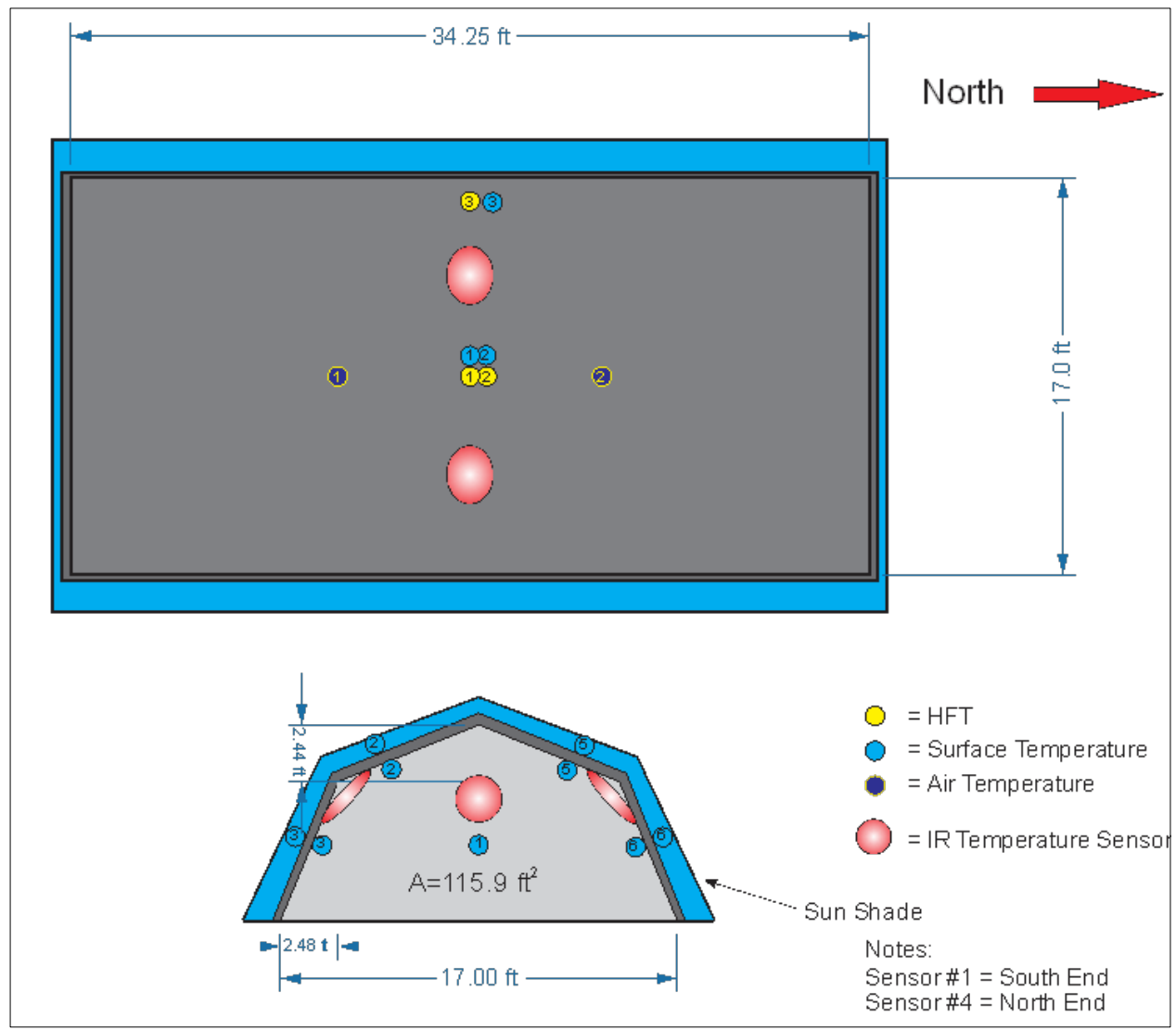


Figure 5. Sensor placement in the AirBeam shelter.

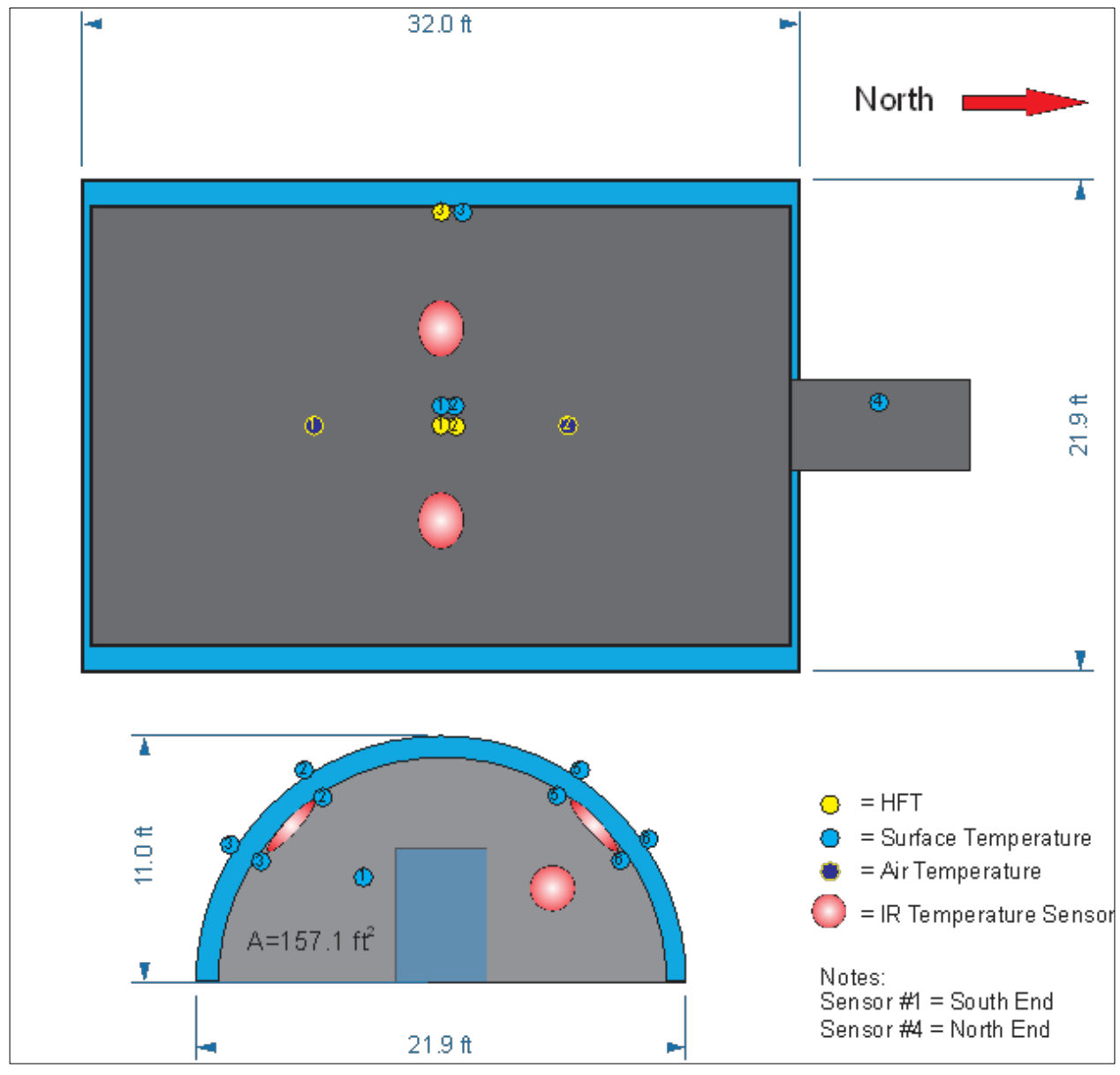

\subsubsection{Interior air temperature}

Interior dry-bulb temperature was measured with thermocouples enclosed in mechanically aspirated radiation shields, shown in Figure 6. The small fan blows air across the sensor, greatly increasing the convection heattransfer coefficient and reducing the effects of thermal radiation on the sensor. An aspirated radiation shield improves the accuracy of air temperature measurement in an environment where the temperatures of the surrounding surfaces (wall, roof, and floor) are markedly different from the air temperature. The interior dry-bulb temperature was measured at two points in each shelter approximately $4 \mathrm{ft}$ (1.2 $\mathrm{m})$ above the floor, located one-third of the distance from each end of the shelter and centered between the long sides of the shelter. The positions of the sensors in the two shelters are shown in Figure 4 and Figure 5. 
Figure 6. Aspirated temperature shield.

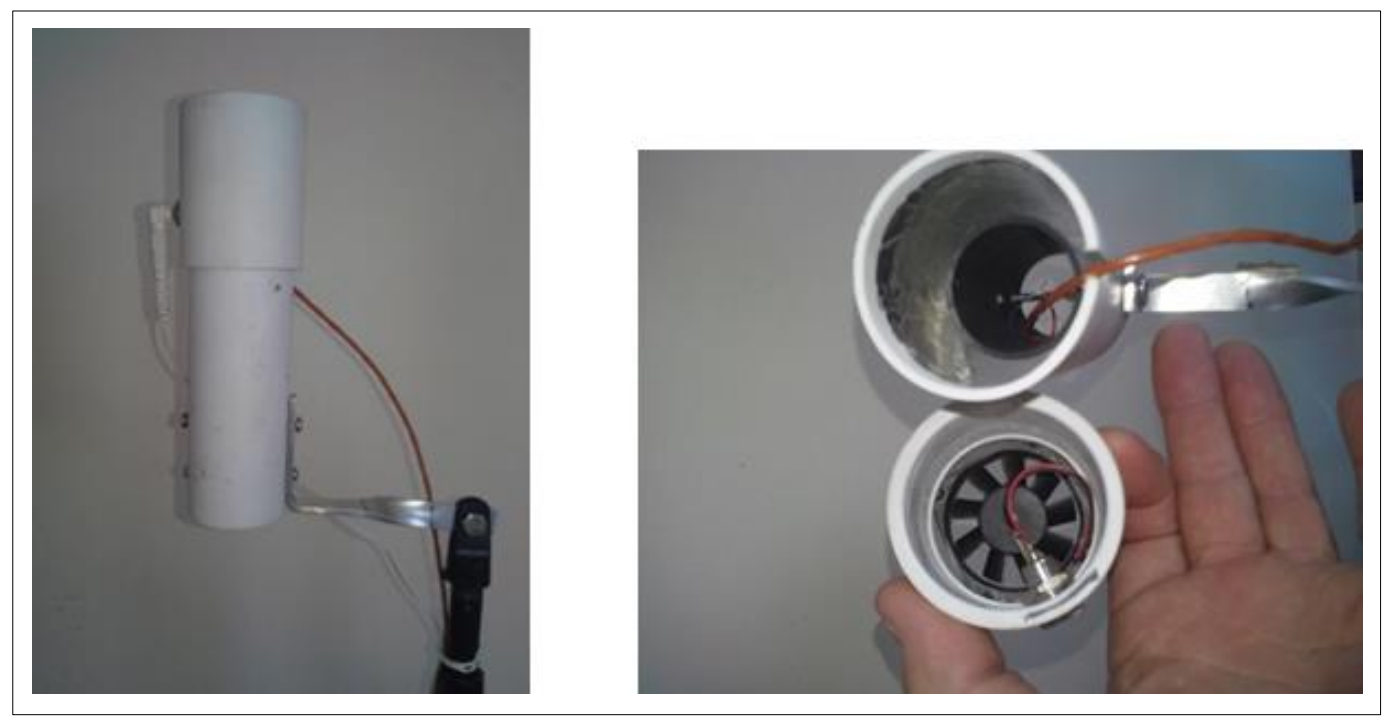

\subsubsection{Surface temperatures}

Each shelter has an inner and outer fabric layer. These layers offer very little thermal resistance, and the heat transfer between the inside and outside of the shelters is dominated by convection and radiation at the surface of each layer. We placed thermocouples in pairs (inner and outer surface) on each of the four sides of the shelters; and on each of the two sloped roof surfaces of the Utilis shelter and both sides of the semicircular crosssection of the AirBeam shelter. Each thermocouple was attached to its respective surface by adding a small amount of thermally-conductive grease to the thermocouple bead and taping the bead (plus 6 inches of lead wire) using 1 mil thick polyester tape with a silicone adhesive. The thermocouples on exterior surfaces were covered with a patch of the shelter material to provide the same radiative heat exchange as the shelter surface. These surface temperature measurements were later compared to the surface temperatures predicted by the simulation model as a way of understanding differences between the measured and modeled thermal performance. We also placed two thermocouples on the top surface of the floor (or insulation during the cooling season tests) in each shelter, in addition to two infrared temperature sensors pointed at the east and west areas of the floor, in order to obtain an approximation of floor surface temperature. 
Figure 7. IR temperature sensors, with two facing the east and west walls and two facing the floor.

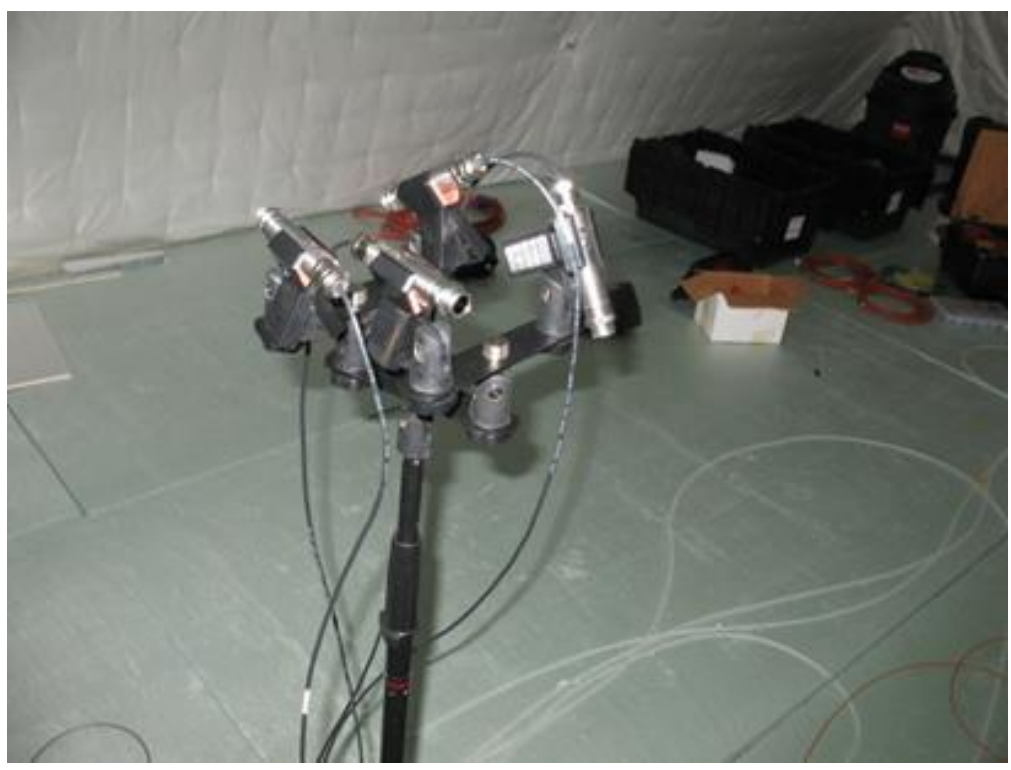

Figure 8. Thermocouple measuring outside surface temperature, covered with a patch of the shelter material.

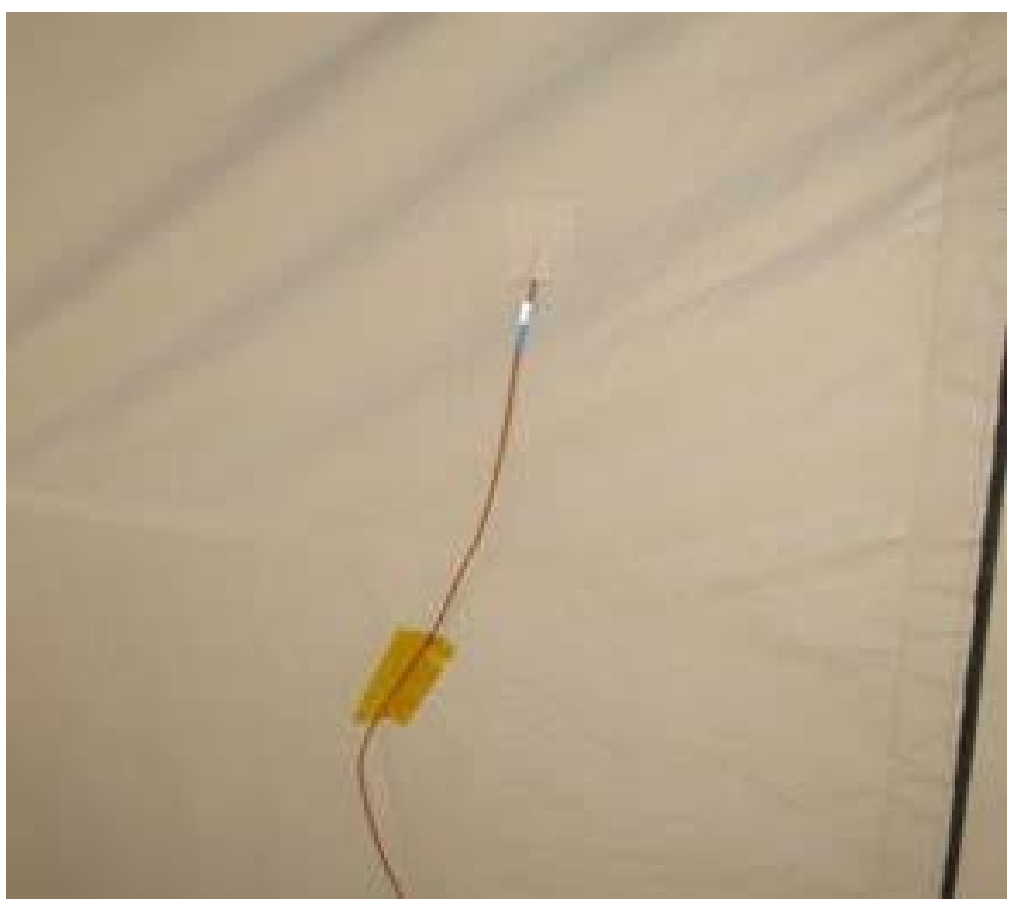

\subsubsection{Air infiltration}

Infiltration - air exchange between the inside and outside of the shelter-is a potentially significant portion of the total heat transfer from a shelter, and it is difficult to predict through simulation without measurements to calibrate the models. The infiltration rate was measured directly during 
the testing period using a tracer gas technique that introduces a small amount of sulfur hexafluoride $\left(\mathrm{SF}_{6}\right)$ into the shelter and measures its concentration every five minutes. The rate of decay in the concentration was used to calculate the rate of air infiltration in the shelter. This measured infiltration rate served as a known input to the simulation model during the calibration period. However, an improved model of the infiltration as a function of the driving functions (wind speed, wind direction, and inside/ outside temperature difference) is needed for better predictions of the infiltration during the annual simulations.

For simple, single-zone buildings, EnergyPlus estimates the infiltration with an approach based on the Sherman-Grimsrud model (DOE 2014b), as shown in Equation 1. Time-dependent inputs to the model include wind speed and inside/ outside temperature difference, while constants affecting the prediction include the equivalent leakage area (ELA) and coefficients for the temperature and wind-speed terms. The schedule multiplier can be used to model different modes of operation that affect the infiltration level.

$$
\text { Infiltration }=F_{s c h} \frac{E L A}{1000} \sqrt{\left(C_{s} \cdot \Delta T+C_{w} \cdot V_{w}^{2}\right)}
$$

where

$$
\begin{aligned}
\mathrm{F}_{\text {sch }} & =\text { scheduled fractional multiplier } \\
\mathrm{ELA} & =\text { equivalent leakage area at } 4 \mathrm{~Pa}\left[\mathrm{~cm}^{2}\right] \\
\Delta T & =\text { average inside-outside temperature }\left[{ }^{\circ} \mathrm{C}\right] \\
\mathrm{V}_{\mathrm{w}} & =\text { average wind speed }[\mathrm{m} / \mathrm{s}] \\
\mathrm{C}_{\mathrm{s}} & =\text { stack or temperature coefficient }\left[(\mathrm{L} / \mathrm{s})^{2} /\left(\mathrm{cm}^{4} \cdot \mathrm{K}\right)\right] \\
\mathrm{C}_{\mathrm{w}} & =\text { wind pressure coefficient }\left[(\mathrm{L} / \mathrm{s})^{2} /\left(\mathrm{cm}^{4} \cdot(\mathrm{m} / \mathrm{s})^{2}\right)\right]
\end{aligned}
$$

The ELA is most commonly measured by performing a blower-door test on the building, where the blower is used to either pressurize or depressurize the building over a range of flow rates, resulting in a range of inside/ outside pressure differences. The flow versus pressure difference curve is best-fit to the form

$$
F_{v}=C \cdot \Delta P^{n}
$$

where

$$
\begin{aligned}
\mathrm{F}_{\mathrm{v}} & =\text { volume flow rate } \\
\Delta P & =\text { inside-outside pressure difference }
\end{aligned}
$$


$\mathrm{C}, \mathrm{n}=$ constants derived from a regression of the data

The blower-door fan was installed in the rigid doorway of the Utilis shelter as shown in Figure 10, and pressurization tests were performed over a range of 15 - $35 \mathrm{~Pa}$. Blower-door tests in buildings are performed up to 50 $\mathrm{Pa}$, but we were concerned that the shelter might be damaged under too much pressure (although a 50 Pa pressure differential can certainly be induced by a strong wind). The resulting flow-rate curve is shown in Figure 9 , and the ELA was determined to be $41 \mathrm{in}^{2}\left(264 \mathrm{~cm}^{2}\right)$.

Figure 9. Utilis shelter blower-door test results.

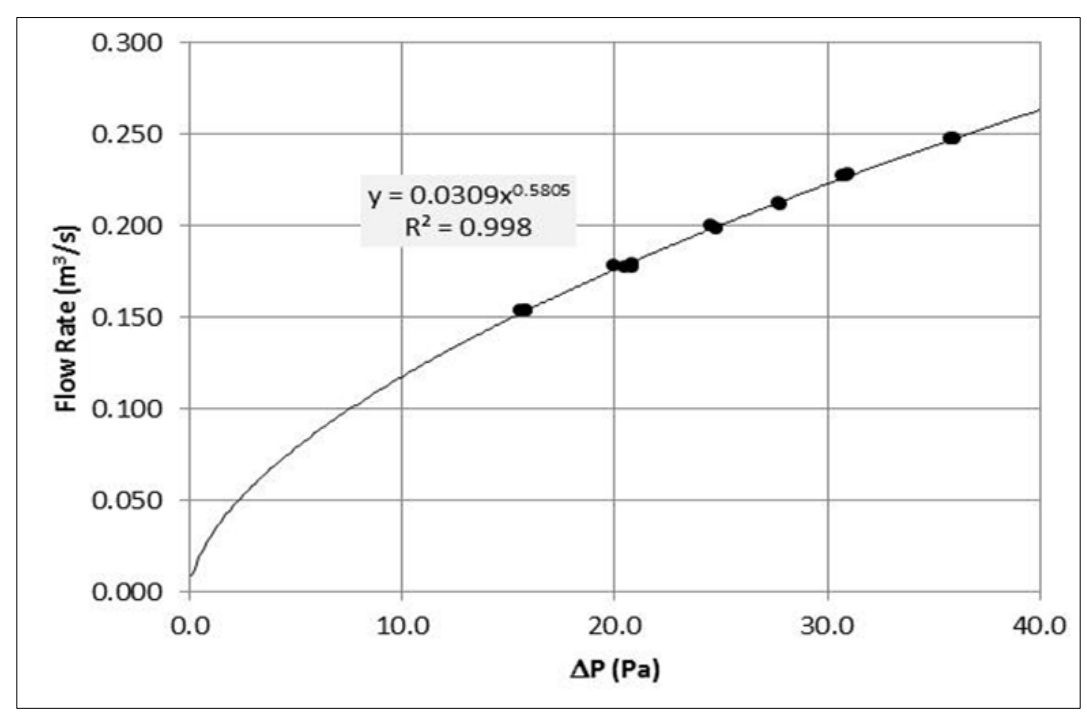

Figure 10. Blower door installed on the Utilis shelter.

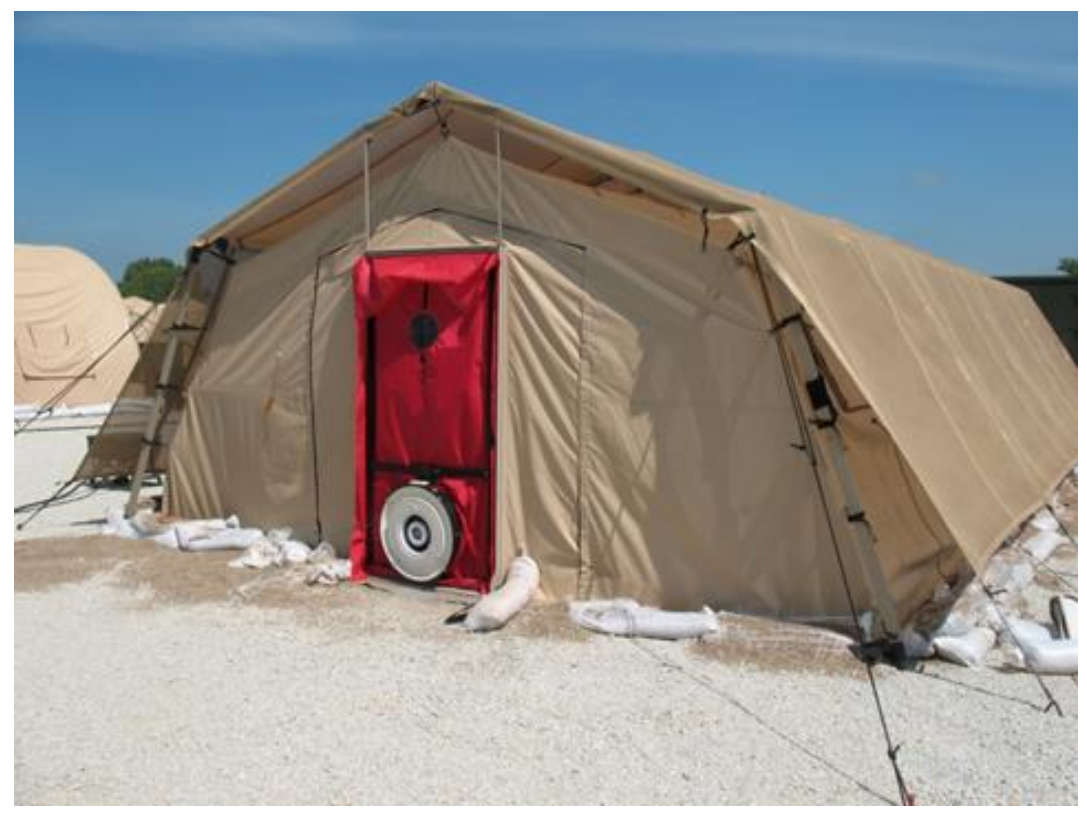


The AirBeam shelter does not have a rigid doorway to mount the blowerdoor fan, so we created a frame for the fan out of polystyrene insulating board and taped it into the south doorway as shown in Figure 11. On the AirBeam shelter we completed both pressurization and depressurization tests from $10-30 \mathrm{~Pa}$. The results of the two tests are shown in Figure 12, and the ELA from the pressurization tests was determined to be $72 \mathrm{in}^{2}$ $\left(466 \mathrm{~cm}^{2}\right)$.

Figure 11. Blower-door fan installed in the AirBeam shelter.

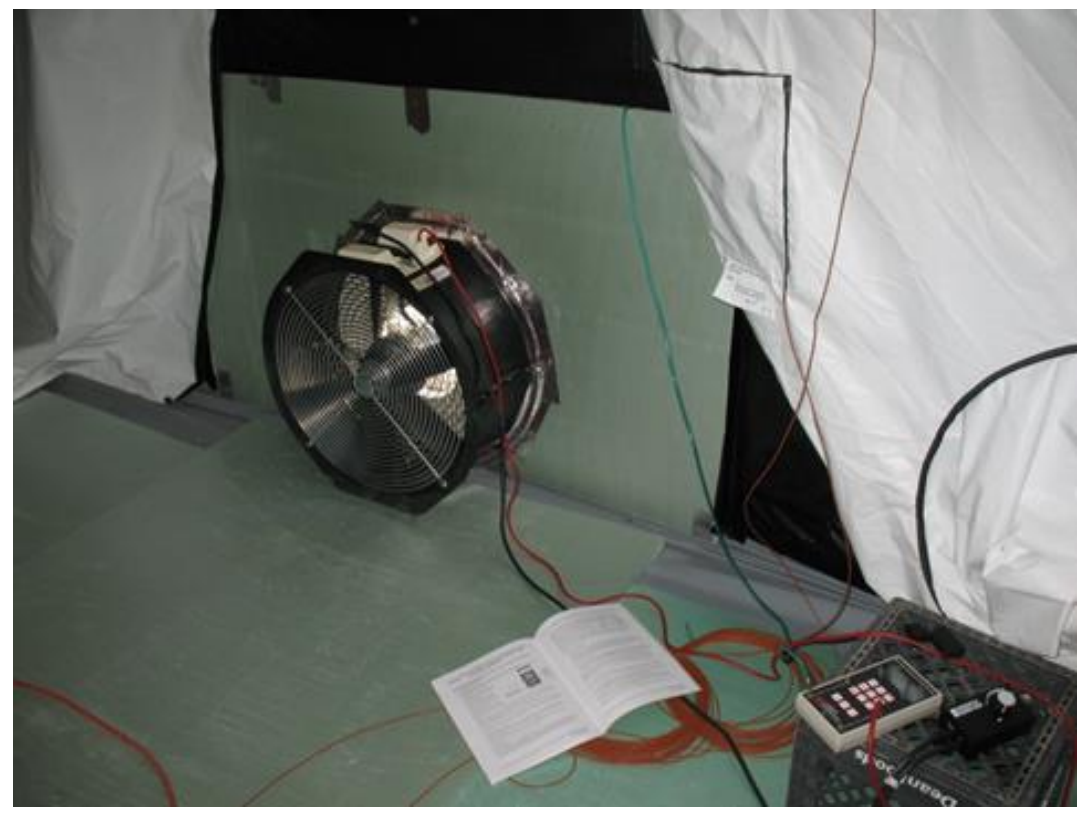

Figure 12. AirBeam shelter blower-door test results.

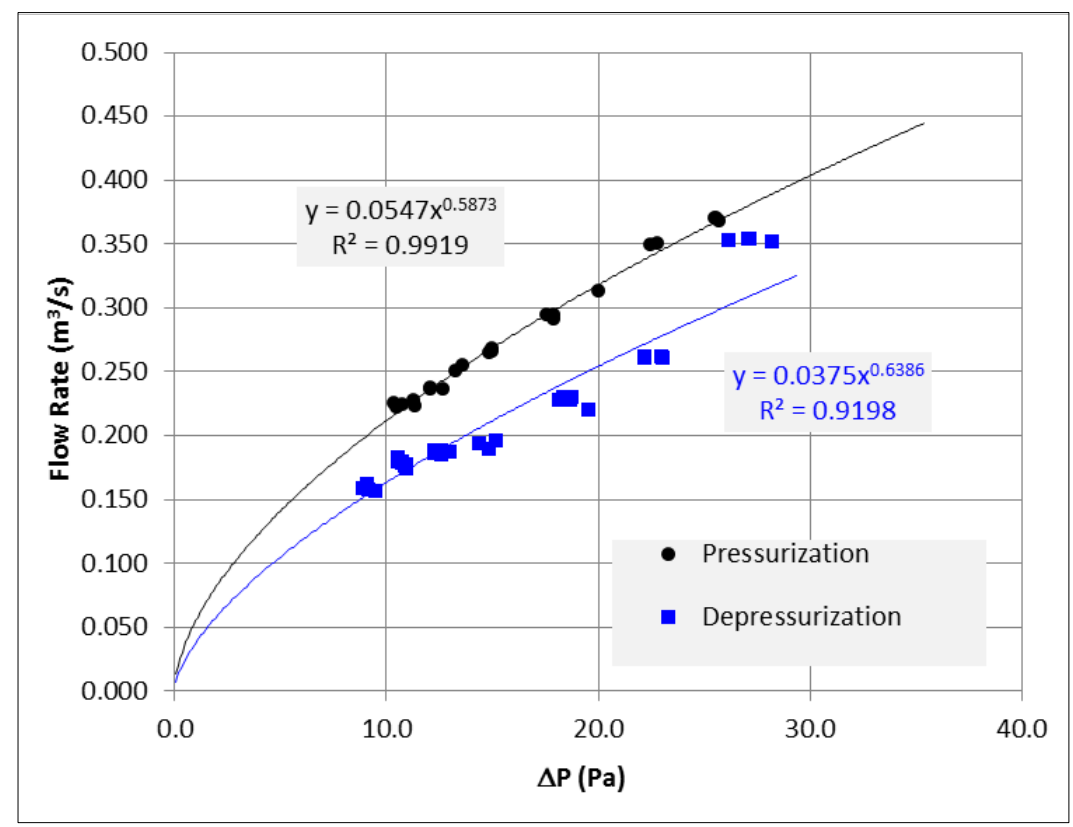


The equation fit for the depressurization tests in Figure 12 is not as good as for the pressurization tests, especially the three points at the highest pressures. We believe that this occurred because the conditions were not at a steady state while the measurements were being taken; in fact, we observed that the floor of the shelter was gradually rising while the shelter was under negative pressure (see Figure 13). When inflating, the shelter comes to a steady state fairly quickly (on the order of 30 seconds); however, we never saw it come to a steady state while deflating because the volume of the shelter was still changing. For comparison, a blower-door test on a rigid structure quickly comes to a steady state condition.

Figure 13. The floor of the AirBeam shelter gradually rising during the depressurization test.
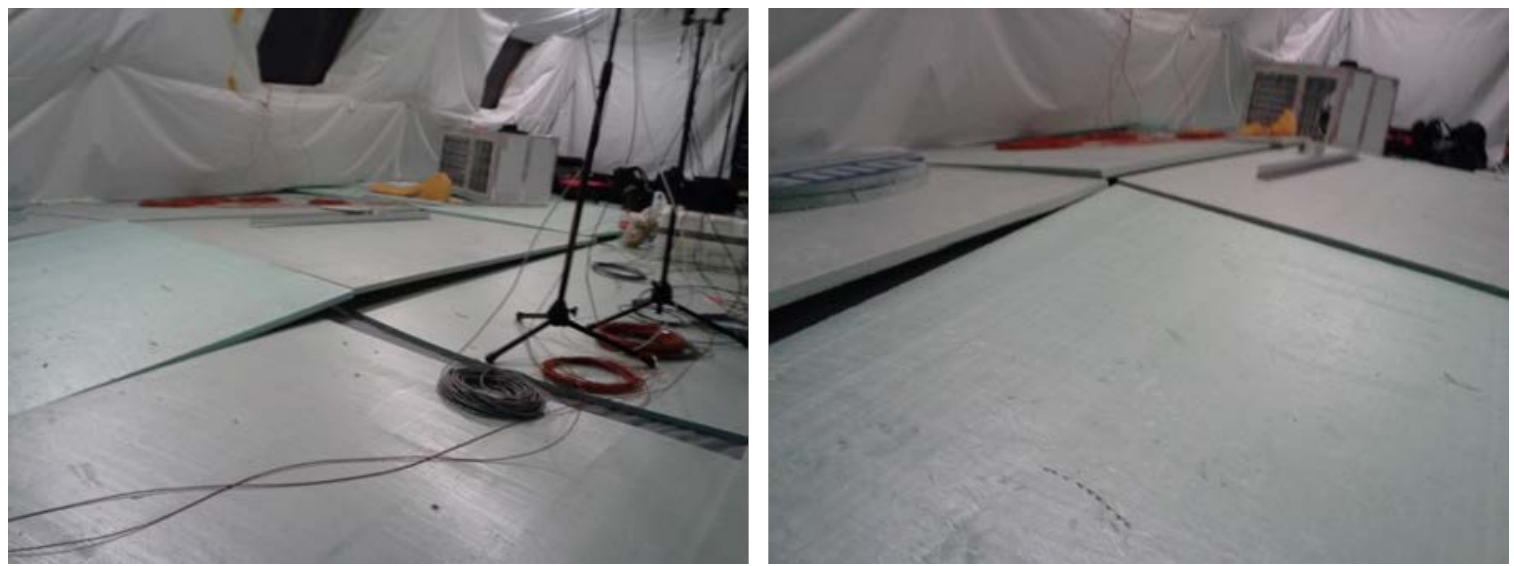

\subsubsection{Heating and cooling energy}

The heating- and cooling-season tests were performed by inducing a large heat flow on the shelters that could be measured accurately over the period of the test. For each test, the shelters were conditioned to constant temperatures to create a large temperature difference across the envelope $\left(>30^{\circ} \mathrm{F}\right.$ ). If the shelters were simply allowed to "float" with little or no artificially induced heat flow, it would be difficult to adjust any assumptions in the model to match the measurements. For example, with very little temperature difference between the inside and outside of the shelter, the simulated thermal conductivity of the walls could be changed by a large factor without affecting the simulated interior temperature.

\subsubsection{Heating season}

The shelters were heated using electric convection heaters to a temperature of $64.4^{\circ} \mathrm{F}\left(18^{\circ} \mathrm{C}\right)$ for the duration of the test. This approach provides 
a well known energy input and a strong driver to force a large heattransfer rate from the inside to the outside of the shelter. Small fans were installed in each shelter to attempt to keep the air inside the shelter well mixed in order to simplify the assumptions about stratification in the simulation model. Total electrical power entering the shelter (heaters, fans, lights, data acquisition equipment) was measured for each shelter. All of this electrical energy eventually becomes sensible internal gain to the shelter and was included in calibrating the model.

\subsubsection{Cooling season}

The shelters were cooled using the standard heat pump units used by the Army, known as ECUs (Environmental Control Units), to a controlled temperature of approximately $64.4^{\circ} \mathrm{F}\left(18{ }^{\circ} \mathrm{C}\right)$ in the Utilis shelter and 68 ${ }^{\circ} \mathrm{F}\left(20^{\circ} \mathrm{C}\right)$ in the AirBeam shelter through the duration of the test. The set points were arbitrary; in fact, the thermostats on the ECUs have no values written on them, just an analog hot-to-cold dial. The goal was simply to induce a large heat-transfer rate from the (hot) outside to the (cool) inside of the shelter.

Because the ECUs deliver air to the shelters through a series of air jets well distributed along the length of the shelter, it was expected that the air in the shelters would be isothermal. Total electrical power entering the shelter (lights, data acquisition equipment, etc.) was measured for each shelter and added to the calibration model as sensible internal gain to the shelter.

The normal operation mode of an ECU is with constant evaporator fan operation, and compressor and condenser fan engaging as cooling is required. The air volume flow rate of each ECU was measured using a "TrueFlow Plate" manufactured by The Energy Conservatory, Minneapolis, MN (see Figure 14). This is a device with a number of calibrated orifices and an array of pitot tubes used to measure the air-flow rate in heating and cooling systems, and has a published accuracy of $+/-7 \%$. We assumed that the ECU air flow rate was maintained relatively constant throughout the testing period. 
Figure 14. Temporary installation of the TrueFlow

Plate for a one-time measurement of ECU air flow.

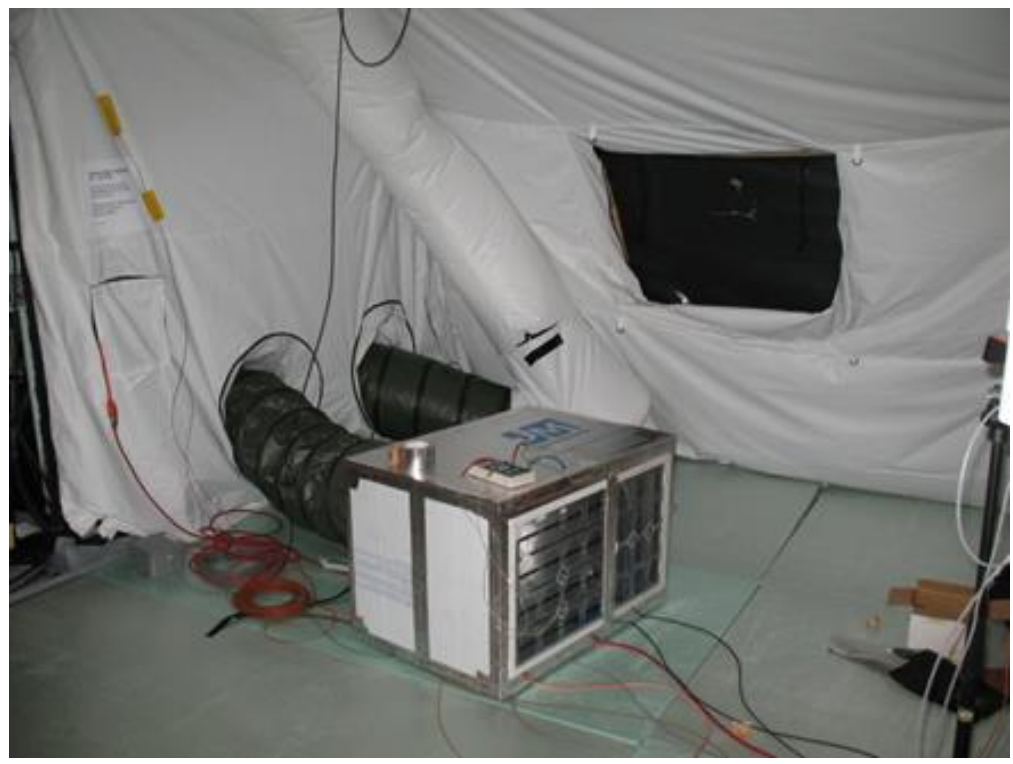

Temperature and humidity sensors were placed in the air streams of both the supply and return ducts in each shelter as shown in Figure 15. Using the one-time measurement of air flow rate and the measured temperature and humidity conditions at the supply and return ducts, total, sensible, and latent heat removed by the ECU were calculated in real time in the data acquisition system.

Figure 15. Measurement point for return air temperature and humidity.

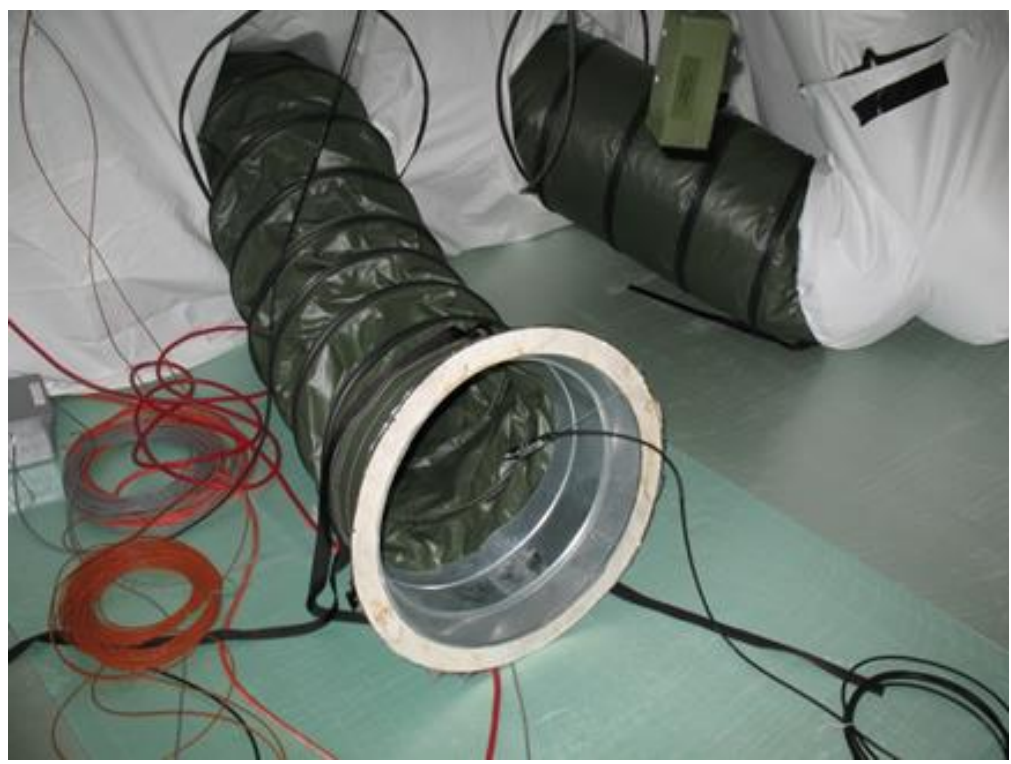




\subsubsection{Floor surface heat flux}

Heat-transfer rate to the ground was measured using three heat flux transducers in each shelter. Application of the transducers was slightly different between heating- and cooling-season tests. The measured heat fluxes through the floor were used as inputs to the calibration models with no attempt to model the behavior of the ground itself.

\subsubsection{Heating season}

Heat-transfer rate to the ground was measured using three heat flux transducers in each shelter. The heat flux transducers were placed on the floor with heat-conductive grease to ensure good thermal contact with the shelter floor fabric. Sensor 1 was placed in the center of the floor; sensor 3 was placed approximately 6 in. $(15 \mathrm{~cm}$ ) from the outer edge of the floor; and sensor 2 was placed at a point equidistant between the first two (see section 2.3.4.1, Figure 22 and Figure 23).

\subsubsection{Cooling season}

The heat flux transducers were adhered to the polystyrene floor insulation with heat-conductive grease to ensure good thermal contact with the polystyrene sheet. The sensors were placed at the center of the floor on the top surface of the polystyrene (sensor 2), in the center of the floor on the bottom surface of the polystyrene (sensor 1), and at a point about 12 in. (30 $\mathrm{cm}$ ) from the eastern edge on the top surface of the polystyrene (sensor 3), as shown previously in Figure 4 and Figure 5. Sensors 1 and 2 were placed on the top and bottom of the insulating sheet in the same central location to confirm that the two sensors read the same heat flux when averaged over time; it was expected that the sensor on the top would react quickly to changes in convective and radiative heat transfer, while the one on the bottom would be a damped signal representing the signal from the top sensor averaged over time.

\subsubsection{Weather}

Outdoor weather conditions of dry-bulb temperature, relative humidity, wind speed, wind direction, and global horizontal solar radiation were measured during the tests using field-grade instruments mounted on a temporary tripod near the shelters. These measurements were used as guides during the test, but for comparison of model to field data, measurements collected onsite concurrently by Oak Ridge National Laborato- 
ries (ORNL) were used. An ORNL weather station set up to support a separate EFOB-L project included research-grade instruments for measuring air temperature and humidity, wind speed and direction, beam and diffuse components of solar radiation, and infrared sky radiation. The direct measurement of sky radiation was used as a direct input to the simulation model, bypassing the correlation typically used in building simulations for predicting sky radiation.

\subsection{Observations for model calibration}

\subsubsection{Infiltration}

The infiltration rate calculated from the decay rate of $\mathrm{SF}_{6}$ in each shelter varied from 0.1 to 0.6 air changes per hour $(\mathrm{ACH})$. As we observed during our tests in March, the infiltration rate appeared to be not only highly correlated with wind speed and inside/ outside temperature difference (as expected), but with wind direction. When the wind was coming from the northwest, the AirBeam shelter showed much higher infiltration rates than the Utilis. When the wind was in the opposite direction, the opposite trend was true. Two possible explanations for this are that (1) the Utilis has its door facing south while the AirBeam has its door facing north, and (2) the Utilis is sheltered by a building to its northeast and the AirBeam is sheltered by a building to its south.

This behavior illustrates the need to use measured infiltration rates as an input to the simulation model in order to calibrate the model of the shelters. Trying to predict the infiltration rates under the exact conditions at ERDC-CERL during the tests would likely prove unsuccessful because the typical approach in building simulation, using the Sherman-Grimsrud model (DOE 2014b) and blower-door results, does not account for small wind disturbances that appear to play a major role in the infiltration rates of the shelters. Results from the blower-door test were used to generate inputs to models for the purpose of long-term prediction of shelter infiltration rates.

Because the concentration of the tracer gas introduced in each shelter gradually diminishes over time as the indoor air is mixed with outdoor air, the concentration eventually becomes close to the outdoor background level, at which point the infiltration rate cannot be inferred from the concentration measurement. When the infiltration rate was high (near 1 $\mathrm{ACH}$ ) the total time between the initial injection of the gas and the point at 
which the concentration was too low to measure was on the order of 5 hours. Because the research team did not have access to the site between 1700 and 0500 hours the following day, there were significant periods during which the concentrations of tracer gas were too low and infiltration measurement rates could not be collected. To fill in the gaps in the data, we created, correlations to fit the measured infiltration rates to the measured wind speed and direction (as noted earlier, the wind direction appeared to have a large impact on the infiltration rate of each shelter), and inside/ outside temperature difference. The three independent variables in the fit were defined as wind speed $(\mathrm{m} / \mathrm{s})$, the cosine of the wind direction in degrees, and inside/ outside temperature difference. The cosine was chosen to allow the wind-direction variable to have a continuous function; in contrast, the wind direction in degrees is a discontinuous function where it transitions from 359.999 degrees (almost exactly north) to 0.000 degrees (exactly north). A sine function would have served equally well. Equation 3 is the best-fit equation for the Utilis measured infiltration data and Equation 4 was the best for the AirBeam, both during the heatingseason tests. The forms of the best-fit equations have no particular physical significance. The uncertainties in the fits are illustrated by graphing the predicted infiltration rates versus the measured infiltration rates in Figure 16 and Figure 17 for the two shelters.

$$
\begin{gathered}
A C H=a+b x_{1}+c x_{2}+d x_{1}^{2}+e x_{2}^{2}+f x_{1} x_{2}+g x_{1}^{3}+h x_{2}^{3}+i x_{1} x_{2}^{2}+j x_{1}^{2} x_{2} \\
A C H=a x_{1}^{b} c^{x_{2}}
\end{gathered}
$$

where

$$
\begin{aligned}
& \mathrm{x}_{1}=\text { wind speed }[\mathrm{m} / \mathrm{s}] \\
& \mathrm{x}_{2}=\cos (\text { wind direction }[\mathrm{deg}]) \\
& \mathrm{x}_{3}=\Delta \mathrm{T}\left[{ }^{\circ} \mathrm{C}\right]
\end{aligned}
$$


Figure 16. Goodness of fit of air-change rates as a function of wind speed, wind direction, and inside/outside temperature difference for the Utilis shelter in the heating season.

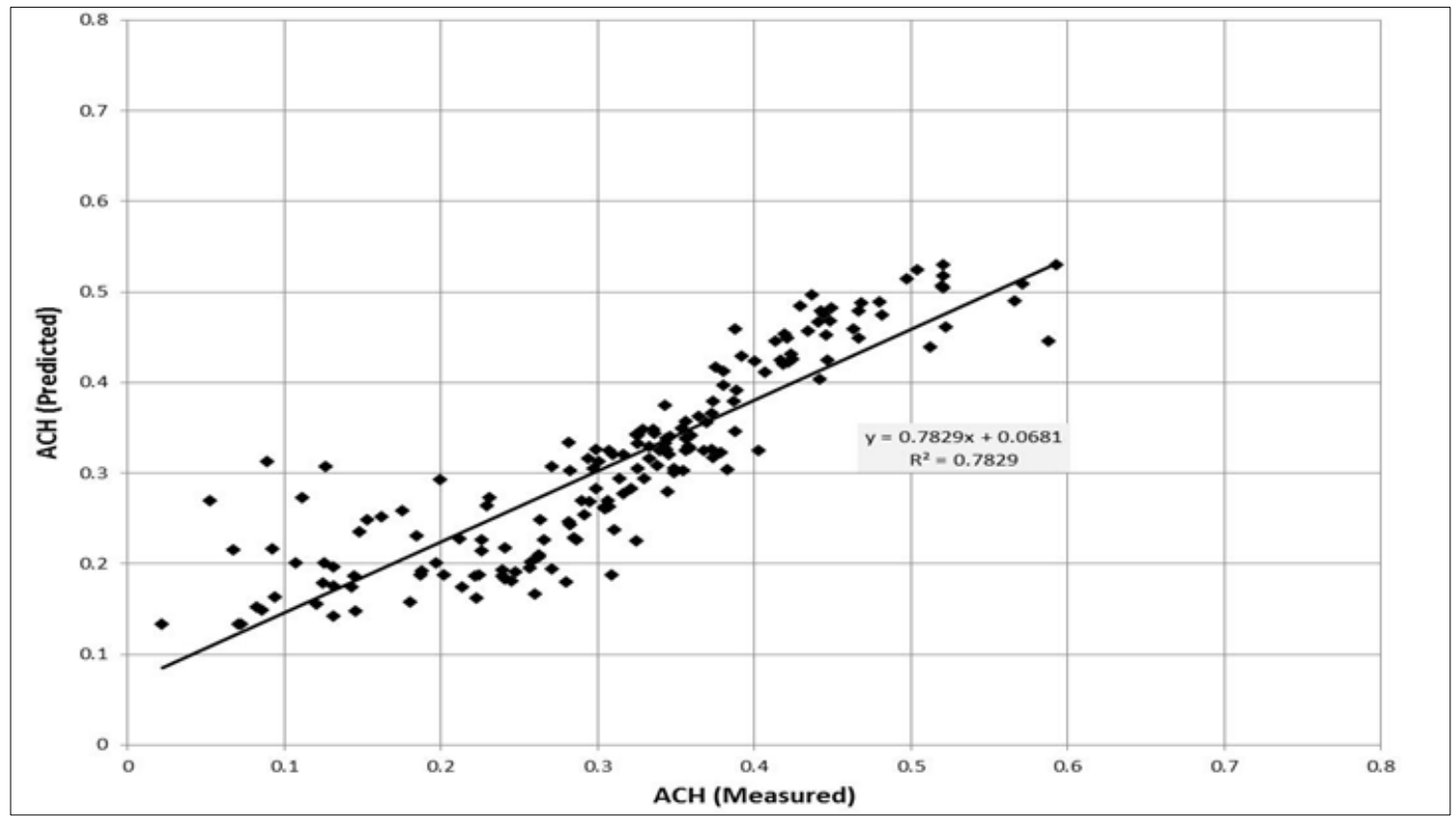

Figure 17. Goodness of fit of air-change rates as a function of wind speed, wind direction, and inside/outside temperature difference for the AirBeam shelter in the heating season.

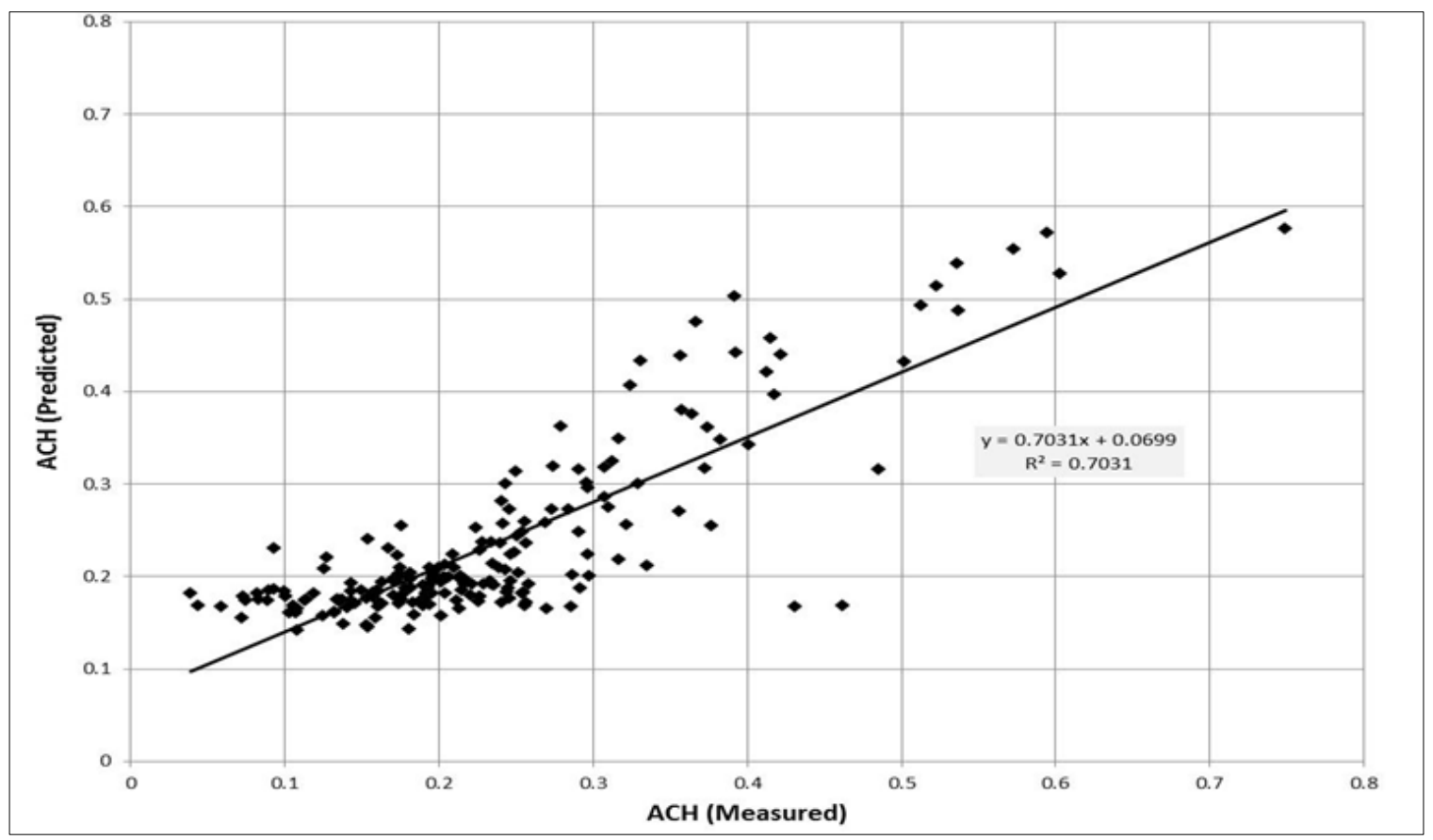




\subsubsection{Floor heat flux}

From experience with buildings, we expect the heat flow through the floor to be largest near the edge since that represents a shorter heat-flow path to the outdoors and the ground under the center of the building is closer to the building temperature. We also normally expect the heat-transfer rate at any point on the floor to be fairly steady if the indoor air temperature is steady because buildings have thermally massive layer in contact with the ground that dampens variations in the heat flows. With the shelters we found neither of these expectations to be correct. Likely explanations include the thin floor liner in contact with the ground, the ground under the shelter was close to the undisturbed ground surface temperature, and that the heat transfer to the ground in the shelters was very dependent on convective heat transfer with the air and radiant exchange with the inside shelter surfaces, whose temperatures changed dramatically depending on the outdoor conditions. In a typical insulated building the inside surface temperatures do not change much due to a change in the outdoor conditions.

\subsubsection{Heating season}

Because these shelters were unconditioned until we began heating them for our tests, the ground started out cold and was expected to be a large heat sink. We placed 3 heat flux transducers on the floor of each tent, one in the center, one near the edge, and one between the first two.

The hourly-averaged heat flux measurements for each shelter are shown in Figure 18. Note that the trend among the three measurements is different between the two shelters. The highest heat-transfer rate in the Utilis is near the edge as measured by heat flux transducer 3 (HFT 3), but the highest rate in the AirBeam is at the center (HFT 1). The difference is likely due to the radically different radiant environment created by the insulated surfaces of the Utilis compared with the conditions created by the uninsulated surfaces of the AirBeam. 
Figure 18. Floor heat flux for each shelter in the heating season.

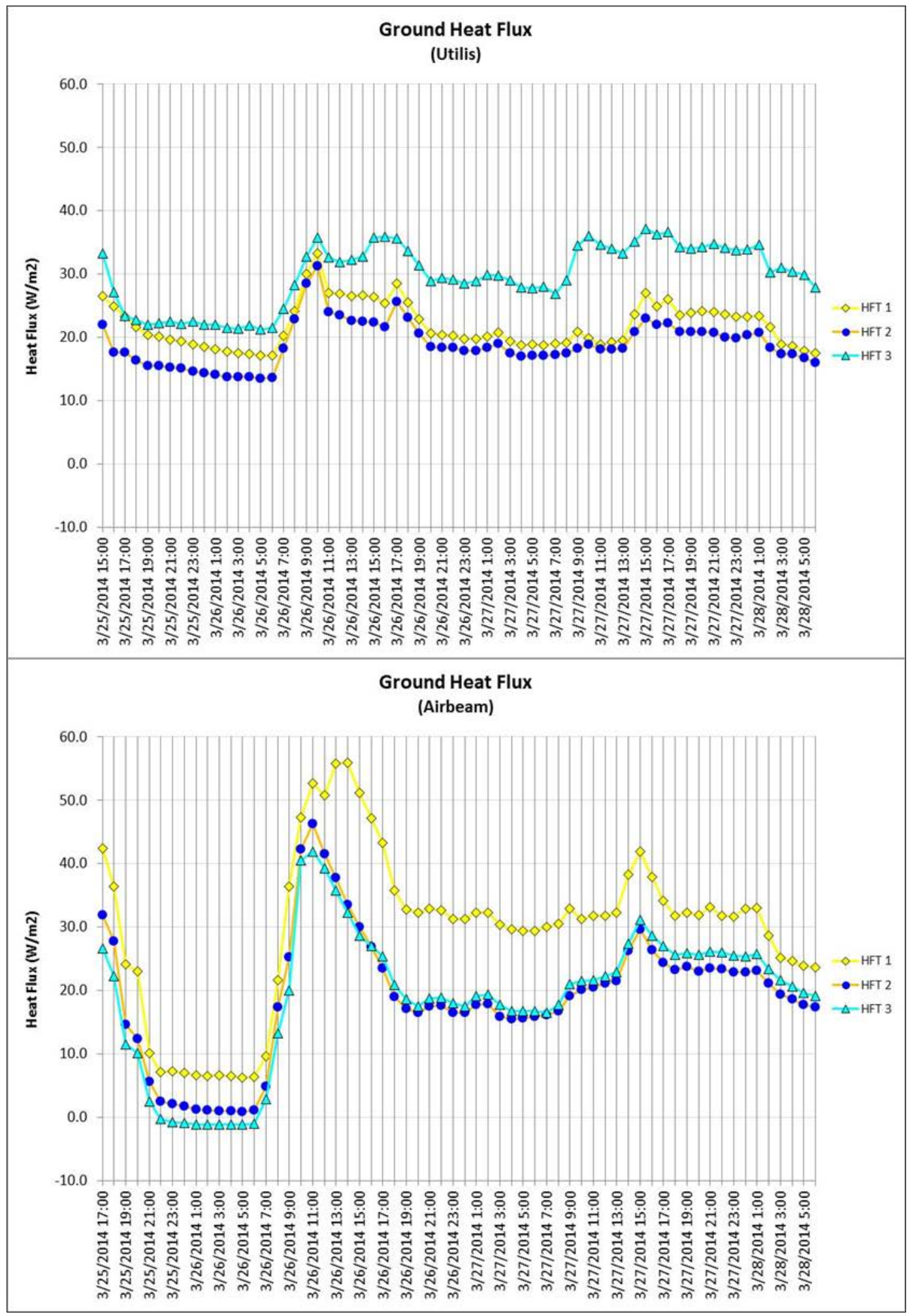




\subsubsection{Cooling season}

For the summer cooling season monitoring, the Utilis shelter was conditioned (cooled) until a few days before testing began, while the AirBeam shelter had been unconditioned for many months. The ground temperature was an unknown initial condition for both shelters; however, it was expected to be cooler for the Utilis shelter because of the conditioning, and was expected to be warmer for the AirBeam shelter. To reduce the magnitude of the heat flow through the floor we placed $1 \mathrm{in}$. thick extruded polystyrene insulation on the floors of both shelters. We placed three HFTs on the floor of each shelter, as discussed in section 2.2.5.

The 15 minute averaged floor heat flux measurements for each shelter are shown in Figure 19. The trends among the three measurements are similar between the two shelters; the top-surface heat fluxes are similar in magnitude regardless of whether they are close to the edge or in the center, and their values change rapidly on a 15 minute basis compared to the heat fluxes measured underneath the insulation. As expected, the rapidlychanging values measured at the top surface of the insulation average out to the slowly-changing values measured at the bottom surface of the insulation. A trend that is different between the two shelters is that the overall direction of the heat flux in the Utilis shelter was from the ground to the inside of the shelter, while for the AirBeam shelter the heat flux tended to be from the shelter to the ground during the middle of the day. This is likely because the AirBeam had no insulating liner so that when the roof and wall surfaces of the shelter became hot due to solar radiation, the heat was radiated to the cooler ground surface. The insulating liner in the Utilis shelter greatly attenuated this effect. 
Figure 19. Floor heat flux measurements in each shelter (positive value indicates heat flow from the shelter to the ground).

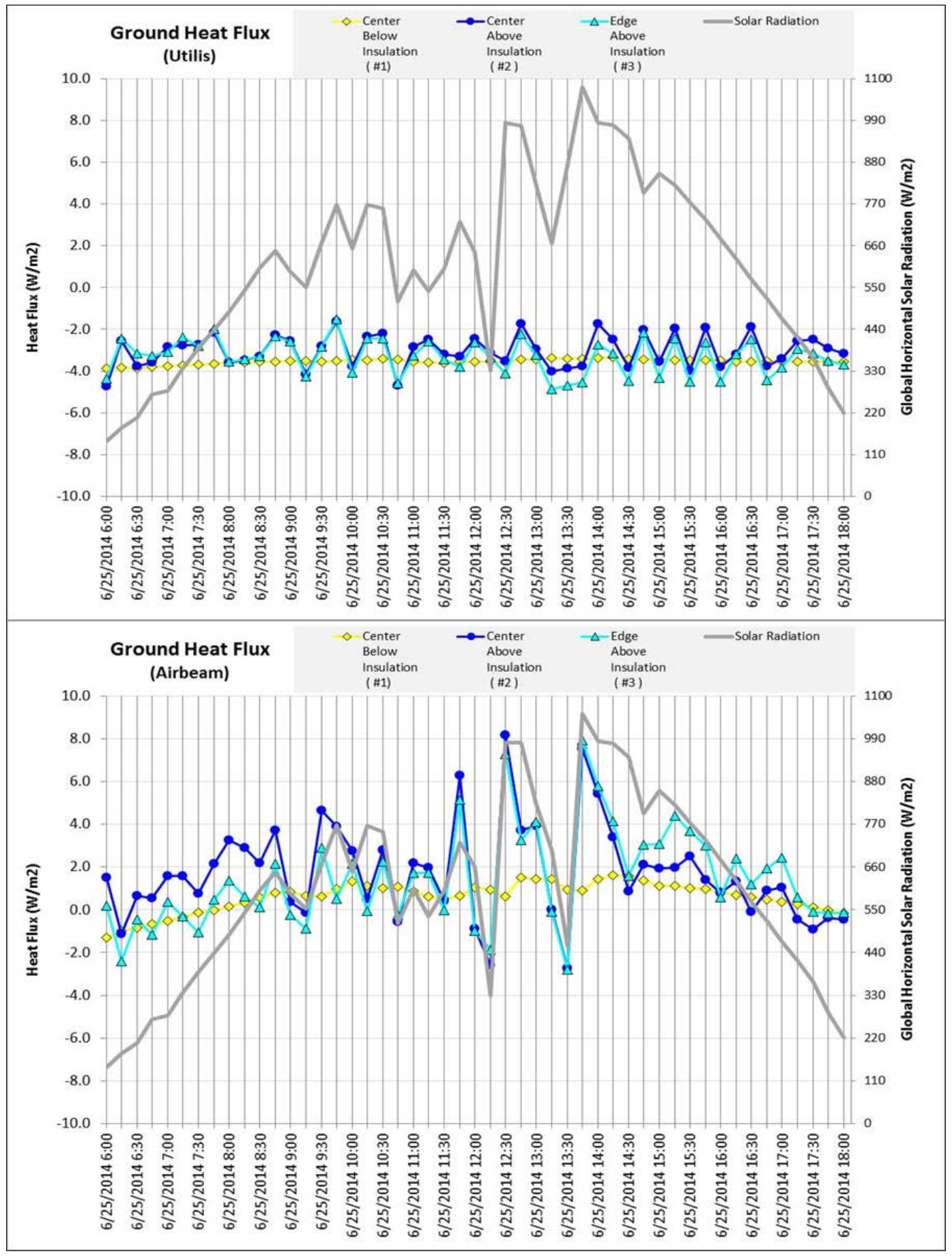

\subsubsection{Observations from thermography}

Infrared images were taken during the heating season testing to provide a qualitative understanding of the heat-transfer paths and relative magnitudes in the shelters. The images in Figure 20 show the high heat flow 
around the door, at the edge of the floor-wall intersection, and through the points where the Thinsulate liner is tacked together in the Utilis shelter. The image of the floor also shows the increased heat flow where the floor liner is in contact with the ground. The images of the AirBeam shelter in Figure 21 show the high flows through the door and the window. The window is closed in the image, but the heat flow is higher here because there is no air gap between the inner liner and the outer shell.

Figure 20. Infrared images of the Utilis shelter door, walls, and floor.
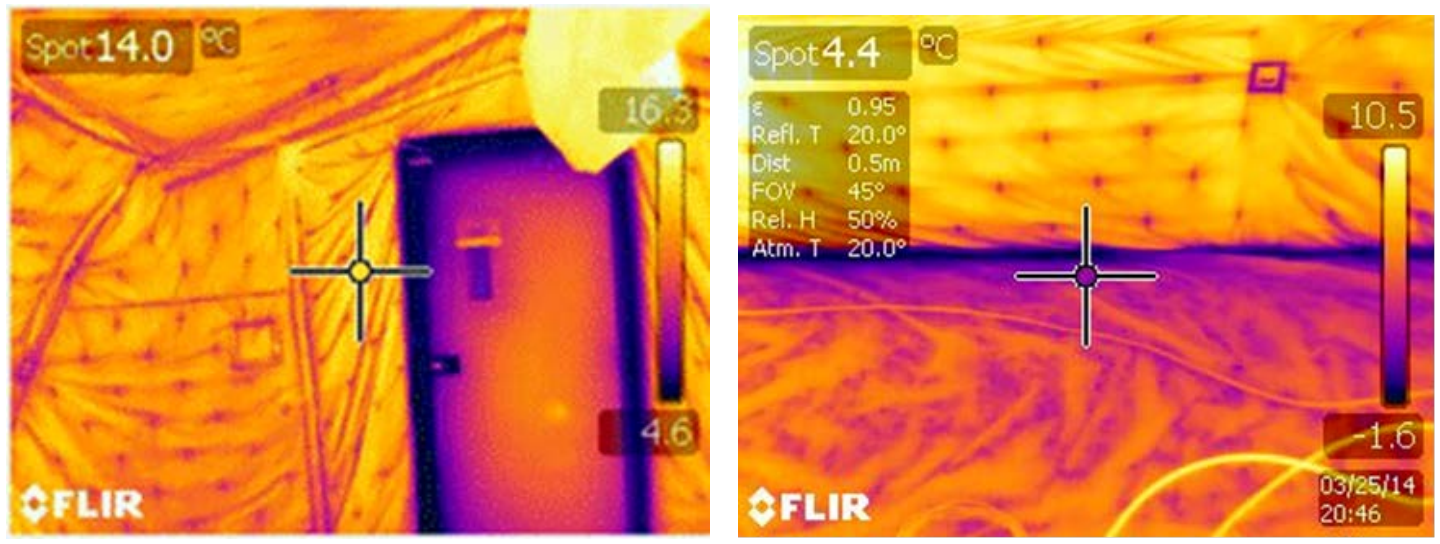

Figure 21. Infrared images of the AirBeam shelter door, walls, and window.
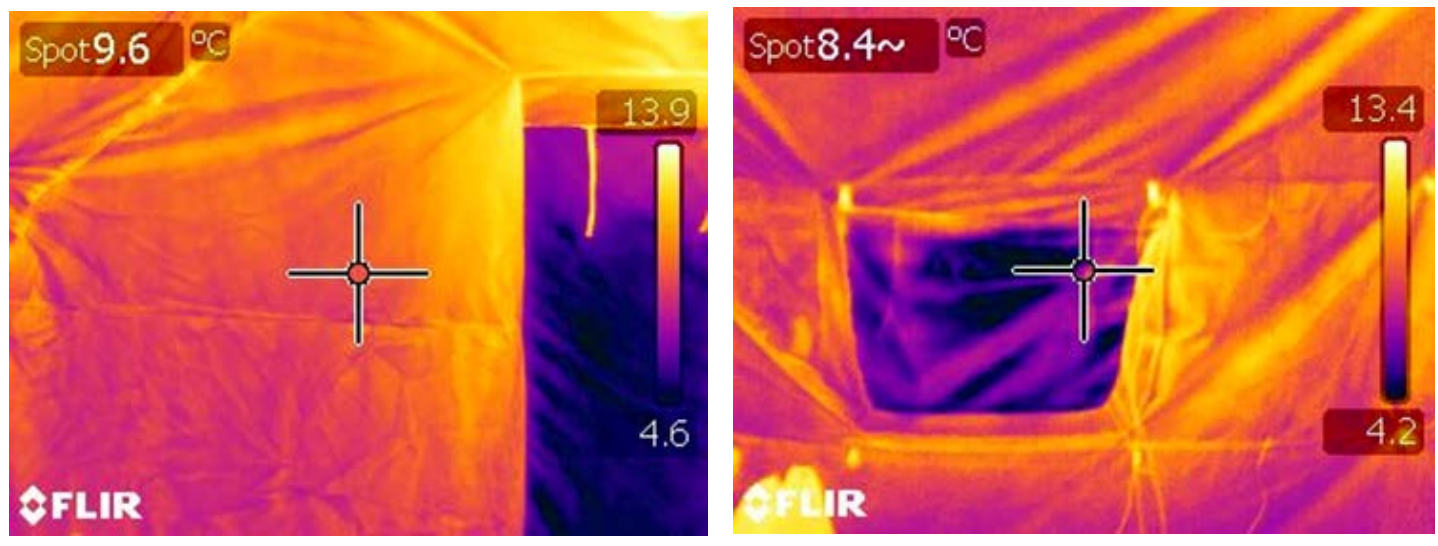

\subsubsection{Total heat-flow calculations}

\subsubsection{Floor heat-flow calculations $\left(Q_{f}\right)$}

A weighted average of the HFT measurements was calculated to represent the total heat flux through the floor for both the heating- and coolingseason tests. Weights were based on the floor areas shown in Figure 22 and Figure 23. 
Figure 22. AirBeam floor area weighting for heat flux measurements.

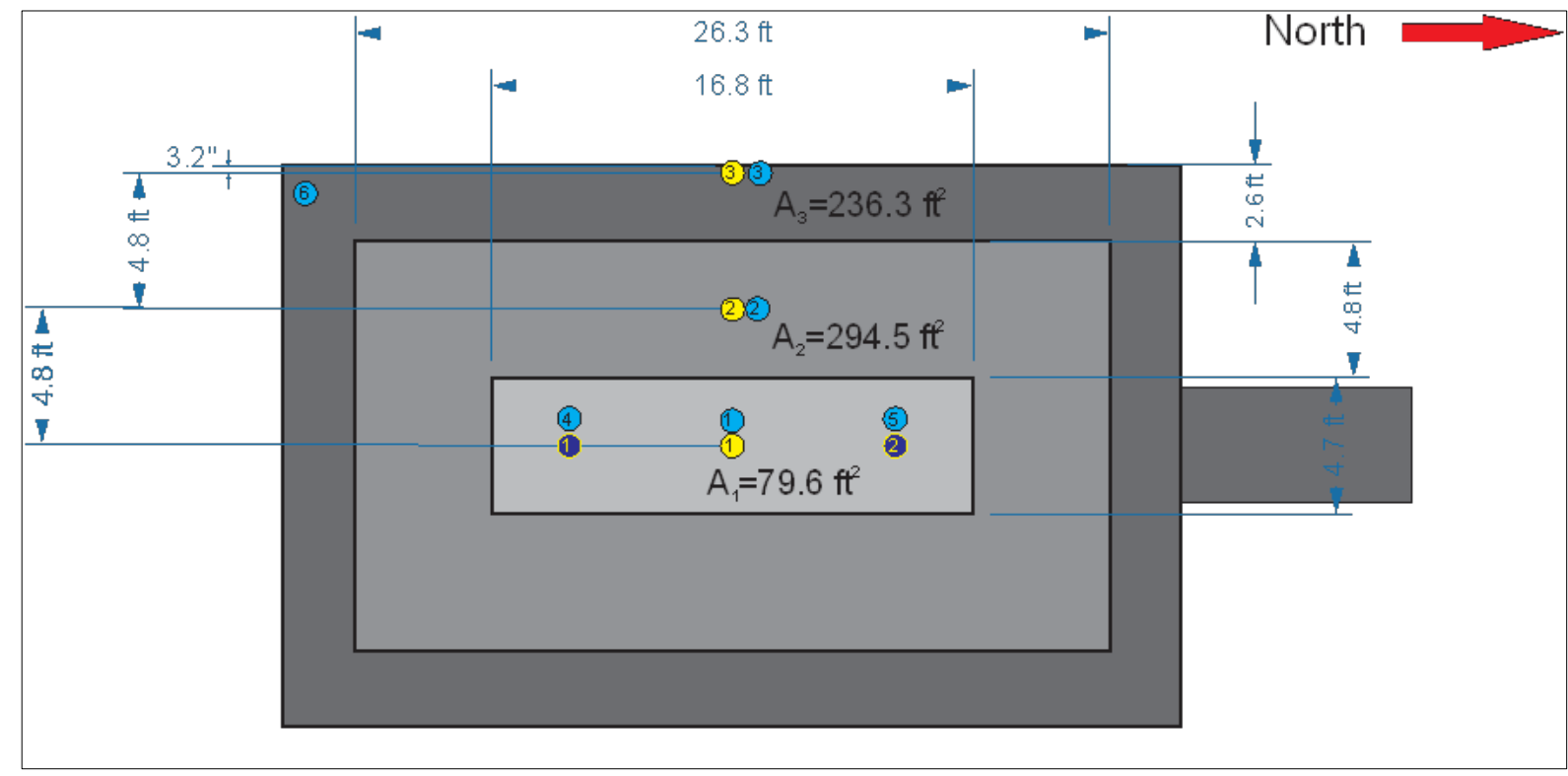

Figure 23. Utilis floor area weighting for heat flux measurements.

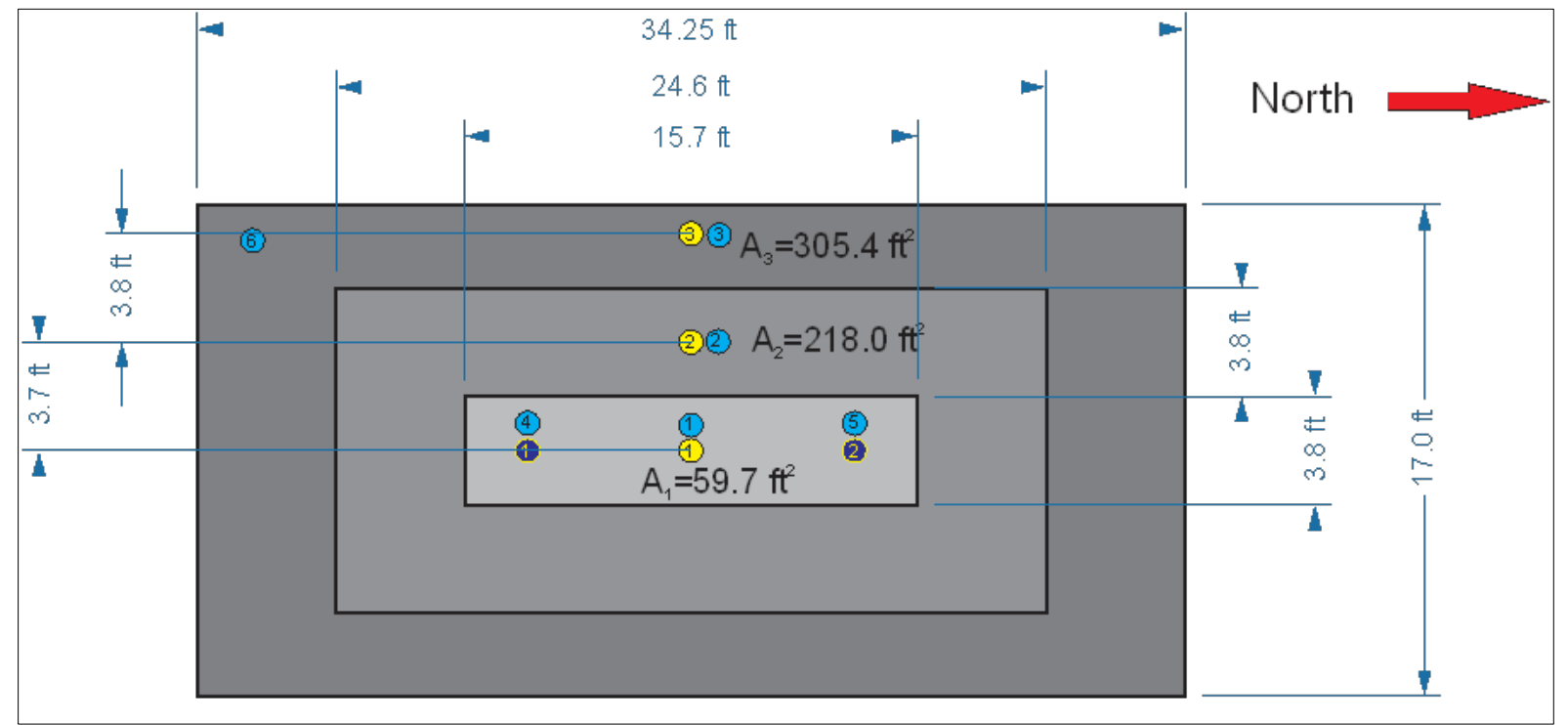

Because the floors were not insulated during the heating-season tests, the total ground heat flux was a significant portion of the total heating load of the shelter. It was expected that the measured heat fluxes would be an exaggerated value since the HFTs were intentionally held down against the floor with no air gap beneath them. From a visual inspection, it was estimated that approximately half the floor area had small gaps or bubbles of air between the floor fabric and the ground. As a best-guess approach to calculating the total heat flux through the floor for the heating-season tests, we assumed that $50 \%$ of the floor fabric was touching the ground 
while the other half had a $1 \mathrm{~cm}$ ( 0.4 inch) air gap beneath it. It was further assumed that the temperature difference observed between the warmer (with air gaps) and cooler (without air gaps) sections of the floor was approximately $3.6^{\circ} \mathrm{F}\left(2^{\circ} \mathrm{C}\right)$. This value was inferred by observing the temperature differences shown in infrared photographs of the floor in Figure 20.

Total heat flux through the floor was calculated using Equation 5:

$$
Q_{f}=\left(1-f_{\text {air }}\right)\left(A_{1} Q_{1}+A_{2} Q_{2}+A_{3} Q_{3}\right) /\left(A_{1}+A_{2}+A_{3}\right)+f_{\text {air }}\left(\left(k_{\text {air }} / d\right) \Delta T\right)
$$

where

$$
\begin{aligned}
\mathrm{Q}_{\mathrm{f}} & =\text { total heat flux through the floor }\left[\mathrm{W} / \mathrm{m}^{2}\right] \\
\mathrm{f}_{\text {air }} & =\text { fraction of floor with air gaps }
\end{aligned}
$$

$\mathrm{A}_{1}, \mathrm{~A}_{2}, \mathrm{~A}_{3}=$ weighting areas [ $\left.\mathrm{m}^{2}\right]$

$\mathrm{Q}_{1}, \mathrm{Q}_{2}, \mathrm{Q}_{3}=$ heat flux measurements [W/ $\left.\mathrm{m}^{2}\right]$

$\mathrm{k}_{\mathrm{air}}=$ thermal conductivity of air $[\mathrm{W} / \mathrm{m} \cdot \mathrm{K}]$

$\mathrm{d}=$ thickness of air gap [m]

$\Delta \mathrm{T}=$ air gap temperature difference between fabric and ground [K]

In calculating $\mathrm{Q}_{\mathrm{f}}$ for the cooling season data, fair was assumed equal to zero since the floors were covered in rigid insulation and any air gaps below the floor would have an insignificant effect on the uniformity of heat flux across the floor.

\subsubsection{Infiltration thermal load ( $\left.Q_{\text {inf }}\right)$}

Heat lost due to infiltration was calculated according to Equation 6:

$$
Q_{\text {inf }}=A C H \cdot V \cdot C_{p} \cdot \rho \cdot\left(T_{\text {in }}-T_{\text {out }}\right)
$$

where

$$
\begin{aligned}
\mathrm{Q}_{\text {inf }}= & \text { rate of energy lost due to infiltration }[\mathrm{W}] \\
\mathrm{ACH}= & \text { rate of infiltration, air changes } / \text { hour } \\
\mathrm{V}= & \text { interior volume of shelter (cross-sectional area times length) } \\
& {\left[\mathrm{m}^{3}\right] } \\
\mathrm{C}_{\mathrm{p}}= & \text { specific heat of outdoor air }[\mathrm{J} / \mathrm{kg} \cdot \mathrm{K}] \\
\rho= & \text { density of outdoor air }\left[\mathrm{kg} / \mathrm{m}^{3}\right] \\
\mathrm{T}_{\text {in }}= & \text { average interior dry bulb temperature }\left[{ }^{\circ} \mathrm{C}\right]
\end{aligned}
$$




$$
\mathrm{T}_{\text {out }}=\text { outdoor dry bulb temperature }\left[{ }^{\circ} \mathrm{C}\right]
$$

\subsubsection{Mechanical heating or cooling total heat flow ( $\left.Q_{\text {tot }}\right)$}

For the heating-season tests, the total heat flow due to mechanical heating was the total electrical power to all devices within the shelter. For the cooling-season tests, the total heat flow into the shelter was calculated as the energy added by all electrical devices within the shelter minus the total sensible energy removed by the ECU, as shown in Equation 7:

$$
Q_{\text {tot }}=Q_{\text {elec }}-m C_{p}\left(T_{\text {ret }}-T_{\text {sup }}\right)
$$

where

$$
\begin{aligned}
\mathrm{Q}_{\text {tot }}= & \text { total sensible energy added to the shelter via mechanical } \\
& \text { means }[\mathrm{W}] \\
\mathrm{Q}_{\text {elec }}= & \text { total electrical energy added to interior of shelter }[\mathrm{W}] \\
\mathrm{m}= & \text { mass flow rate of air through ECU }[\mathrm{kg} / \mathrm{s}] \\
\mathrm{C}_{\mathrm{p}}= & \text { specific heat of air }[\mathrm{J} / \mathrm{kg} \cdot \mathrm{K}] \\
\mathrm{T}_{\text {ret }}= & \text { ECU return air temperature }\left[{ }^{\circ} \mathrm{C}\right] \\
\mathrm{T}_{\text {sup }}= & \text { ECU supply air temperature }\left[{ }^{\circ} \mathrm{C}\right]
\end{aligned}
$$

Equation 7 is valid for both heating and cooling seasons, where the ECU air mass flow rate was equal to zero during the heating-season tests. For the cooling season $\mathrm{Q}_{\text {tot }}$ was generally negative, indicating more energy removed from the shelter than added to it by electrical devices within the shelter.

\subsubsection{Wall and roof total heat flow ( $\left.Q_{w r}\right)$}

The total heat flow through the walls and roof of each shelter was calculated using Equation 8:

$$
Q_{w r}=Q_{t o t}-Q_{f} A_{f}-Q_{i n f}
$$

where

$$
\mathrm{A}_{\mathrm{f}}=\text { floor area }\left[\mathrm{m}^{2}\right]
$$


The calculated components of heat flow for each shelter for the heatingand cooling-season tests are shown in Figure 24 through Figure 27. A few trends are noteworthy:

- The cooling load due to ground heat flow was almost negligible during the cooling-season tests, whereas it was a significant portion of the total heating load for the heating-season tests. This was largely because we had installed insulation on the floors of both shelters for the cooling-season tests to minimize the ground heat flow and thus minimize the importance of uncertainty in its measurement.

- The magnitudes of the heat flows through the walls and roof of each shelter were much smaller for the Utilis shelter than for the AirBeam shelter. Some of this effect was due to the larger size of the AirBeam shelter, but the most significant cause was most likely that the Utilis shelter had an insulated liner installed.

- The magnitudes of the heat transfer due to infiltration were much smaller during the cooling-season tests for both shelters. This was due to a combination of lower wind speeds and lower indoor/ outdoor temperature differences during the cooling-season tests.

Figure 24. AirBeam winter heat flows.

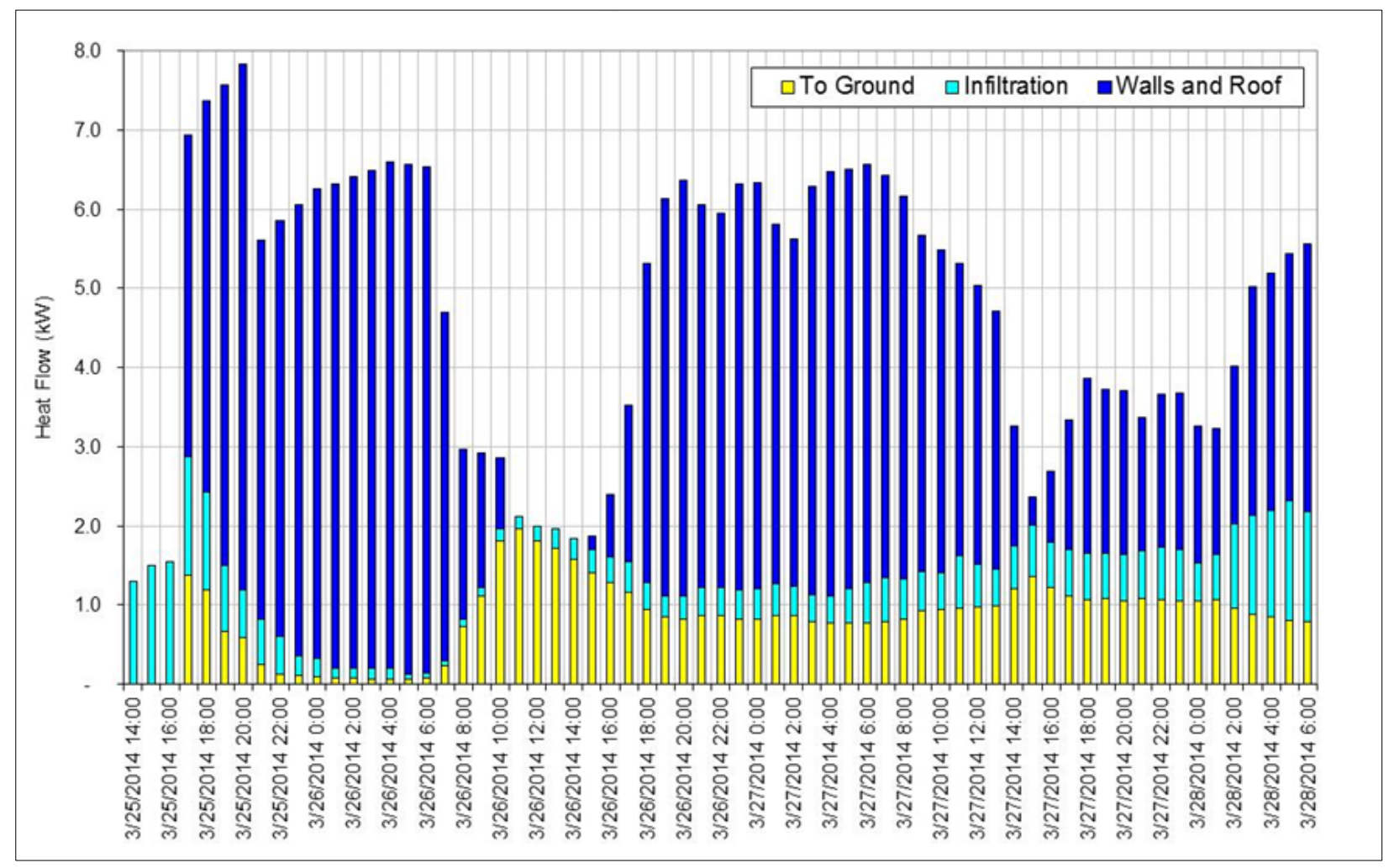


Figure 25. Utilis winter heat flows.

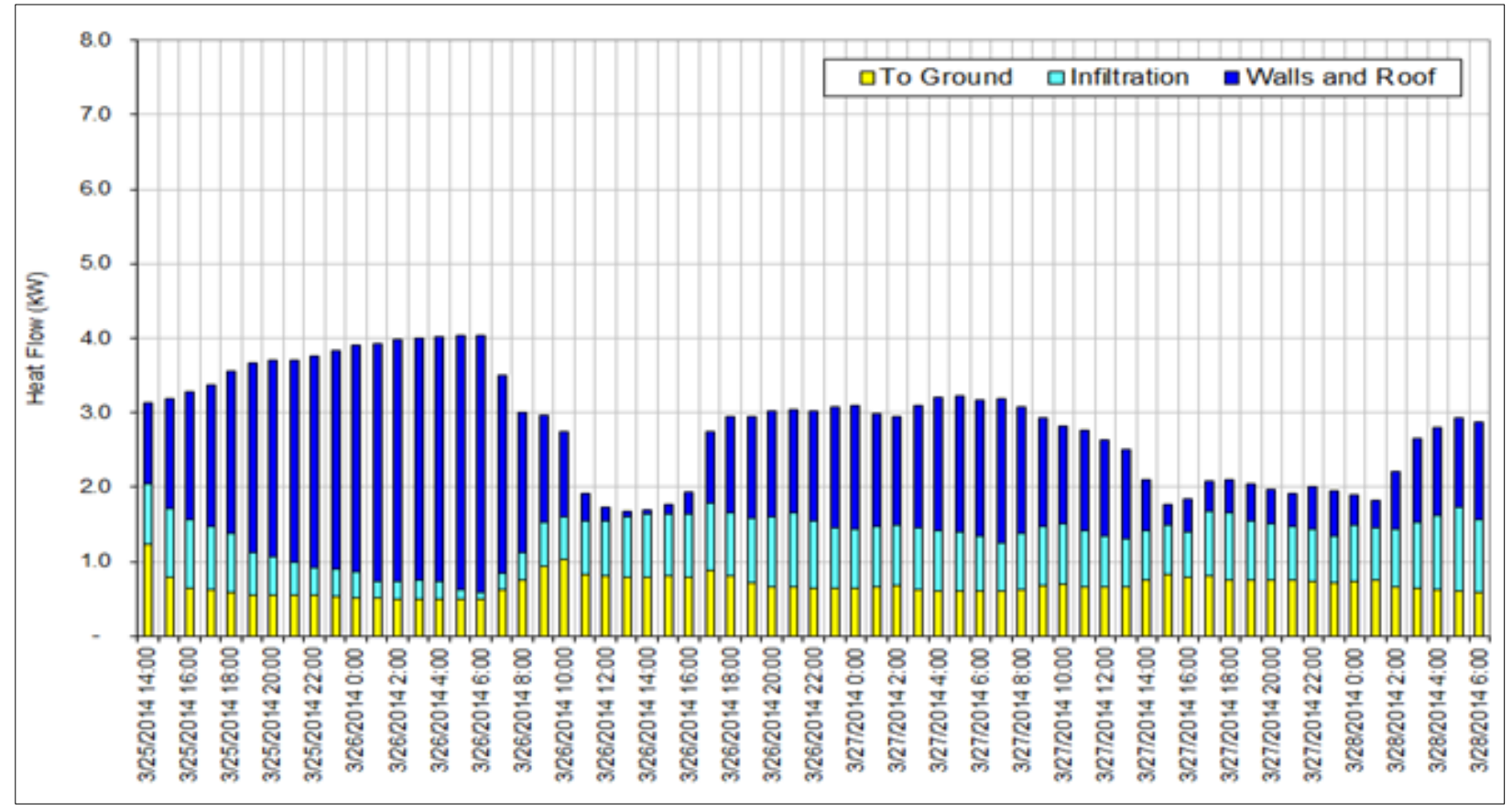

Figure 26. AirBeam summer heat flows.

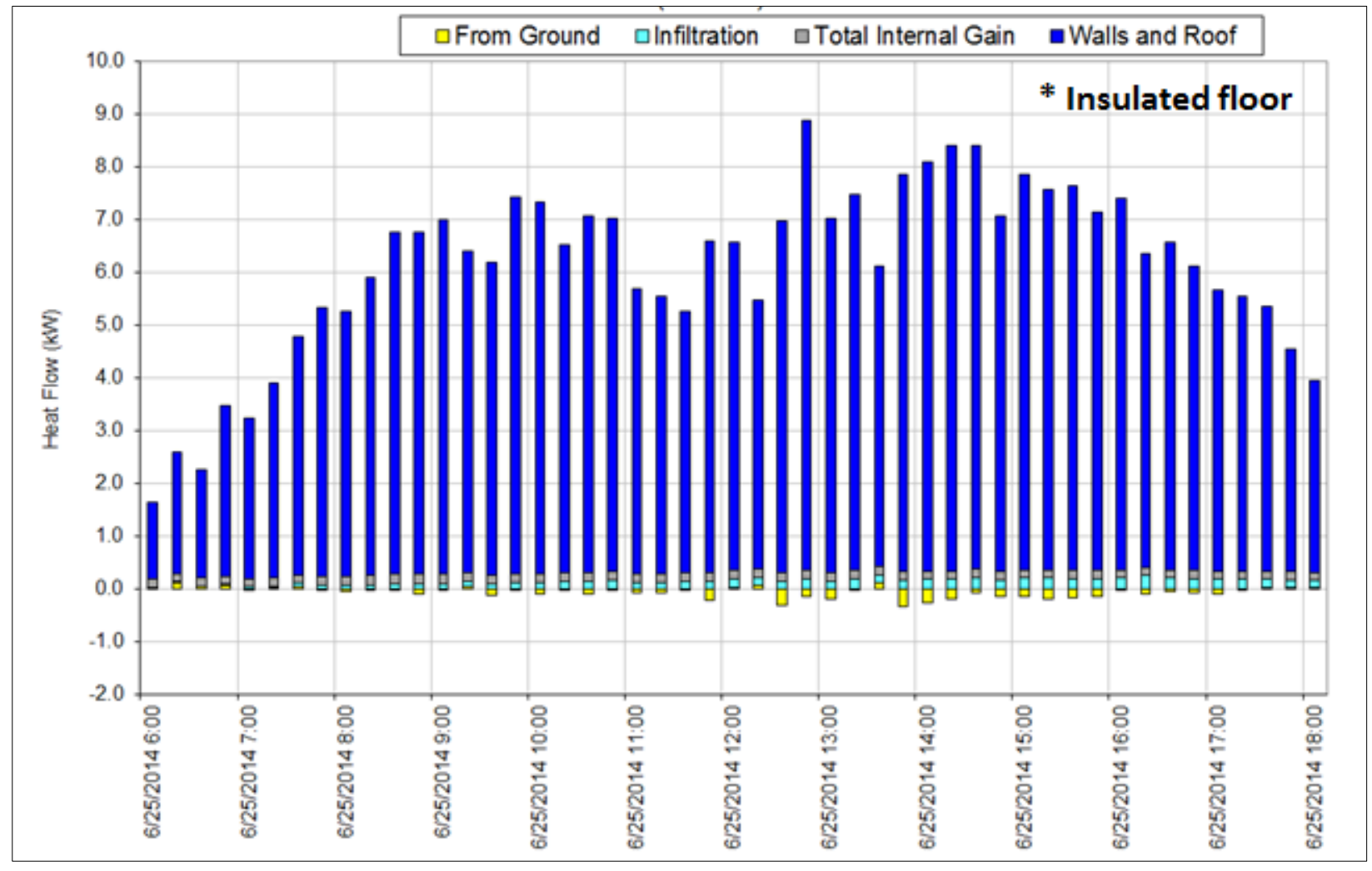


Figure 27. Utilis summer heat flows.

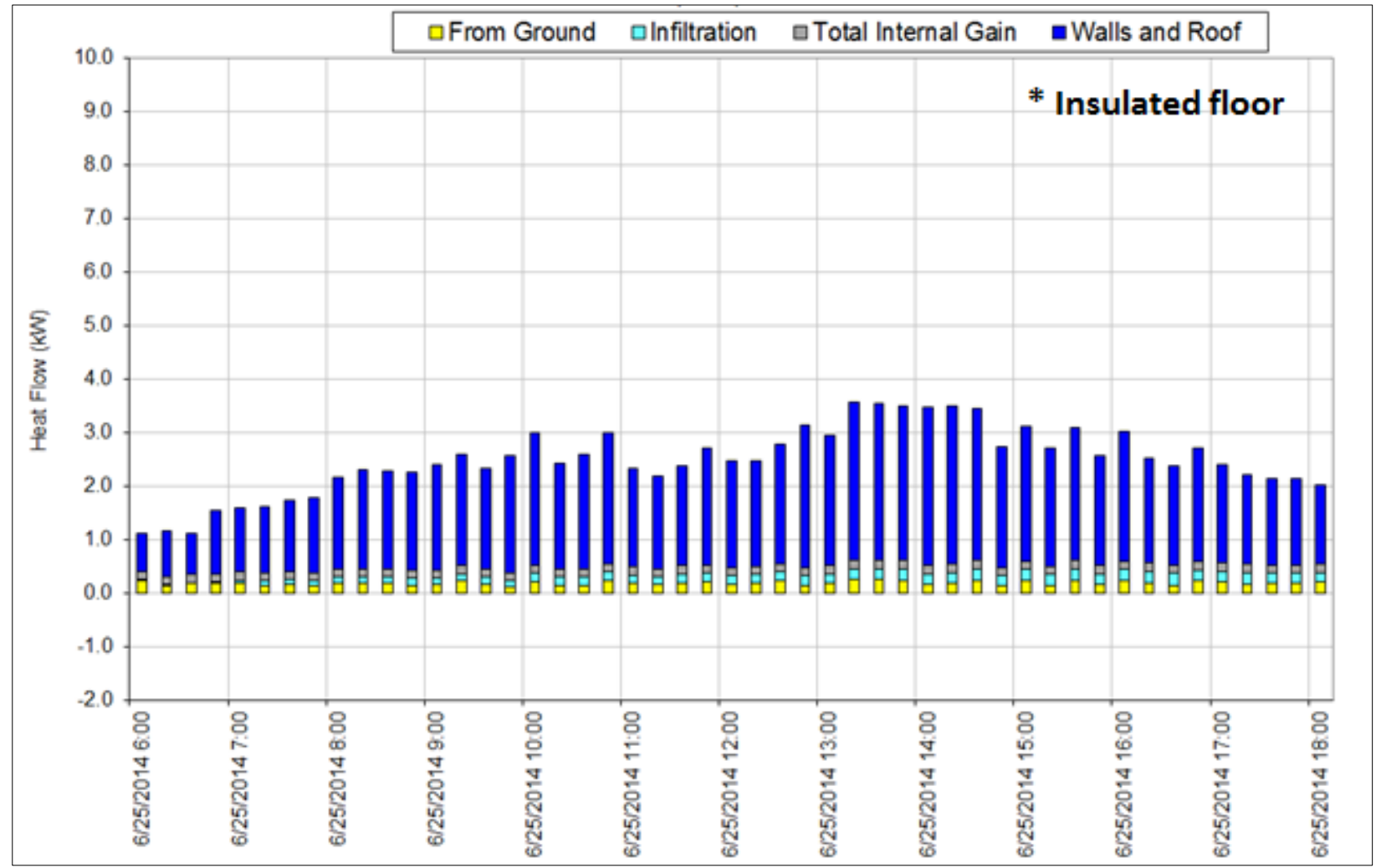




\section{Model Development and Calibration}

\subsection{Method}

EnergyPlus Version 8.1 (DOE 2014a) was used to develop the energy models of the AirBeam and Utilis shelters. These models were developed based on engineering drawings, envelope material specifications, material property measurements, ECU specification sheets, field measurements, and observations.

\subsubsection{Geometry}

The geometry of the AirBeam and Utilis shelters are shown in Figure 28 and Figure 29, respectively. The air gap formed by the inner and outer liners was represented by individual zones surrounding the inner occupied zone. Mixing objects between air-gap zones were used to model the air flow in the air gap. The air flow in this gap was set to a constant value of about $1 \mathrm{CFM}\left(0.00049 \mathrm{~m}^{3} / \mathrm{s}\right)$.

Figure 28. AirBeam shelter model.

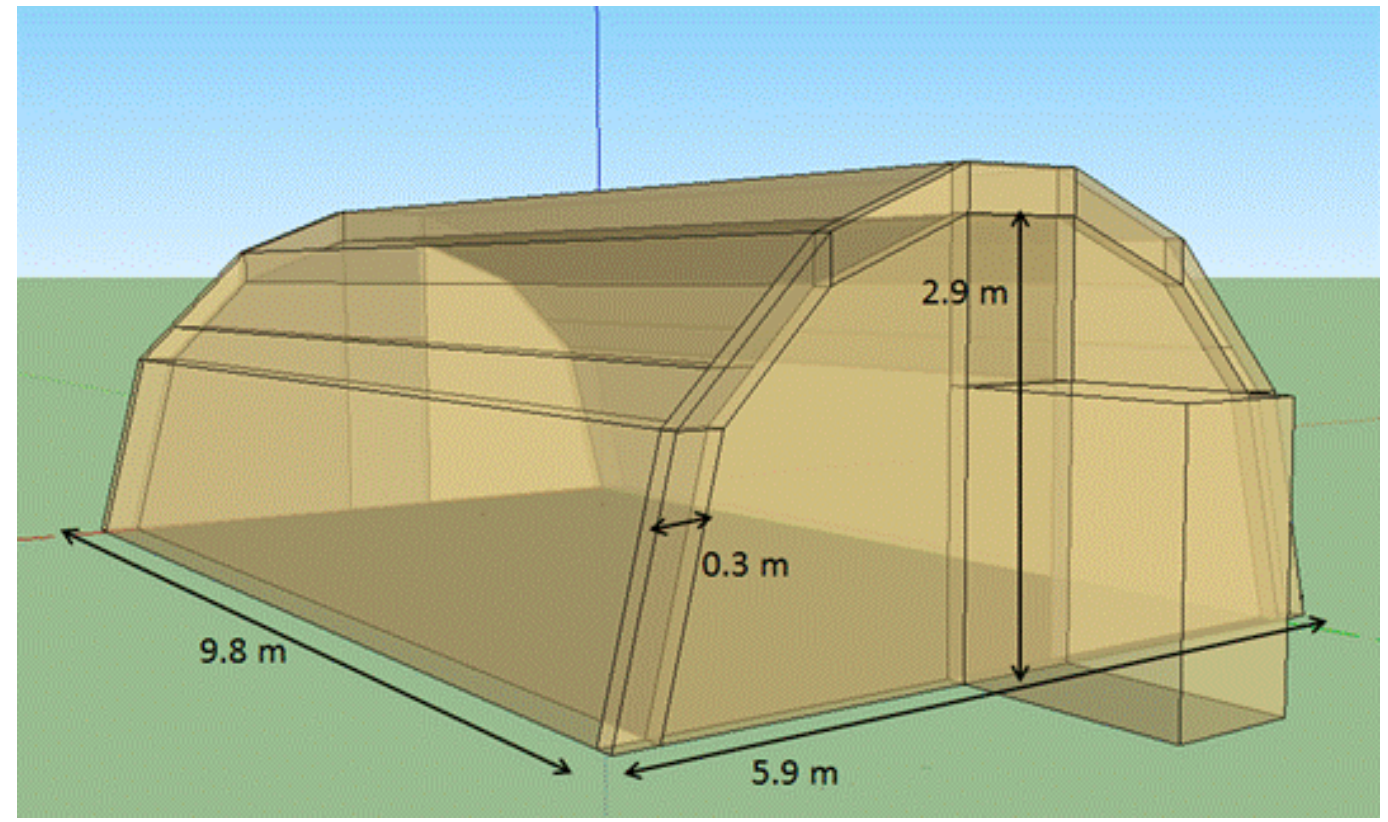


Figure 29. Utilis shelter model.

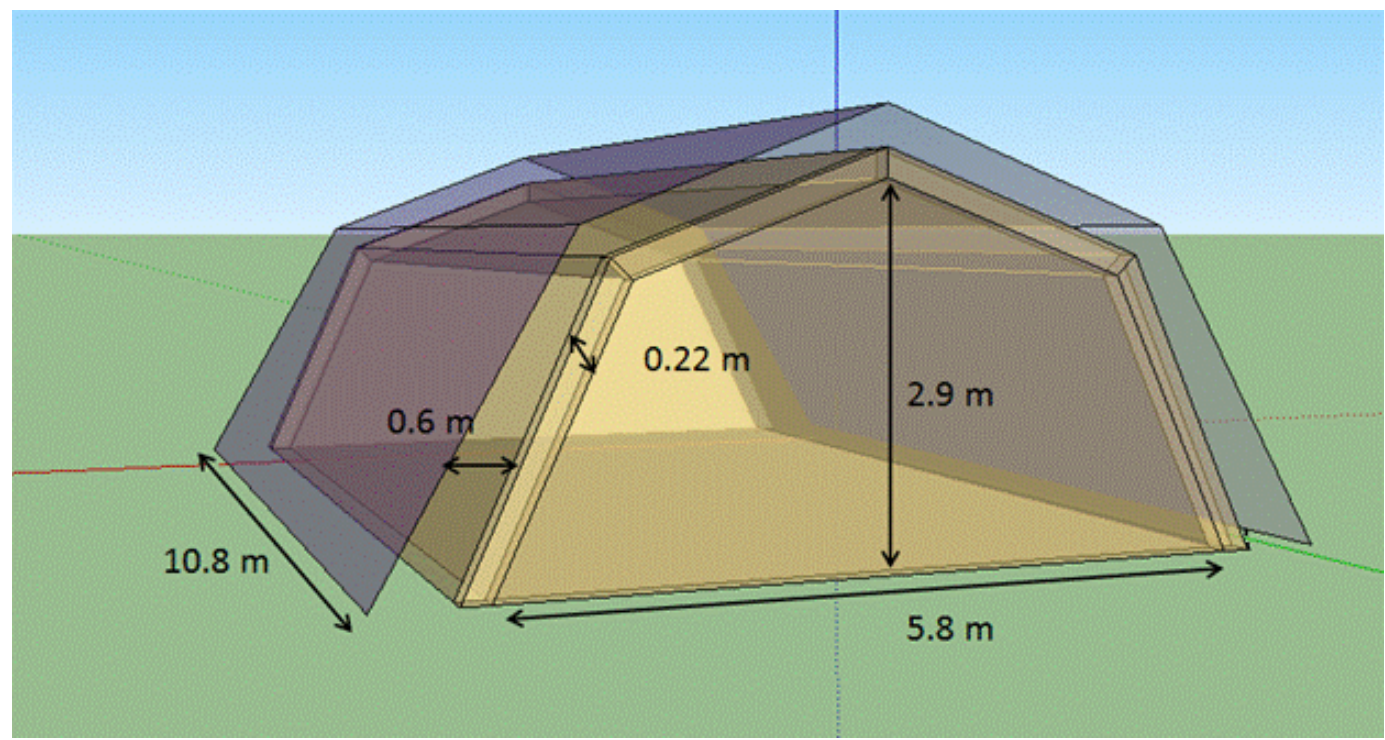

\subsubsection{Material properties}

The surface properties of the inner shell, outer liner, and shade fly were based on laboratory measurements performed at NREL. Thermal resistance properties came from manufacturer data or estimates based on engineering tables for similar materials. The properties are given in Table 3 and Table 4.

Table 3. AirBeam shelter material properties for model calibration.

\begin{tabular}{|l|c|c|c|c|c|c|}
\hline \multirow{2}{*}{ Property } & \multirow{2}{*}{ Units } & \multicolumn{2}{|c|}{ Exterior Shell } & \multicolumn{2}{c|}{ Inner Liner } & Floor \\
\cline { 3 - 7 } & & $\begin{array}{c}\text { Outer } \\
\text { Surface }\end{array}$ & $\begin{array}{c}\text { Inner } \\
\text { Surface }\end{array}$ & $\begin{array}{c}\text { Outer } \\
\text { Surface }\end{array}$ & $\begin{array}{c}\text { Inner } \\
\text { Surface }\end{array}$ & $\begin{array}{c}\text { Inner } \\
\text { Surface }\end{array}$ \\
\hline Roughness & - & $\begin{array}{c}\text { Medium } \\
\text { Smooth }\end{array}$ & $\begin{array}{c}\text { Medium } \\
\text { Smooth }\end{array}$ & $\begin{array}{c}\text { Medium } \\
\text { Smooth }\end{array}$ & $\begin{array}{c}\text { Medium } \\
\text { Smooth }\end{array}$ & $\begin{array}{c}\text { Medium } \\
\text { Smooth }\end{array}$ \\
\hline Thermal absorptance & Fraction & 0.897 & 0.90 & 0.889 & 0.899 & $0.72^{\mathrm{a}} / 0.742^{\mathrm{b}}$ \\
\hline Solar absorptance & Fraction & 0.571 & 0.9 & 0.13 & 0.13 & 0.2 \\
\hline Visible absorptance & & 0.6 & 0.9 & 0.13 & 0.13 & 0.2 \\
\hline Thermal resistance & $\mathrm{m}^{2} \mathrm{~K} / \mathrm{W}$ & \multicolumn{2}{|c|}{0.0088} & & 0.0088 & $0.5^{\mathrm{a}} / 0.0176^{\mathrm{b}}$ \\
\hline
\end{tabular}

a Surface property of polystyrene for cooling season tests

b Surface property of standard floor material for heating season tests 
Table 4. Utilis shelter material properties for model calibration.

\begin{tabular}{|l|c|c|c|c|c|c|}
\hline \multirow{2}{*}{ Property } & \multirow{2}{*}{ Units } & \multicolumn{2}{|c|}{ Exterior Shell } & \multicolumn{2}{c|}{ Inner Liner } & Floor \\
\cline { 3 - 7 } & & $\begin{array}{c}\text { Outer } \\
\text { Surface }\end{array}$ & Inner Surface & $\begin{array}{c}\text { Outer } \\
\text { Surface }\end{array}$ & $\begin{array}{c}\text { Inner } \\
\text { Surface }\end{array}$ & Inner Surface \\
\hline Roughness & - & $\begin{array}{c}\text { Medium } \\
\text { Smooth }\end{array}$ & Smooth & Smooth & Smooth & Smooth \\
\hline Thermal absorptance & Fraction & 0.897 & 0.900 & 0.799 & 0.780 & $0.72^{\mathrm{a}} / 0.742^{\mathrm{b}}$ \\
\hline Solar absorptance & Fraction & 0.571 & 0.9 & 0.13 & 0.13 & 0.2 \\
\hline Visible absorptance & & 0.571 & 0.9 & 0.13 & 0.13 & 0.2 \\
\hline Thermal resistance & $\mathrm{m}^{2} \mathrm{~K} / \mathrm{W}$ & \multicolumn{3}{|c|}{0.088} & \multicolumn{3}{|c|}{$0.46^{\mathrm{c}}$} & $0.5^{\mathrm{a}} / 0.0176^{\mathrm{b}}$ \\
\hline
\end{tabular}

a Surface property of polystyrene for cooling season tests

b Surface property of standard floor material for heating season tests

c Bondcote specification sheet for Extreme 250 insulating fabric with Thinsulate

\subsubsection{Shade fly thermal performance}

The shade fly for both shelters is a tan colored mesh that is supported 6 12 in. above the shelter. The detached shade model in EnergyPlus is a simple model created for solid or partial shading of direct and diffuse solar radiation. However, it is thought to be inadequate for the shade fly on the shelters for several reasons:

- The shading model does not include transmittance as a function of solar angle of incidence.

- The shading model does not include the partial blocking of infrared heat exchange that occurs between the outer fabric of the shelter and the sky.

- The shading model does not include the effect that solar radiation striking the shading fabric will have on the infrared heat exchange between the outer surface of the shelter and the shading fabric. The shading fabric will be warm when irradiated by the sun, which will reduce the infrared heat loss from the shelter fabric to the shading fabric.

- The shading model does not correctly model the convective thermal conditions between the outer surface of the shelter and the shading fabric.

New thermal models were developed for the shade fly on each shelter in an attempt to model these heat-transfer paths. These models are described in sections 3.1.3.1 and 3.1.3.2, and are implemented in the EnergyPlus Energy Management System (EMS) code that sits outside of the EnergyPlus simulations. 


\subsubsection{Heat exchange through shading fabrics}

Figure 30 shows the thermal network used to calculate convective and radiative heat loss from the outside surface of a shelter when a fabric is placed as a shade fly over the shelter. The total convective and radiative heat loss from the shelter surface in the "correct" circuit is equal to the total convective and radiative heat loss in the "equivalent" circuit. At each time step in the simulation, the "correct circuit" is iteratively solved in the EMS code and then used to calculate values for the convection heattransfer coefficient, emissivity, and amount of solar radiation reaching the shelter's outer surface in the "equivalent circuit." These calculated heattransfer coefficients are used in the EnergyPlus simulation.

Figure 30. Thermal models for heat transfer through the shading fabric.
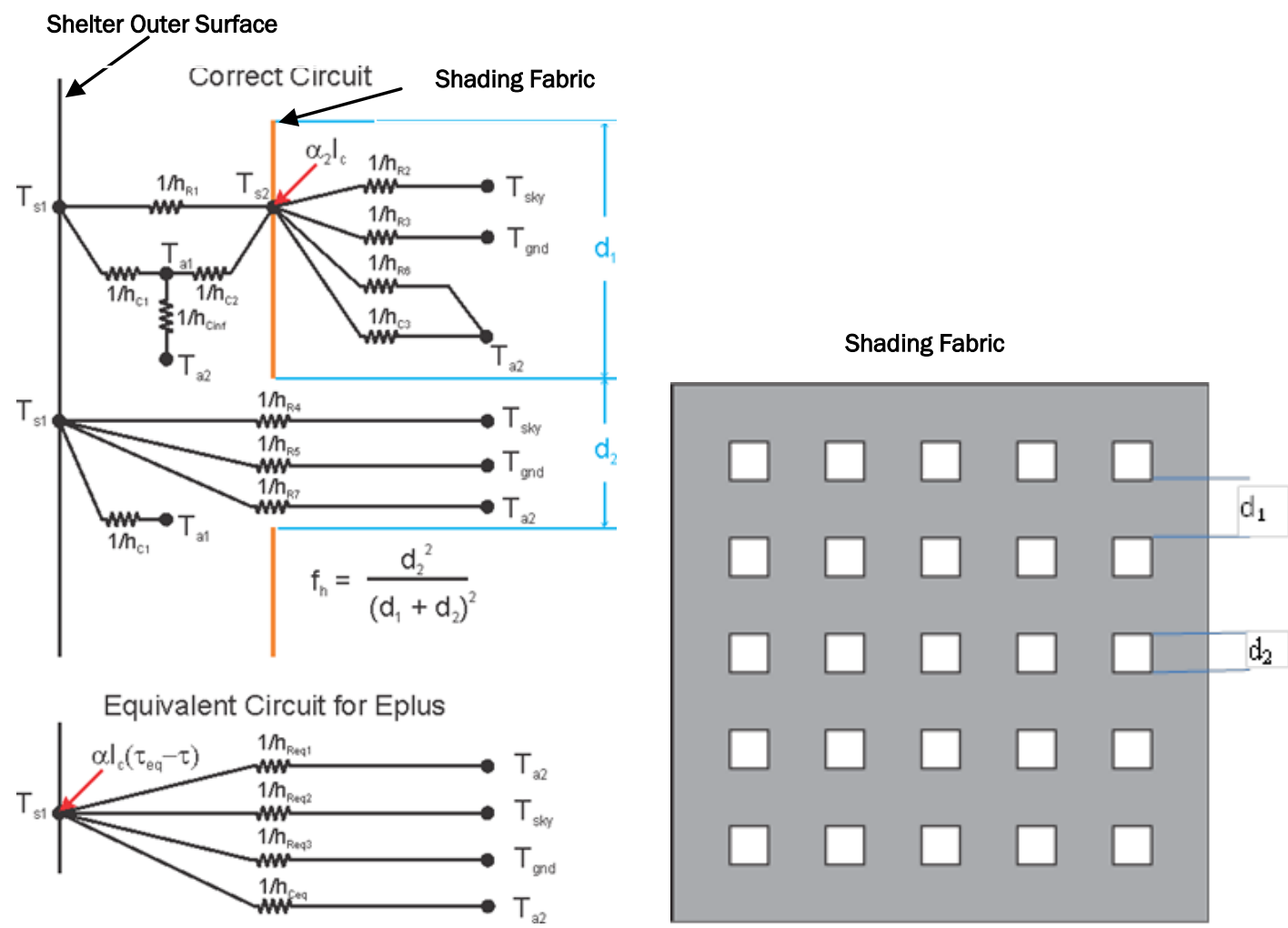

The following is a key to the notation in Figure 30

$\mathrm{d}_{1}=$ distance between edges of square holes in shading fabric

$\mathrm{d}_{2}=$ length of side of one square hole in shading fabric

$\mathrm{T}_{\mathrm{s} 1}=$ temperature, shelter surface

$\mathrm{T}_{\mathrm{a} 1}=$ temperature, air gap between shelter surface and shading fabric 


$$
\begin{aligned}
& \mathrm{T}_{\mathrm{a} 2}=\text { temperature, outdoor air } \\
& \mathrm{T}_{\text {sky }}=\text { temperature, effective sky } \\
& \mathrm{T}_{\text {gnd }}=\text { temperature, ground surface } \\
& \mathrm{h}_{\mathrm{c} 1}=\text { convective heat-transfer coefficient, shelter surface to air in } \\
& \text { gap } \\
& \mathrm{h}_{\mathrm{c} 2}=\text { convective heat-transfer coefficient, air in gap to inside surface } \\
& \text { of shading fabric } \\
& h_{\text {cinf }}=\text { heat-transfer coefficient, gap to outdoor air (i.e. infiltration } \\
& \text { into gap) } \\
& \mathrm{h}_{\mathrm{c} 3}=\text { convective heat-transfer coefficient, outside surface of shading } \\
& \text { fabric to outdoor air } \\
& \mathrm{h}_{\text {Ceq }}=\text { equivalent convective heat-transfer coefficient, outside surface } \\
& \text { of shading fabric to outdoor air } \\
& \mathrm{h}_{\mathrm{R} 1}=\text { radiative heat-transfer coefficient, shelter surface to inside } \\
& \text { surface of shade } \\
& \mathrm{h}_{\mathrm{R} 2}=\text { radiative heat-transfer coefficient, outside shade surface to sky } \\
& \mathrm{h}_{\mathrm{R} 3}=\text { radiative heat-transfer coefficient, outside shade surface to } \\
& \text { ground } \\
& \mathrm{h}_{\mathrm{R} 4}=\text { radiative heat-transfer coefficient, shelter surface to sky } \\
& \mathrm{h}_{\mathrm{R} 5}=\text { radiative heat-transfer coefficient, shelter surface to ground } \\
& \mathrm{h}_{\mathrm{R} 6}=\text { radiative heat-transfer coefficient, outside shade surface to } \\
& \text { outdoor air } \\
& \mathrm{h}_{\mathrm{R} 7}=\text { radiative heat-transfer coefficient, shelter surface to outdoor } \\
& \text { air } \\
& \mathrm{h}_{\text {Req1 }}=\text { equivalent radiative heat-transfer coefficient, shelter surface to } \\
& \mathrm{h}_{\text {Req2 }}=\text { equivalent radiative heat-transfer coefficient, shelter surface to } \\
& \text { sky } \\
& \mathrm{h}_{\text {Req3 }}=\text { equivalent radiative heat-transfer coefficient, shelter surface to } \\
& \text { ground } \\
& \mathrm{f}_{\mathrm{h}}=\text { hole fraction of shade fabric } \\
& \alpha=\text { solar absorptance of shelter surface } \\
& \mathrm{I}_{\mathrm{C}}=\text { global solar radiation incident on shelter surface } \\
& \tau=\text { true overall solar transmittance of shading fabric } \\
& \tau_{\mathrm{eq}}=\text { equivalent solar transmittance of shading fabric }
\end{aligned}
$$

The radiative heat-transfer coefficients are defined as:

$$
h_{R}=\sigma \varepsilon_{1} F\left(T_{1}^{2}-T_{2}^{2}\right)\left(T_{1}+T_{2}\right)
$$


where

$$
\begin{aligned}
\sigma & =\text { Stefan-Boltzmann constant } \\
\varepsilon_{1} & =\text { emissivity of surface } 1 \\
\mathrm{~F} & =\text { view factor of surface } 1 \text { to surface } 2 \\
\mathrm{~T}_{1} & =\text { temperature of surface } 1 \\
\mathrm{~T}_{2} & =\text { temperature of surface } 2
\end{aligned}
$$

The total rate of energy leaving the node $\mathrm{T}_{\mathrm{s} 1}$ is calculated as two different values: the first $\left(\mathrm{Q}_{1}\right)$ as if the shading fabric has no holes, the second $\left(\mathrm{Q}_{2}\right)$ as if the fabric is not there (i.e., "all holes"). The total rate of convective and radiative loss from $T_{\mathrm{s} 1}$ is then calculated in Equation 10 as a weighted average of the two values, weighted by the hole fraction, $\mathrm{f}_{\mathrm{h}}$ :

$$
Q_{t o t}=Q_{1}\left(1-f_{h}\right)+Q_{2}\left(f_{h}\right)
$$

It should also be noted that in our analysis we have assumed a high enough value of $h_{\text {cinf }}$ such that $T_{a 1}$ is almost equal to $T_{a}$, implying a very large infiltration rate into the gap between the shelter surface and the shading fabric.

\subsubsection{Solar transmittance of shade fabric}

The results of solar transmittance tests on the shading material are shown in Figure 31 and Figure 32 for the Utilis and AirBeam shelters. The graphs show the strong dependence of beam solar transmittance on the incidence angle. The data were collected by simultaneously measuring the beam and diffuse solar radiation on a clear day in front of and behind a sample of the shading fabric at various angles relative to the sun's position. 
Figure 31. Solar transmittance as a function of beam incidence angle for the Utilis shading fabric.

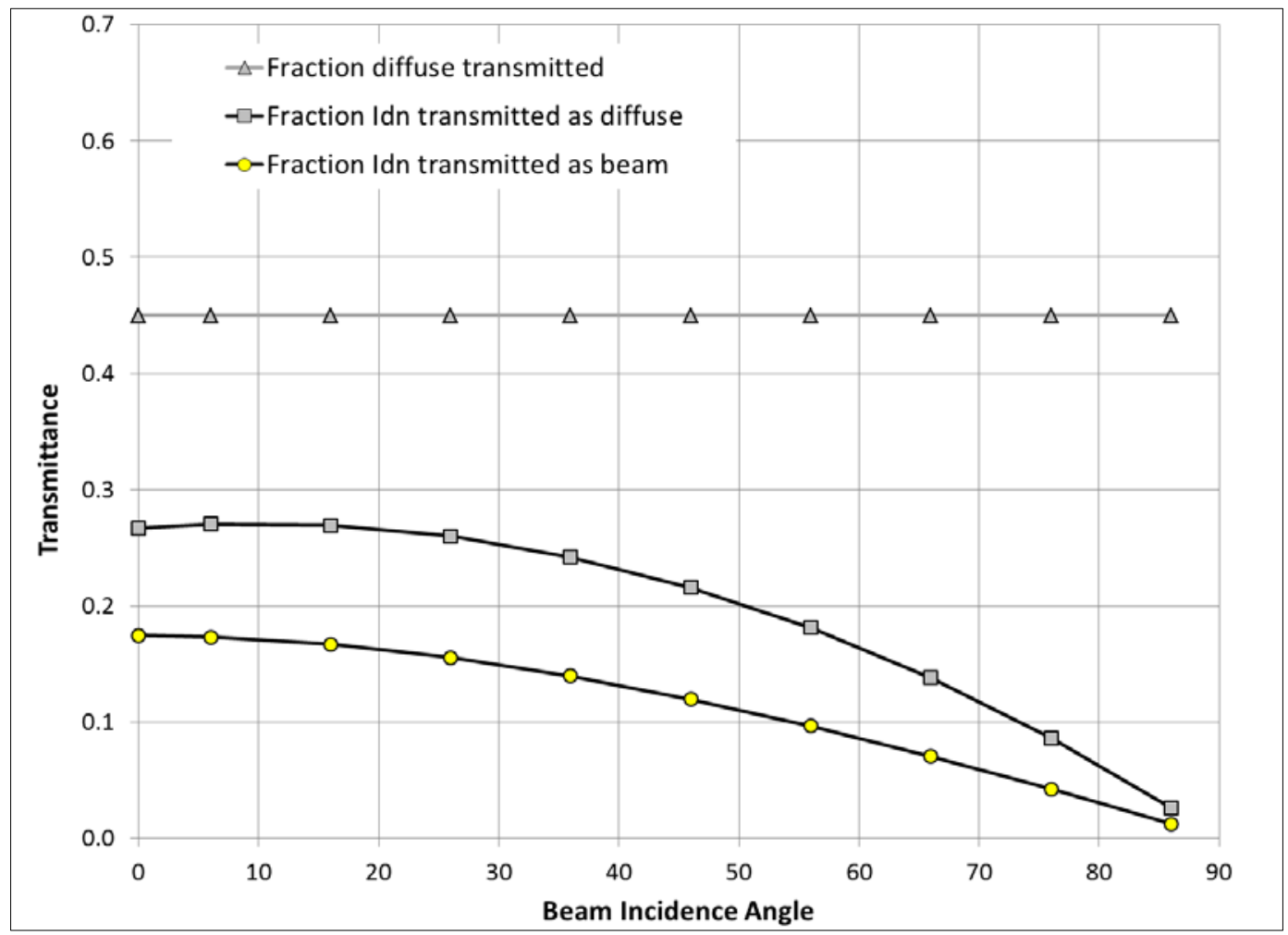

Figure 32. Solar transmittance as a function of beam incidence angle for the AirBeam shading fabric.

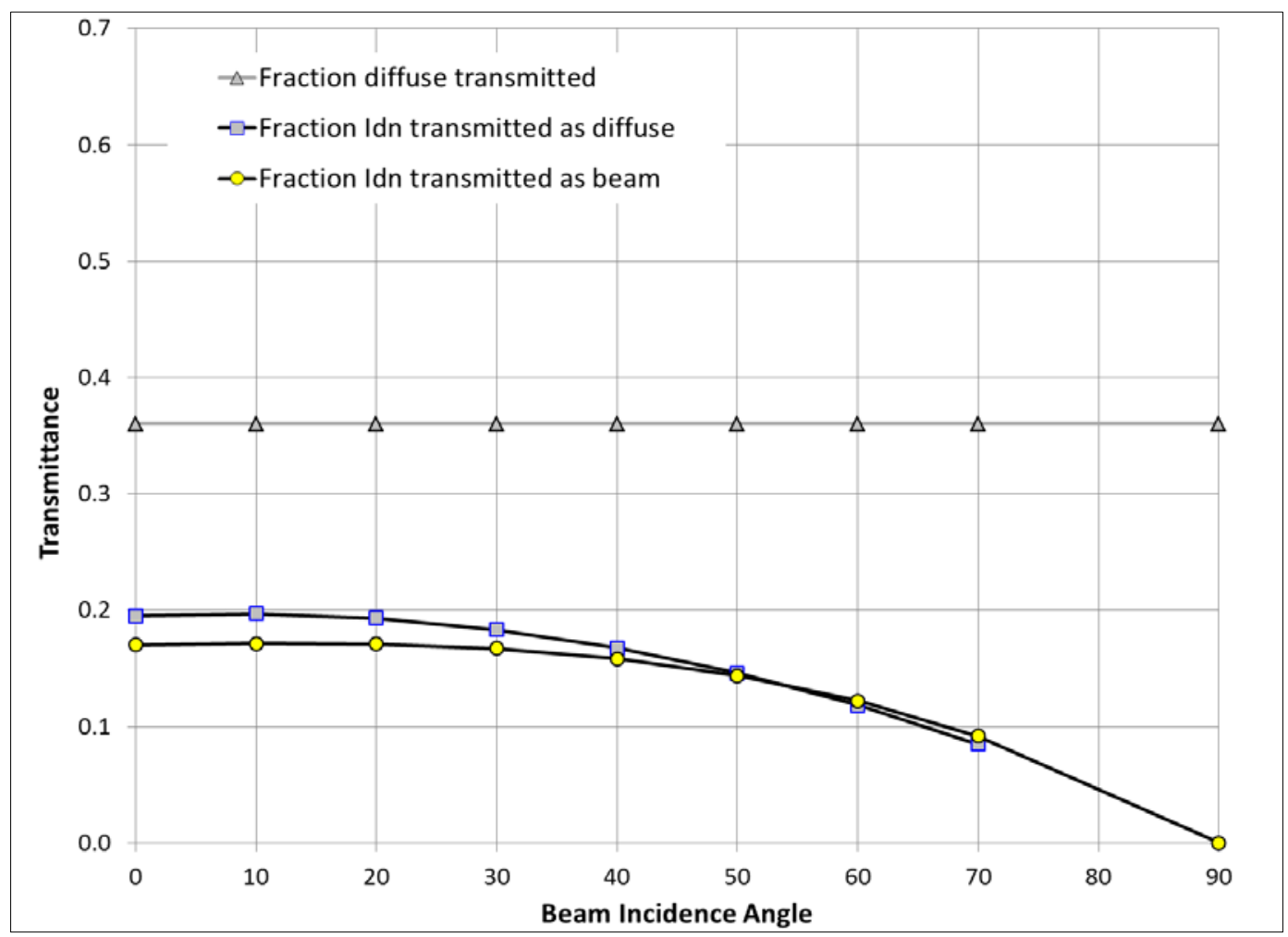


A new model was created to approximate the effects of the shade fly mesh that takes into account the angular dependence of the solar transmittance. This algorithm was implemented in the EnergyPlus EMS code as Equations 11 and 12:

$$
\begin{gathered}
I_{g, s h}=f_{b} I_{d n} \cos \theta_{i}+f_{b d} I_{d n}+f_{d} I_{d} \\
\tau_{s h}=I_{g, s h} / I_{g}
\end{gathered}
$$

where

$$
\begin{aligned}
I_{g, s h}= & \text { global solar radiation on the shelter surface }\left[\mathrm{W} / \mathrm{m}^{2}\right] \\
I_{d n}= & \text { direct normal solar radiation on the shading surface }\left[\mathrm{W} / \mathrm{m}^{2}\right] \\
I_{d}= & \text { total diffuse (sky and ground) solar radiation on the shading } \\
& \text { surface }\left[\mathrm{W} / \mathrm{m}^{2}\right] \\
I_{g}= & \text { global solar radiation on the shading surface }\left[\mathrm{W} / \mathrm{m}^{2}\right] \\
\theta_{i}= & \text { incidence angle of direct normal solar radiation } \\
f_{b}= & \text { fraction of } I_{d n} \text { transmitted through the shade as beam radiation } \\
f_{b d}= & \text { fraction of } I_{d n} \text { transmitted through the shade as diffuse } \\
& \text { radiation } \\
f_{d}= & \text { fraction of } I_{d} \text { transmitted through the shade } \\
\tau_{s h}= & \text { effective transmittance of the shade fly }
\end{aligned}
$$

Equation 11 estimates the global solar radiation that is transmitted through the shade fly mesh and is incident on the outer surface of the shelter. Equation 12 is the effective solar transmittance that is calculated as the ratio of the global solar radiation transmitted through the shade fly to the global solar radiation on the shade fly. This transmittance is calculated in the EnergyPlus EMS code and inserted into the EnergyPlus simulation at each time step during daytime hours.

The fractions of the transmitted solar radiation were derived from the graphs in Figure 31 and Figure 32. The equations for these correlations are shown in Equations 13 - 15, and the coefficients are shown in Table 5.

$$
\begin{gathered}
f_{d}=a_{0} \\
f_{b}=b_{1}\left(90-\theta_{i}\right)+b_{2}\left(90-\theta_{i}\right)^{2}+b_{3}\left(90-\theta_{i}\right)^{3} \\
f_{b d}=c_{1}\left(90-\theta_{i}\right)+c_{2}\left(90-\theta_{i}\right)^{2}
\end{gathered}
$$


Table 5. Coefficients for solar fraction correlations.

\begin{tabular}{|l|c|c|}
\hline \multicolumn{1}{|c|}{ Coefficient } & Utilis (tan) & HDT (tan) \\
\hline ao & 0.45 & 0.36 \\
\hline $\mathrm{b}_{1}$ & $3.104 \mathrm{E}-03$ & $5.747 \mathrm{E}-03$ \\
\hline $\mathrm{b}_{2}$ & $-4.681 \mathrm{E}-06$ & $-6.257 \mathrm{E}-05$ \\
\hline $\mathrm{b}_{3}$ & $-9.193 \mathrm{E}-08$ & $2.189 \mathrm{E}-07$ \\
\hline $\mathrm{c}_{1}$ & $6.759 \mathrm{E}-03$ & $4.824 \mathrm{E}-03$ \\
\hline $\mathrm{C}_{2}$ & $-4.217 \mathrm{E}-05$ & $-2.954 \mathrm{E}-05$ \\
\hline
\end{tabular}

\subsubsection{Details specific to model calibration study}

Test data were stored as 15 minute averages or totals for all measurement points. All simulations were run on a 15 minute time step. Schedules on 15 minute time intervals of infiltration and indoor air temperature were created from the measured data and used as inputs to the models. The time series of indoor air temperature was used in the models as the thermostat heating set point.

The model of the floor of each shelter for calibration runs was designed to ensure that the modeled total heat flow through the floor would be equal to the measured heat flow (see Equation 5). The approach used was to model a fictitious, massless insulating layer of arbitrary thermal resistance $\left(0.5 \mathrm{~m}^{2} \cdot \mathrm{K} / \mathrm{W}\right)$ on the floor with a calculated temperature on the bottom side of the insulating layer for each 15 minute time step. This is shown in Equation 16:

$$
T_{b o t}=T_{f}-Q_{f} R
$$

where

$$
\begin{aligned}
\mathrm{T}_{\text {bot }}= & \text { temperature of bottom surface of fictitious insulating layer } \\
& {\left[{ }^{\circ} \mathrm{C}\right] } \\
\mathrm{T}_{\mathrm{f}}= & \text { measured floor surface temperature }\left[{ }^{\circ} \mathrm{C}\right] \\
\mathrm{Q}_{\mathrm{f}}= & \text { measured floor heat flux }\left[\mathrm{W} / \mathrm{m}^{2}\right] \\
\mathrm{R} & =\text { thermal resistance of fictitious layer }\left[\mathrm{m}^{2} \cdot \mathrm{K} / \mathrm{W}\right]
\end{aligned}
$$

A schedule of values of $\mathrm{T}_{\text {bot }}$ for each 15 minute time interval during the test was created using Equation 14. Using this temperature schedule as an input, the model then calculated the resulting top surface temperature and 
resulting heat flow through the floor. If the model were perfect, the modeled top surface temperature would equal the measured temperature at each simulation time step, and the heat flow to the ground would, by definition, match the measured heat flux. Trying to match the modeled floor surface temperature to the measured temperature was part of the modelcalibration process.

During the heating-season tests the indoor air temperature was maintained by controlling convective electric heaters. To emulate this type of heating in the model for the purposes of model calibration, the "Baseboard:RadiantConvective" model available in EnergyPlus was used, with a radiant fraction of 0.0 .

During the cooling-season tests, a 5 ton ECU was used to maintain the cooling set point. To emulate this type of cooling device in the model, the "Packaged Terminal Air Conditioner" (PTAC) model was used in EnergyPlus to represent the ECU. The model merely had to maintain the air temperature of the interior of the structure by removing sensible energy from the air, and the magnitude of this energy removal was compared to the measured value (Equation 8). Therefore, the PTAC's modeled efficiency was not relevant to calibrating the thermal performance of the shelter itself.

Custom fifteen-minute-interval weather files were generated with the EnergyPlus Weather Converter program using one-minute averaged weather station data collected during each field test. The following measurements were included:

- Outdoor dry bulb temperature

- Relative humidity

- Wind speed

- Wind direction

- Sky radiation

- Global horizontal solar radiation

- Direct normal solar radiation 


\subsection{Calibration study}

\subsubsection{Approach}

The general philosophy of model calibration is to limit the calibration to the adjustment of parameters that cannot be known with enough certainty to be incorporated into the model. For example, the solar absorptance of the outer fabric of the shelter was measured in a laboratory at NREL. By measuring difficult-to-predict heat flows (infiltration, ground heat flux) the calibration process was made simpler: the heat flows not measured were the heat flows through the walls and roof of the shelter, so that only those parameters that affect the heat flow through the roof and walls need to be adjusted to match model to measurement. Among those parameters, many are constants that were measured in the laboratory (i.e., fabric properties listed in Table 3 and Table 4).

Figure 33 is a simplified diagram of the thermal network in the Utilis model. Resistances to heat flow are shown as resistor symbols as used in electronics circuit diagrams. Resistances between a surface temperature and an air temperature represent resistance to convective heat flow, governed by convective heat-transfer coefficients. Resistances between two surface temperatures represent resistance to infrared heat flow, governed by surface emissivities. The emissivities of the surfaces were measured in the laboratory, leaving the most significant uncertain heat-flow parameters in the model to be the convection coefficients on each fabric surface.

Figure 33. Simplified thermal network showing resistances to heat flow through various paths.

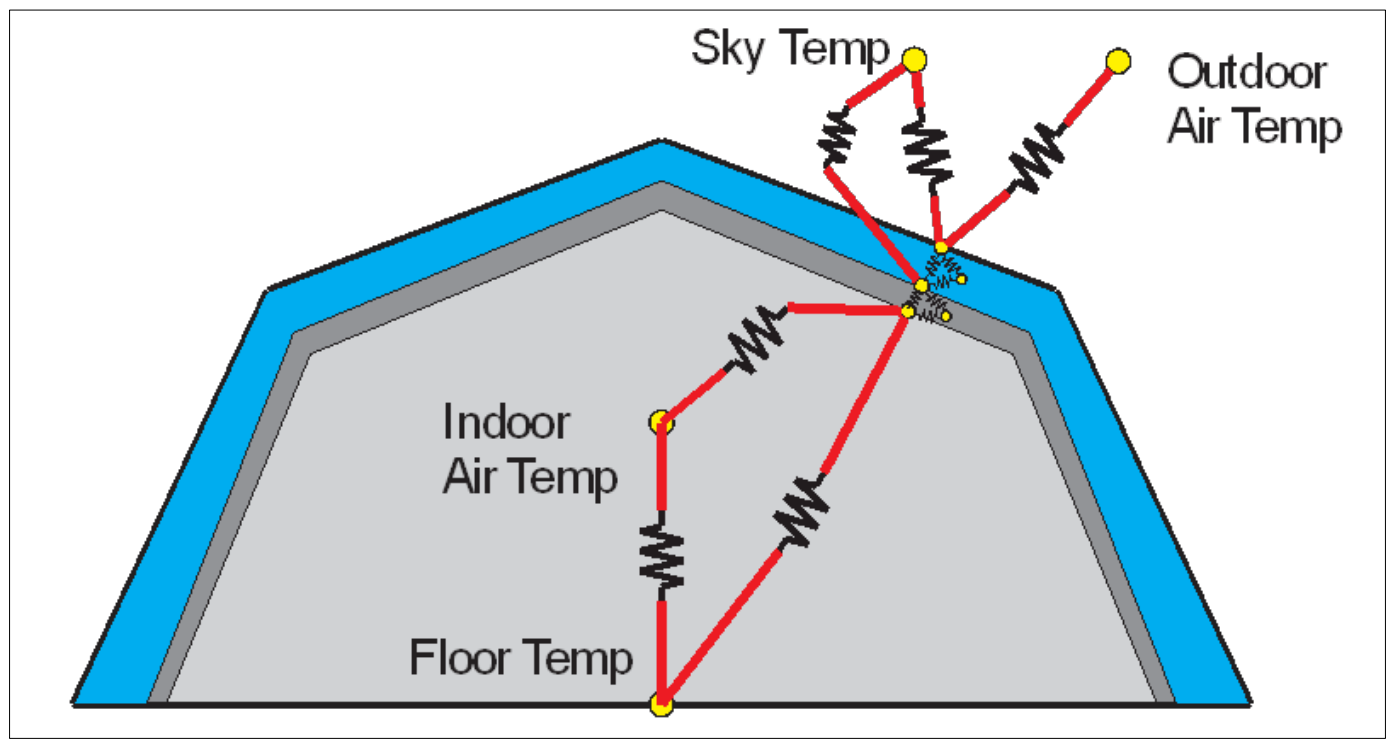


In typical building simulations, the exact magnitudes of convective heattransfer coefficients are not very important because the dominant resistance to heat flow is the thermal conductivity of the walls. In the case of fabric structures, however, the resistance to thermal conduction through the fabric itself is low so the convective and radiative heat transfers are the dominant mechanisms for heat flow. However, the correlations for convective heat-transfer coefficients in EnergyPlus were developed for rigid surfaces found in buildings, and are not appropriate for moving fabric surfaces. A study by Zaki, Al-Turki, and Fatani (1993) estimated that the convective heat-transfer coefficients on taut fabric surfaces could be approximately two to three times the order of magnitude of those for smooth, rigid surfaces. The surfaces in these military shelters are relatively loose and are moved freely by an ECU fan and wind, potentially causing even higher convection heat-transfer coefficients. In addition, the shapes of the shelters are not as precisely aligned in the EFOB-L as the drawings here may imply. The air gaps between the inner and outer fabrics are shaped by draped fabrics enclosing irregular air pockets. The natural convection patterns that develop in the air gaps are most likely not wellbehaved as the convection patterns upon which the standard correlations are based.

Developing new correlations for loose fabric surfaces was beyond the scope of this project. Therefore, we selected the best correlations from the EnergyPlus library for different surface types, surface orientations, and direction of heat flow and applied scaling factors for each surface type that could be adjusted to calibrate the models with the measured energy data.

Comparing model to measurement requires an output or outputs from the simulation that can be compared to measured values. In this case the principal measured quantity for comparison was the total heating or cooling needed to maintain the shelter's indoor air temperature. Secondary measured quantities included the surface temperatures of the fabrics. These secondary comparison points are useful in deciding whether or not the correct convection heat-transfer coefficients are being used on each surface. If only the total heating or cooling energy is used as a basis for comparison between model and measurement there would likely be more than one combination of adjustments to the many convection coefficients that would yield similar agreement of total energy between model and measurement for the test period. Some of these combinations would not necessarily yield good agreement between model and measurement under a 
different set of test conditions. Since the goal in calibrating the model is to gain confidence in a model's ability to correctly predict performance over a wider range of conditions than were encountered during field measurements, it was important to have the secondary comparisons to be sure all parts of the model are behaving correctly.

The energy models are made up of many surfaces as shown previously in Figure 28 and Figure 29, and each has an associated convection coefficient. To simplify the calibration process, we broke these "faces" into five categories:

- Floor surface

- Inside face of inside liner

- Outside face of inside liner (inside the air gap)

- Inside face of outer shell (inside air gap)

- Outside face of outer shell

Five custom scaling factors, each applying to the convection coefficients associated with each surface category were developed by calibrating the models for each shelter to the measured data. EnergyPlus does not allow the convection heat-transfer coefficients to be adjusted or scaled; therefore, the convection heat-transfer coefficients are calculated outside of the EnergyPlus simulation in the EnergyPlus EMS code. Then the calculated heat-transfer coefficients with the appropriate scaling factors are inserted into the EnergyPlus simulation for each surface at each time step.

The scaling factors were determined during the model-calibration process with the measured field data in a custom optimization routine built in Microsoft Excel Visual Basic for Applications (VBA). The objective function was the root mean square (RMS) errors between modeled and measured heating load and the modeled and measured surface temperatures. The optimization routines were run to minimize the RMS errors to determine the values of the five independent variables (i.e., the scaling factors). These scaling factors were then used for the annual simulations.

\subsubsection{Results}

The models were calibrated on the measured energy flows of the ECU and the ground heat flux by adjusting the convection heat-transfer coefficient scaling factors across the March and J une calibration periods. The AirBeam model was calibrated in the baseline condition because that is the 
configuration that was field tested. The Utilis shelter was field monitored with a shade fly and a Thinsulate liner with an added radiant barrier, so the calibration energy model included these features. We attempted to calibrate the Utilis energy model with the newly derived models described in section 3.1.3.1 and section 3.1.3.2; however, the calibration results were not physically sensible and resulted in high errors and unrealistic scaling factors. We were unable to determine the source of these errors and instead used the EnergyPlus detached shading model with a solar transmittance of 0.44 .

Table 6 shows the average ECU energy and the ground heat flux with the model errors. Table 7 shows the scaling factors that are applied to the surface convection heat-transfer coefficients calculated during the annual simulations.

Table 6. Model calibration results.

\begin{tabular}{|l|c|c|c|c|c|c|c|c|}
\hline \multirow{2}{*}{ Shelter } & \multicolumn{4}{|c|}{ Total ECU Energy } & \multicolumn{4}{c|}{ Ground Heat Flux } \\
\cline { 2 - 10 } & \multicolumn{2}{|c|}{ March } & \multicolumn{2}{c|}{ June } & \multicolumn{2}{c|}{ March } & \multicolumn{2}{c|}{ June } \\
\cline { 2 - 9 } & Avg (kW) & RMS Error & Avg (kW) & RMS Error & Avg (kW) & RMS Error & Avg (kW) & RMS Error \\
\hline AirBeam & 5.37 & $9.2 \%$ & 6.36 & $7.9 \%$ & 0.67 & $46.9 \%$ & -0.07 & $34.9 \%$ \\
\hline Utilis & 2.89 & $15.6 \%$ & 2.59 & $10.6 \%$ & 0.93 & $15.8 \%$ & 0.20 & $10.2 \%$ \\
\hline
\end{tabular}

Table 7. Convection heat-transfer coefficient scaling factors

\begin{tabular}{|l|c|c|c|c|c|}
\hline \multirow{2}{*}{ Shelter } & \multicolumn{2}{|c|}{ Inner Shell } & \multicolumn{2}{c|}{ Outer Shell } & Floor \\
\cline { 2 - 6 } & Inner Face & Outer Face & Inner Face & Outer Face & Inner Face \\
\hline AirBeam & 4.58 & 13.62 & 7.01 & 0.50 & 1.25 \\
\hline Utilis & 5.14 & 6.37 & 11.19 & 0.50 & 0.50 \\
\hline
\end{tabular}

Use of the calibrated scaling factors is not ideal, but it does allow the energy simulation to capture some of the dynamic effects of the convection coefficients with changing conditions and provides an adjustment for the fabric surface. These scaling factors are derived for these specific shelter configurations and conditions, so they may not translate very well to other applications. 


\section{Simulations and Analyses}

The calibrated models were used to assess the performance of alternative envelope configurations in four locations to determine potential energy savings. These locations included the EFOB-L at Champaign, IL; Fort Devens, MA; Ali Al Salem, Kuwait; and Panama City, FL.

\subsection{Annual model descriptions}

Adjustments were made to the calibrated energy models for the annual simulations. Changes to the calibrated models are explained below.

\subsubsection{Ground heat transfer}

The floor was modeled as 1 meter of soil with a half cm air gap and the floor liner. However, the combination of the thin floor liner and the thermally massive soil caused the simulation to be unstable and stop prematurely, and the liner was eliminated from the construction. The annual model uses average monthly ground temperatures at $1 \mathrm{~m}$ depth, which were interpolated from the monthly ground temperatures at $0.5 \mathrm{~m}, 2 \mathrm{~m}$, and $4 \mathrm{~m}$ from the EnergyPlus statistical weather information file for each location. The floor material properties are listed in Table 8.

Table 8. Floor material properties.

\begin{tabular}{|l|c|c|c|}
\hline Property & Units & 1 meter soil & Half-inch air gap \\
\hline Roughness & - & Smooth & Smooth \\
\hline Thickness & $\mathrm{m}$ & 1 & 0.005 \\
\hline Conductivity & $\mathrm{W} / \mathrm{m} \cdot \mathrm{K}$ & 0.88 & \\
\hline Density & $\mathrm{Kg} / \mathrm{m}^{3}$ & 1200 & \\
\hline Specific heat & $\mathrm{J} / \mathrm{kg} \cdot \mathrm{K}$ & 2192 & \\
\hline Thermal absorptance & Fraction & 0.9 & 0.9 \\
\hline Solar absorptance & Fraction & 0.5 & 0.45 \\
\hline Visible absorptance & Fraction & 0.5 & 0.6 \\
\hline Thermal resistance & m².K/W & - & 0.47 \\
\hline
\end{tabular}




\subsubsection{Infiltration}

Infiltration was modeled in EnergyPlus using the ZoneInfiltration: EffectiveLeakageArea object following Equation 1 and the equivalent leakage areas (ELA) measured during the summer monitoring period using a blower-door analysis as shown in Table 9. The stack and wind coefficients were taken from the EnergyPlus Input/ Output Reference for a one-story house with no obstructions or shielding of the wind (DOE 2014b). We do not know the application of the shelters in the field, but we selected the no-shielding case because the shelters are sensitive to wind speed and it is the most conservative scenario. The stack and wind coefficients for Equation 1 are 0.000145 and 0.000319 , respectively.

Table 9. Infiltration ELA and leakage rates.

\begin{tabular}{|l|c|c|c|c|}
\hline Shelter & ELA $\left(\mathrm{cm}^{2}\right)$ & ELA $\left(\mathrm{in}^{2}\right)$ & $\mathrm{cfm} / \mathrm{ft}^{2} @ 4 \mathrm{~Pa}$ & $\mathrm{cfm} / \mathrm{ft}^{2} @ 75 \mathrm{~Pa}$ \\
\hline AirBeam & 466 & 41 & 0.13 & 0.70 \\
\hline Utilis & 264 & 72 & 0.18 & 0.98 \\
\hline
\end{tabular}

\subsubsection{Thermostat set points and control}

The assigned heating and cooling set points were $20^{\circ} \mathrm{C}\left(68^{\circ} \mathrm{F}\right)$ and 26.7 ${ }^{\circ} \mathrm{C}\left(80^{\circ} \mathrm{F}\right)$, respectively. The ECU model allowed for heating or cooling whenever necessary.

\subsubsection{Internal loads}

It was assumed that the shelters were command and control centers with continuous operation. It was assumed that the internal electrical equipment loads were $5 \mathrm{~kW}$ and that there were 20 occupants.

\subsection{Alternative envelope configurations}

The calibrated models were used to assess the performance of alternative envelope configurations to determine the impact on ECU energy consumption. The alternative envelope options are listed in Table 10 and the material properties are listed in Table 11. 
Table 10. Alternative envelope options.

\begin{tabular}{|l|l|l|}
\hline Envelope Options & \multicolumn{1}{|c|}{ Materials } & \multicolumn{1}{c|}{ Shelter } \\
\hline Baseline & Inner liner & AirBeam; Utilis \\
\hline Option 1 & Baseline + radiant barrier & AirBeam; Utilis \\
\hline Option 2 & Baseline + shade fly & AirBeam; Utilis \\
\hline Option 3 & Thinsulate liner * & AirBeam; Utilis \\
\hline Option 4 & Thinsulate liner and radiant barrier & AirBeam; Utilis \\
\hline Option 5 & Baseline + PCM & AirBeam \\
\hline
\end{tabular}

* The Thinsulate liner replaces the baseline inner liner.

Table 11. Envelope material properties.

\begin{tabular}{|l|c|c|c|c|c|}
\hline Property & Units & $\begin{array}{c}\text { Radiant } \\
\text { Barrier }\end{array}$ & Thinsulate & PCM & Shade \\
\hline Roughness & - & $\begin{array}{c}\text { Medium } \\
\text { Smooth }\end{array}$ & Smooth & Smooth & - \\
\hline Thickness & $\mathrm{m}$ & - & - & 0.01 & - \\
\hline Conductivity & $\mathrm{W} / \mathrm{m} \cdot \mathrm{K}$ & - & - & 0.2 & - \\
\hline Density & $\mathrm{Kg} / \mathrm{m}^{3}$ & - & - & 850 & - \\
\hline Specific heat & $\mathrm{J} / \mathrm{kg} \cdot \mathrm{K}$ & - & - & 2100 & - \\
\hline Thermal absorptance & Fraction & 0.05 & 0.8 & 0.9 & - \\
\hline Solar absorptance & Fraction & 0.05 & 0.3 & 0.7 & - \\
\hline Visible absorptance & Fraction & 0.05 & 0.3 & 0.7 & - \\
\hline Thermal resistance & mK/W & 0.03 & 0.46 & - & - \\
\hline Solar Transmittance & Fraction & - & - & - & 0.42 \\
\hline
\end{tabular}

The baseline construction for both shelters consists of an inner liner made of a white polymer canvas and an outer shell made of a slightly heavier polymer canvas. The color of the outer shell is tan on the outside and black on the inside. The radiant barrier is a very thin, highly reflective layer that lays on top of the inner liner. The Thinsulate liner is sandwiched between two layers of the inner liner material with a very thin layer of a radiant barrier material.

A simulation using the AirBeam shelter model was also run with a phasechange material (PCM) liner called BioPCMat ${ }^{\mathrm{TM}}$ (Phase Change Energy Solutions, Asheboro, NC), a sheet-type product that incorporates pockets of a nontoxic, biodegradable soy-based PCM (BioPCM 2013). Stock shelters of the type modeled have near-zero thermal mass except for contact with the ground, so the addition of the PCM liner was expected to have a 
larger impact on the shelter performance than it would in a conventional building. The thermodynamic and enthalpy properties (for cooling mode) are listed in Table 11 (above) and Table 12, respectively. The temperatureenthalpy curve was derived from experimental measurements of temperature and specific heat taken for a concurrent PCM study by ERDC-CERL researchers (results being prepared for publication in separate report. A thin blanket of this material was applied to the outside of the inner liner. The PCM blanket has pockets of PCM material, and it was assumed that the weight of PCM material was $0.53 \mathrm{lb} / \mathrm{ft}^{2}\left(2.59 \mathrm{~kg} / \mathrm{m}^{2}\right)$. The shelter with PCM liner was simulated in the eight U.S. climate zones listed in

Table 13.

Table 12. Temperature vs enthalpy of commercial PCM.

\begin{tabular}{|c|c|}
\hline Temperature $\left({ }^{\circ} \mathrm{C}\right)$ & Enthalpy $(\mathrm{J} / \mathrm{kg})$ \\
\hline 10.01 & 0.0142 \\
\hline 15.18 & 10.398 \\
\hline 21.09 & 107.929 \\
\hline 21.77 & 142.430 \\
\hline 22.05 & 152.413 \\
\hline 23.04 & 154.882 \\
\hline 26.61 & 160.025 \\
\hline
\end{tabular}

Table 13. U.S. climate zones for PCM modeling in AirBeam shelter.

\begin{tabular}{|c|c|c|}
\hline Climate Zone & Climate Description & Representative City \\
\hline 1A & Hot, humid & Miami, FL \\
\hline 2B & Hot, dry & Phoenix, AZ \\
\hline 3B & Warm, dry & Los Angeles, CA \\
\hline 4B & Mild, dry & Albuquerque, NM \\
\hline 5B & Cold, dry & Boulder, CO \\
\hline 6B & Cold, dry & Helena, MT \\
\hline 7 & Very cold & Duluth, MN \\
\hline 8 & Extremely cold & Fairbanks, AK \\
\hline
\end{tabular}

\subsection{Locations}

Simulations of both shelters were run using weather data for Champaign, IL; Fort Devens, MA; and Ali Al Salem, Kuwait. EnergyPlus weather files 
derived from National Solar Radiation Data Base TMY3 (Typical Meteorological Year 3) data were used for each location. In addition, as noted above, the AirBeam shelter with the PCM liner was simulated in eight U.S. locations representing each major climate zone (shown in Table 13).

\subsection{Performance results}

In all cases, the annual energy consumption for lighting and electrical equipment was $43,800 \mathrm{kWh}$, which is roughly two thirds of the total energy consumption. The lighting and equipment along with the occupants represents a significant internal load that has to be removed from the shelter to maintain the cooling set point. The load is so high that it results in very high cooling loads even in the cold months when the shelter is closed up with normal amount of infiltration. A much more efficient way to operate the shelters in this case is to open the doors and windows when it is cool outside. Natural ventilation was included in the EnergyPlus models at $5 \mathrm{ACH}$ to simulate opening the doors and windows when the outside air temperature was between $0{ }^{\circ} \mathrm{C}$ and $16.5^{\circ} \mathrm{C}\left(32^{\circ} \mathrm{F}\right.$ and $\left.62{ }^{\circ} \mathrm{F}\right)$. The natural ventilation is not allowed to cool the shelter below the heating set point of $20^{\circ} \mathrm{C}$. All of the simulations, including the baseline, applied natural ventilation to provide free cooling when it was available. Without the natural ventilation, the liners result in higher ECU energy consumption than the baseline because of the increased cooling loads from the trapped heat.

\subsubsection{AirBeam}

The annual performance for the AirBeam shelter with the alternative envelope configurations are presented in Table 14, Table 15, and Table 16, and shown graphically in Figure 34. The monthly ECU energy totals for the baseline and alternative (radiant barrier) scenarios at Champaign, IL, are shown in Figure 35 through Figure 38.

Table 14. AirBeam results for Champaign, IL.

\begin{tabular}{|l|r|r|r|r|r|}
\hline $\begin{array}{c}\text { Energy Consumption } \\
(\mathrm{kWh})\end{array}$ & Baseline & \multicolumn{1}{c|}{$\begin{array}{c}\text { Radiant } \\
\text { Barrier }\end{array}$} & \multicolumn{1}{c|}{$\begin{array}{c}\text { Thinsulate } \\
\text { Liner }\end{array}$} & \multicolumn{1}{c|}{ PCM Liner } & Shade Fly \\
\hline Heating & 11,017 & 2,914 & 178 & 2,253 & 10,800 \\
\hline Cooling & 11,681 & 12,442 & 13,681 & 12,589 & 10,611 \\
\hline Fans & 5,022 & 5,022 & 5,022 & 5,022 & 5,022 \\
\hline Total ECU & 27,719 & $20,377.8$ & 18,881 & 19,864 & 26,436 \\
\hline ECU Energy Saved & & $7,341.7$ & 8,839 & 7,856 & 1,283 \\
\hline ECU Percent Savings & & $26.5 \%$ & $31.9 \%$ & $28.3 \%$ & $4.6 \%$ \\
\hline
\end{tabular}


Table 15. AirBeam results for Fort Devens, MA.

\begin{tabular}{|l|r|r|r|r|r|}
\hline $\begin{array}{c}\text { Energy Consumption } \\
(\mathbf{k W h})\end{array}$ & Baseline & \multicolumn{1}{c|}{$\begin{array}{c}\text { Radiant } \\
\text { Barrier }\end{array}$} & \multicolumn{1}{c|}{$\begin{array}{c}\text { Thinsulate } \\
\text { Liner }\end{array}$} & PCM Liner & Shade Fly \\
\hline Heating & 13,511 & 3,211 & 142 & 2,425 & 13,381 \\
\hline Cooling & 7,094 & 8,306 & 9,778 & 8,519 & 6,133 \\
\hline Fans & 5,022 & 5,022 & 5,022 & 5,022 & 5,022 \\
\hline Total ECU & 25,631 & $16,538.9$ & 14,942 & 15,964 & 24,536 \\
\hline ECU Energy Saved & & $9,091.7$ & 10,689 & 9,667 & 1,094 \\
\hline ECU Percent Savings & & $35.5 \%$ & $41.7 \%$ & $37.7 \%$ & $4.3 \%$ \\
\hline
\end{tabular}

Table 16. AirBeam results for Ali Al Salem, Kuwait.

\begin{tabular}{|l|r|r|r|r|r|}
\hline $\begin{array}{c}\text { Energy Consumption } \\
(\mathrm{kWh})\end{array}$ & Baseline & \multicolumn{1}{|c|}{$\begin{array}{c}\text { Radiant } \\
\text { Barrier }\end{array}$} & \multicolumn{1}{|c|}{$\begin{array}{c}\text { Thinsulate } \\
\text { Liner }\end{array}$} & PCM Liner & Shade Fly \\
\hline Heating & 56 & - & - & - & 31 \\
\hline Cooling & 44,831 & 40,625 & 40,047 & 40,275 & 43,244 \\
\hline Fans & 5,022 & 5,022 & 5,022 & 5,022 & 5,022 \\
\hline Total ECU & 49,908 & $45,650.0$ & 45,069 & 45,297 & 48,297 \\
\hline ECU Energy Saved & & $4,258.3$ & 4,839 & 4,611 & 1,611 \\
\hline ECU Percent Savings & & $8.5 \%$ & $9.7 \%$ & $9.2 \%$ & $3.2 \%$ \\
\hline
\end{tabular}

Figure 34. Annual ECU energy consumption and savings for the AirBeam shelter.

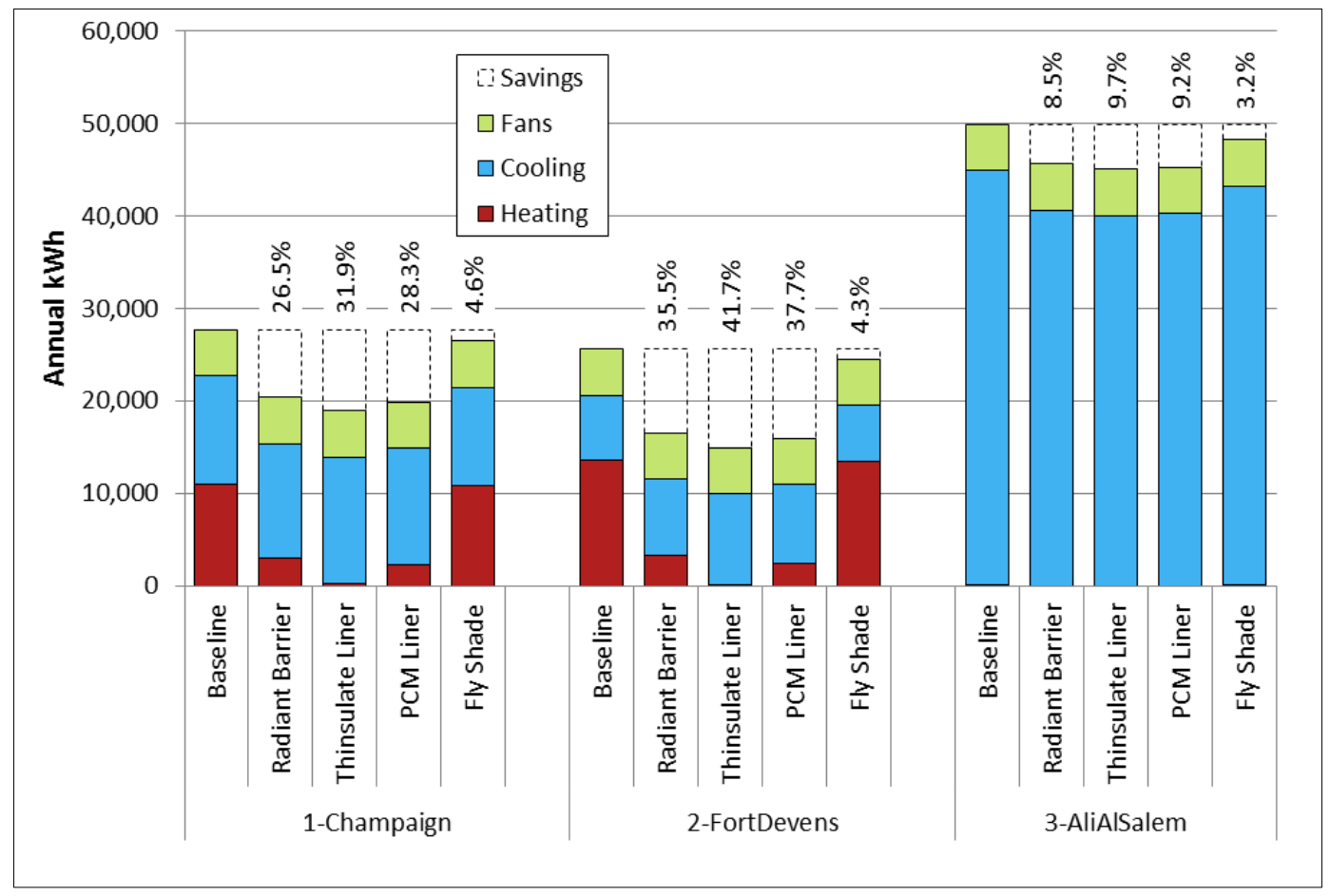


Figure 35. Monthly ECU energy performance for the AirBeam shelter in Champaign, IL for the baseline (left bar) and radiant barrier (right bar) cases.

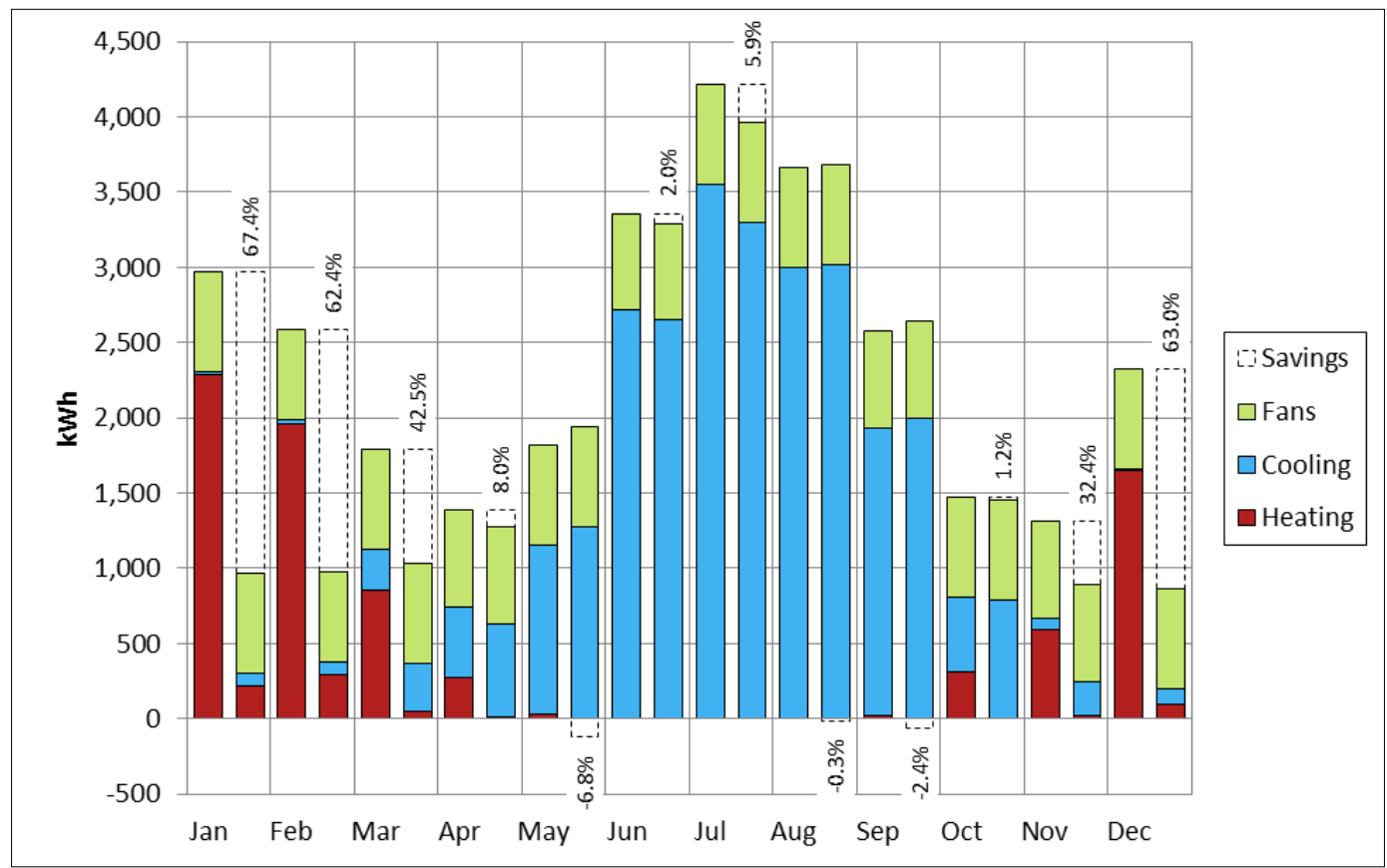

Figure 36. Monthly ECU energy performance for the AirBeam shelter in Champaign, IL for the baseline (left bar) and Thinsulate (right bar) liner cases.

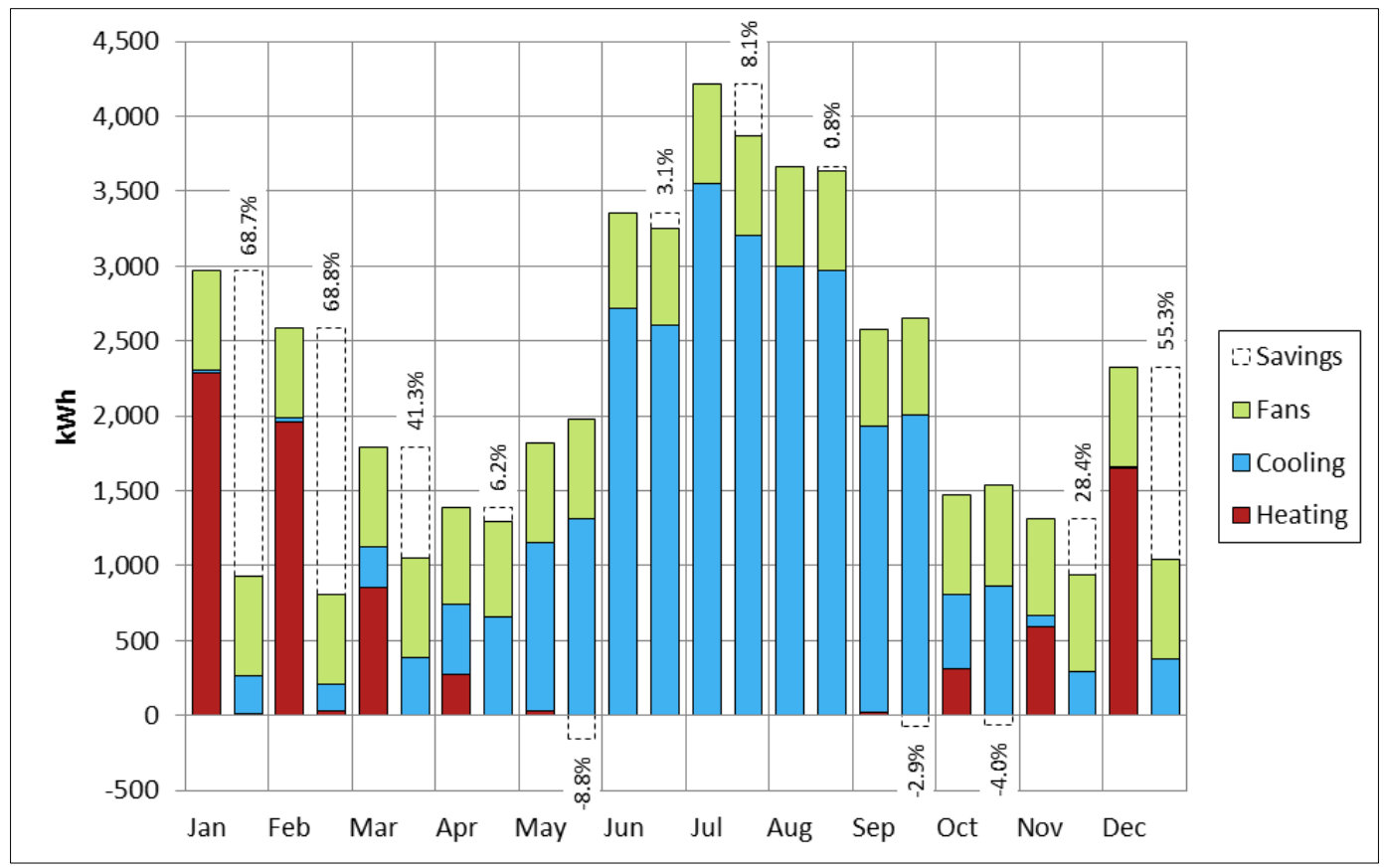


Figure 37. Monthly ECU energy performance for the AirBeam shelter in Champaign, IL for the baseline (left bar) and radiant barrier and Thinsulate liner (right bar) cases.

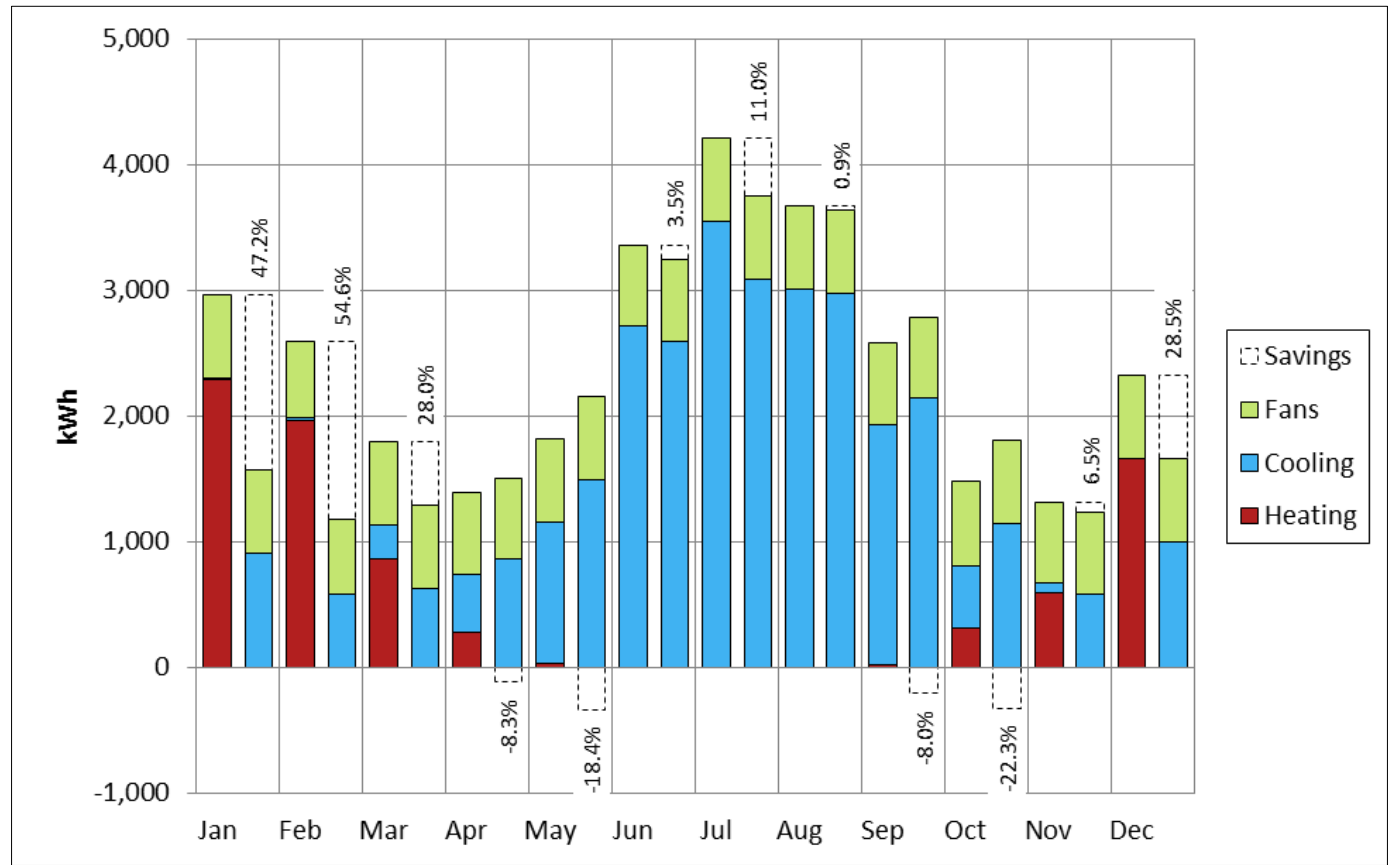

Figure 38. Monthly ECU energy performance for the AirBeam shelter for in Champaign, IL the baseline (left bar) and the shade fly (right bar) cases.

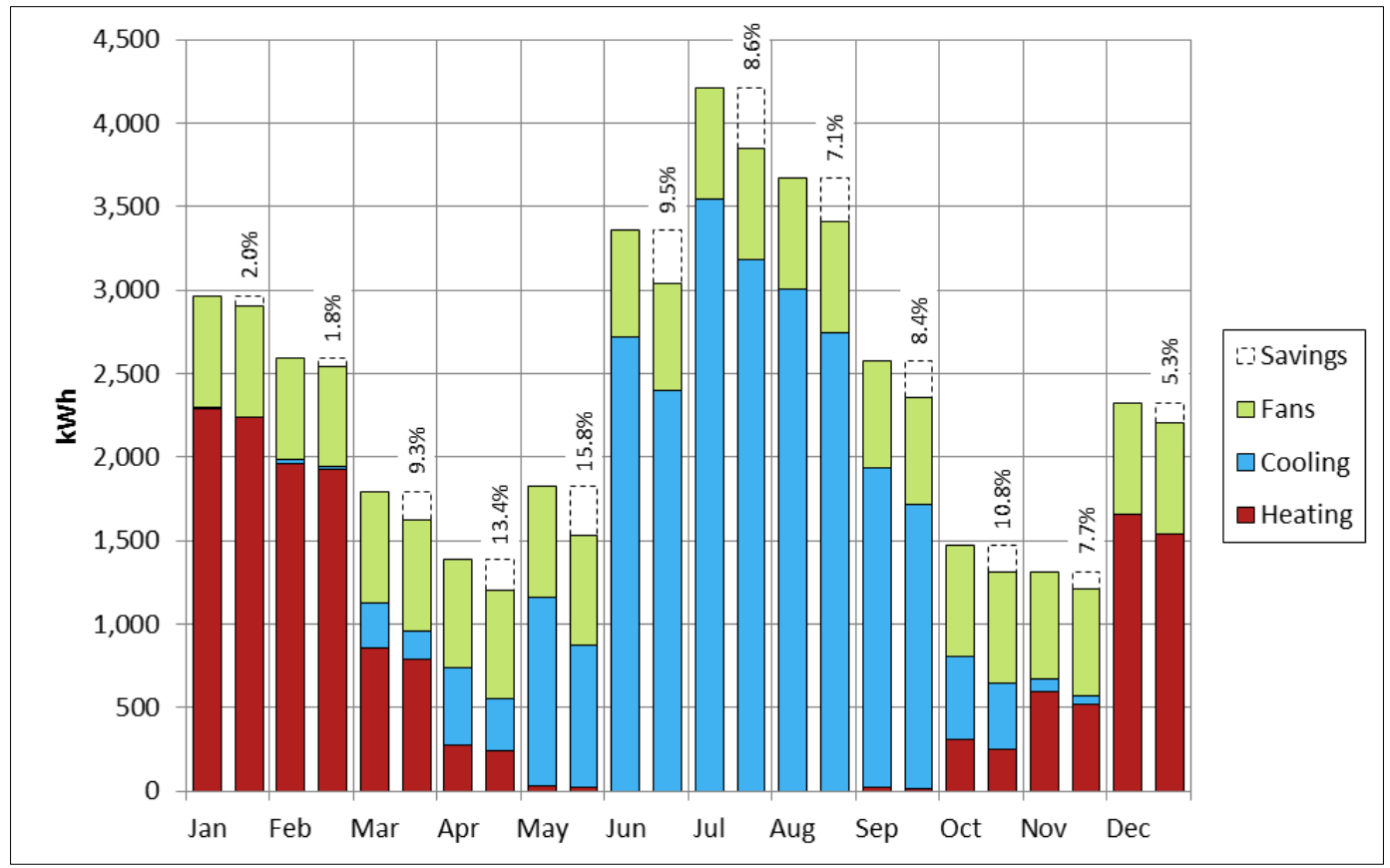

The Thinsulate liner provides the best performance in every climate. However, the radiant barrier and PCM liner provide similar savings. The mesh shade fly provided the smallest savings in all climates. We were not able to 
test the baseline shelter configuration with and without the shade fly, and therefore were not able to validate the model of the shade fly.

The mesh shade fly has multiple impacts on the shelter in that it blocks some of the incoming solar radiation, but it also creates a layer of warm air near the outer surface and blocks nighttime radiation exchange with the sky. During the cooling season, the shade fly blocks solar gain but it can also cause higher convective heat gains by trapping warm air near the surface and reduce heat loss on clear nights by blocking the long-wave radiation exchange. In the heating season, the shade fly reduces heat load by acting as another barrier to convective heat loss to the cold ambient air and partially blocks the long-wave radiation exchange with clear night skies, but it also blocks beneficial solar gains on sunny days. The optimal performance for the shade fly would be to only install it during cooling season and remove it during the heating season, but that scenario was not simulated in this project.

The monthly results for Champaign, IL show the variation in the impact from the different liners on the heating and cooling loads. The Thinsulate liner nearly eliminates the need for heating because most heating is provided by the internal loads. The cooling loads increase in every case except for the shade fly, which reduces the cooling load compared to the baseline.

It should be noted at this point that the results for a shelter used for sleeping quarters would differ greatly because the internal gains would be drastically reduced. The cooling loads would be much lower and the heating loads would be much higher. The savings of each of the liners and shade fly would be different as well. The Thinsulate liner with radiant barrier would probably be the best performer, but that is not certain without additional energy modeling or testing.

The performance results for the AirBeam with the PCM liner are shown in Table 17 and Figure 39 for the eight supplemental locations. The impact of the PCM liner on annual ECU energy consumption is similar to the Thinsulate liner (see Figure 34). The PCM liner slightly increases the cooling load in most climates but has a significant impact on heating energy. In this application, the PCM liner acts as an insulating layer; it absorbs the heat from the internal gains and slowly releases the energy to the air gap between the inner liner and the outer shell. The results for the PCM liner should be taken to be preliminary because the PCM model in EnergyPlus 
has not been rigorously validated at this point, and the PCM liner was not part of the field monitoring in this project.

Table 17. AirBeam ECU energy consumption.

\begin{tabular}{|l|r|r|r|r|r|r|r|r|}
\hline & 1A Miami & 2B Phoenix & 3B Los Angeles & 4B Albuquerque & 5B Denver & 6B Helena & 7 Duluth & 8 Fairbanks \\
\hline Baseline & 40,131 & 37,942 & 17,303 & 23,906 & 22,139 & 22,011 & 30,647 & 35,722 \\
\hline PCM Liner & 39,522 & 35,375 & 21,006 & 20,322 & 16,486 & 14,150 & 16,903 & 19,522 \\
\hline Savings & 608 & 2,567 & $-3,703$ & 3,583 & 5,653 & 7,861 & 13,744 & 16,200 \\
\hline \% Savings & $1.5 \%$ & $6.8 \%$ & $-21.4 \%$ & $15.0 \%$ & $25.5 \%$ & $35.7 \%$ & $44.8 \%$ & $45.3 \%$ \\
\hline
\end{tabular}

Figure 39. Annual ECU energy consumption and savings for the AirBeam shelter with the PCM liner.

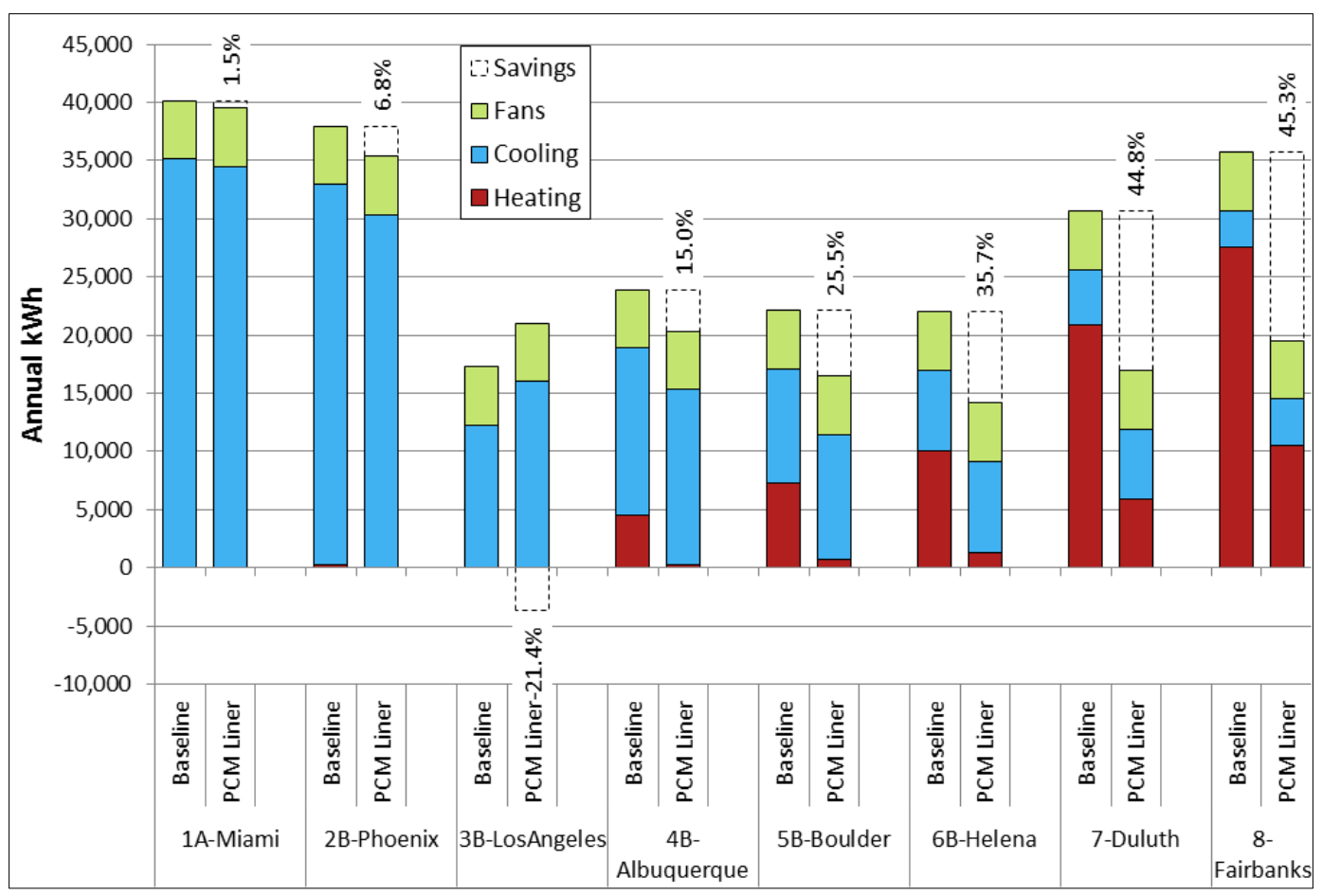

\subsubsection{Utilis}

The results of for the Utilis shelter with the alternative envelope configurations are presented in Table 18 through Table 20, and shown graphically in Figure 40. The radiant liner and the Thinsulate liner provide nearly the same annual energy performance for the two heating-dominated climates, but for slightly different reasons. The Thinsulate liner provides better reduction of the heating loads, but the radiant liner provides the best reduction in cooling loads. Combining the radiant barrier to the Thinsulate liner eliminates the heating load, but increases the cooling load and provides 
smaller savings. This occurs because it traps more of the internal gains thus requiring more cooling. The Thinsulate liner with radiant barrier is the highest performer in the very hot climate because it is the most effective at blocking the solar and conductive heat gains. The mesh shade fly provided the smallest savings in all climates except for Panama City, FL. The shade fly works well for the moderate climates but not for the extreme climates. The performance would probably be improved if it were only installed in the cooling months.

Table 18. Utilis results for Champaign, IL.

\begin{tabular}{|l|r|r|r|r|r|}
\hline $\begin{array}{c}\text { Energy Consumption } \\
(\mathrm{kWh})\end{array}$ & Baseline & \multicolumn{1}{c|}{$\begin{array}{c}\text { Radiant } \\
\text { Barrier }\end{array}$} & \multicolumn{1}{c|}{$\begin{array}{c}\text { Thinsulate } \\
\text { Liner }\end{array}$} & $\begin{array}{c}\text { Radiant \& } \\
\text { Thinsulate }\end{array}$ & Shade Fly \\
\hline Heating & 8,003 & 700 & 56 & - & 7,539 \\
\hline Cooling & 13,653 & 14,444 & 15,117 & 17,964 & 11,825 \\
\hline Fans & 7,825 & 7,825 & 7,825 & 7,825 & 7,825 \\
\hline Total ECU & 29,481 & $22,969.4$ & 22,997 & 25,792 & 27,192 \\
\hline ECU Energy Saved & & $6,511.1$ & 6,483 & 3,689 & 2,289 \\
\hline ECU Percent Savings & & $22.1 \%$ & $22.0 \%$ & $12.5 \%$ & $7.8 \%$ \\
\hline
\end{tabular}

Table 19. Utilis results for Fort Devens, MA.

\begin{tabular}{|l|r|r|r|r|r|}
\hline $\begin{array}{c}\text { Energy Consumption } \\
(\mathbf{k W h})\end{array}$ & Baseline & \multicolumn{1}{c|}{$\begin{array}{c}\text { Radiant } \\
\text { Barrier }\end{array}$} & \multicolumn{1}{|c|}{$\begin{array}{c}\text { Thinsulate } \\
\text { Liner }\end{array}$} & \multicolumn{1}{c|}{$\begin{array}{c}\text { Radiant \& } \\
\text { Thinsulate }\end{array}$} & Shade Fly \\
\hline Heating & 9,425 & 672 & 67 & - & 8,919 \\
\hline Cooling & 9,117 & 10,328 & 11,289 & 14,781 & 7,331 \\
\hline Fans & 7,825 & 7,825 & 7,825 & 7,825 & 7,825 \\
\hline Total ECU & 26,367 & $18,827.8$ & 19,183 & 22,608 & 24,078 \\
\hline ECU Energy Saved & & $7,538.9$ & 7,183 & 3,758 & 2,289 \\
\hline ECU Percent Savings & & $28.6 \%$ & $27.2 \%$ & $14.3 \%$ & $8.7 \%$ \\
\hline
\end{tabular}

Table 20. Utilis results for Ali Al Salem, Kuwait.

\begin{tabular}{|l|r|r|r|r|r|}
\hline $\begin{array}{c}\text { Energy Consumption } \\
(\mathrm{kWh})\end{array}$ & Baseline & \multicolumn{1}{|c|}{$\begin{array}{c}\text { Radiant } \\
\text { Barrier }\end{array}$} & $\begin{array}{c}\text { Thinsulate } \\
\text { Liner }\end{array}$ & $\begin{array}{c}\text { Radiant \& } \\
\text { Thinsulate }\end{array}$ & Shade Fly \\
\hline Heating & 42 & - & - & - & 17 \\
\hline Cooling & 48,128 & 43,361 & 42,128 & 40,836 & 45,264 \\
\hline Fans & 7,825 & 7,825 & 7,825 & 7,825 & 7,825 \\
\hline Total ECU & 55,997 & $51,186.1$ & 49,953 & 48,664 & 53,106 \\
\hline ECU Energy Saved & & $4,811.1$ & 6,044 & 7,333 & 2,892 \\
\hline ECU Percent Savings & & $8.6 \%$ & $10.8 \%$ & $13.1 \%$ & $5.2 \%$ \\
\hline
\end{tabular}


Figure 40. Annual ECU energy consumption and savings for the Utilis shelter.

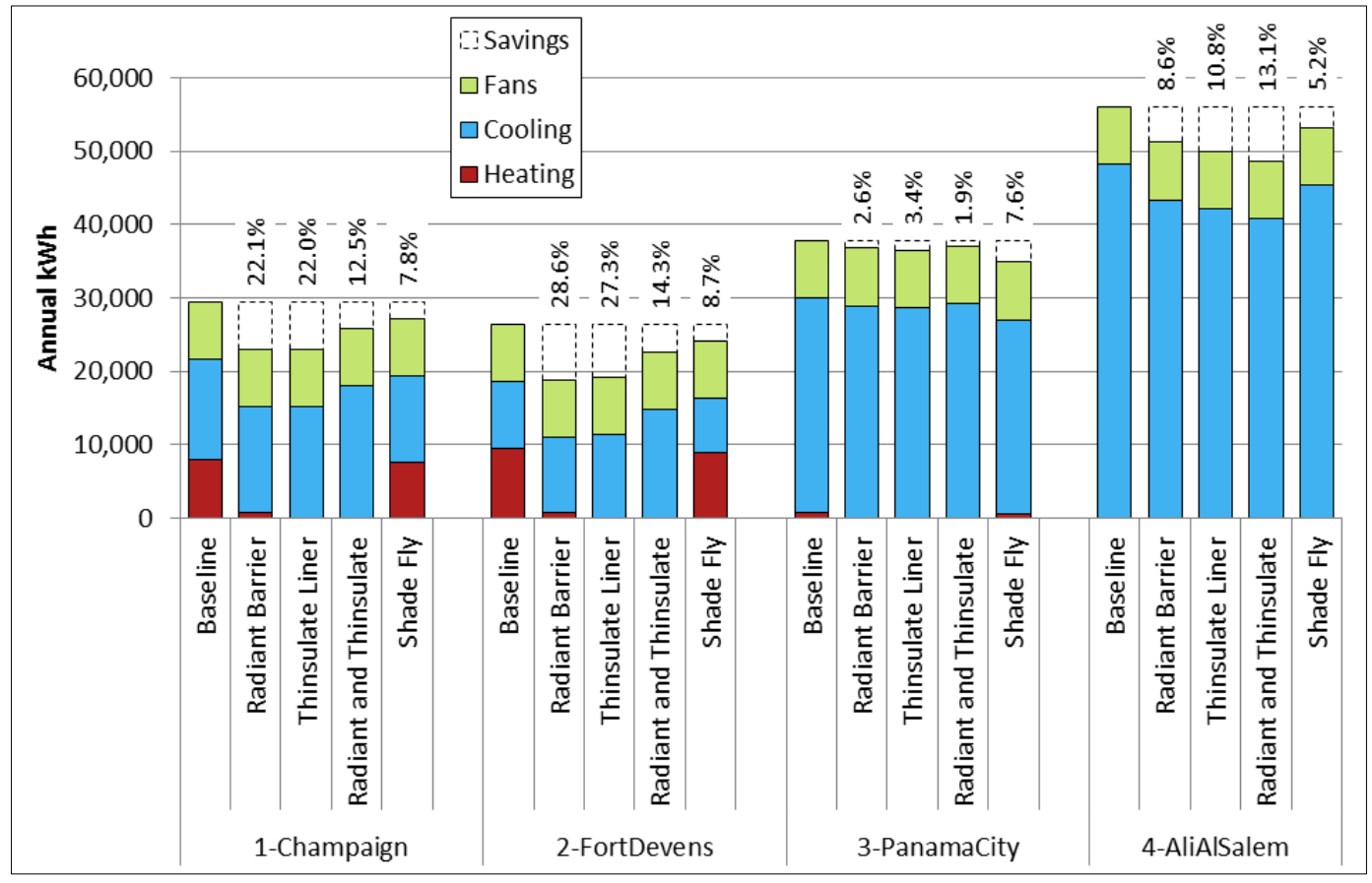




\section{Conclusions}

\subsection{Conclusions}

This project demonstrated that whole-building energy monitoring and modeling techniques can, with minor modifications, be used to develop calibrated simulation models of energy performance for soft-walled military shelters. Some uncertainties in the demonstrated models impose limitations on their applicability, but the usefulness of these calibrated energy models has been demonstrated for purposes of showing the relative energy performance of different shelter configurations, operations, and locations.

The results of the energy modeling show that for a command operations type of shelter with very high internal loads, the radiant barrier or the Thinsulate liner alone provide the best performance in cold climates; and the Thinsulate liner with the radiant barrier provides the best performance in the hot climates. The shade fly provided the least energy savings in all climate simulations except for Panama City, FL, where it provided the highest savings. The results would probably be improved if the shade fly were installed only during hot months and removed for the cooler months.

The simulations predict that the phase-change material (PCM) liner will provide significant savings in the cold climates, although not as much as the Thinsulate liner. The results for the PCM liner should be considered preliminary because we did not take field measurements of the liner's performance, and at this point there has been very little validation of the PCM model in EnergyPlus.

The results presented in this report are highly dependent on the assumptions for shelter operation, including the internal loads, and how tightly the shelter is sealed against infiltration. The results depend greatly on the use of natural ventilation instead of ECU cooling when it is advantageous. Actual results in the field may differ significantly based on the actual shelter operation, ECU performance, and local weather conditions. However, we are confident in the relative performance and the trends shown in the simulation results for the different shelter configurations. 


\subsection{Recommendations}

It is recommended that a tactical soft wall shelter energy "virtual test bed" be developed for DoD soft wall shelters with Energy Plus modeling, simulation and validation to reduce the number of field evaluation tests, since a validated model can predict the shelter performance with various linings (with known properties) in all climate zones to mitigate energy losses.

New shelter linings and shelter designs based on simulation results from this study will be transitioned through the "Sustainability Logistics Basing (SLB-STO-D) Demonstrations and through the Product Manager Force Sustainment System- Program Executive Office "Combat Support \& Combat Service Support" as well as through the Air Force Basic Expeditionary Airfield Resources (BEAR) Program. 


\section{References}

Phase Change Energy Solutions. (2013). BioPCM web page, http:// phasechange.com/index.php/en/about/ our-material. Accessed 16 September 2014.

3M. (n.d.). Extreme 250 Insulating Fabrics Specification Sheet. BONDCOTE Performance Engineered Coated Fabrics.

DOE. (2014a). EnergyPlus Energy Simulation Software Version 8.0. Washington DC: U.S. Department of Energy. www.eere.gov/ buildings/ energyplus. last accessed September 2014.

DOE. (2014b). EnergyPlus Input/ Output Reference. Washington D.C.: U.S. Department of Energy. www.eere.gov/ buildings/ energyplus.

DRS. (2014). Florence, KY: DRS Technologies. www.drs.com.

Hartranft, T.J . (2008). “Sustainable Energy for Deployed Military Bases.” In Proceedings of ES2008 (p 6). J acksonville, FL: ASME.

HDT. (2010). AirBeam 2032 shelter specification sheet. Solon, OH: HDT Global. http:// www.hdtglobal.com/.

Herrmann, L.; Deru, M. (2013). Energy Modeling of Soft-Sided Command Operations Center Shelter Using EnergyPlus. NREL Internal report. J anuary 3, 2014.

Ukponmwan, J .O. (2009). The Thermal-insulation Properties of Fabrics. Textile Progress, 24:4, 1-54.

Utilis. (2014). Fort Walton Beach, FL: Utilis USA. http:// www.utilisusa.com/.

Zaki, G.M., Al-Turki, A., and Fatani, A. (1993). Experimental Investigation on Free Convection Insidea Tent Envelope of Textile Fabric. Energy and Buildings, pp 291- 296. 


\section{Acronyms and Abbreviations}

$\begin{array}{ll}\text { Term } & \text { Definition } \\ \text { ACH } & \text { air changes per hour } \\ \text { CERL } & \text { Construction Engineering Research Laboratory } \\ \text { DB } & \text { dry bulb } \\ \text { DoE } & \text { U.S. Department of Energy } \\ \text { DoD } & \text { U.S. Department of Defense } \\ \text { ECU } & \text { Environmental Control Unit } \\ \text { EFOB-L } & \text { ERDC-CERL Forward Operating Base Laboratory } \\ \text { ELA } & \text { equivalent leakage areas } \\ \text { EMS } & \text { Energy Management System } \\ \text { ERDC } & \text { Engineer Research and Development Center } \\ \text { ERDC-CERL } & \text { Engineer Research and Development Center, Construction } \\ & \text { Engineering Research Laboratory } \\ \text { HFT } & \text { heat flux transducer } \\ \text { IECU } & \text { Improved Environmental Control Unit } \\ \text { JP8 } & \text { Jet Propulsion 8 } \\ \text { MEP } & \text { Mountain Energy Partnership } \\ \text { NREL } & \text { National Renewable Energy Laboratory } \\ \text { OECIF } & \text { Operational Energy Capital Improvement Fund } \\ \text { ORNL } & \text { Oak Ridge National Laboratory } \\ \text { PCM } & \text { phase change material } \\ \text { PTAC } & \text { Packaged Terminal Air Conditioner } \\ \text { RMS } & \text { root mean square }\end{array}$




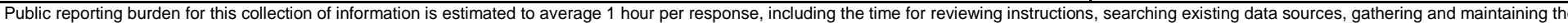

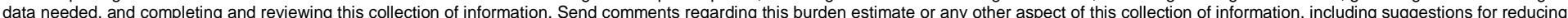

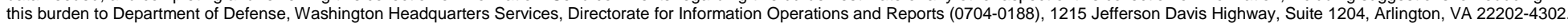

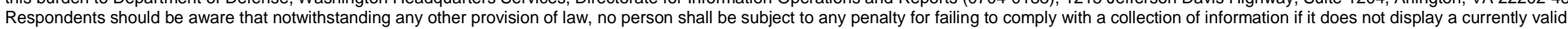
OMB control number. PLEASE DO NOT RETURN YOUR FORM TO THE ABOVE ADDRESS.
1. REPORT DATE (DD-MM-YYYY) July 2015

4. TITLE AND SUBTITLE

Energy Performance Measurement and Simulation Modeling of Tactical Soft-Wall Shelters

Michael Deru, Eric Bonnema, Greg Barker, Ed Hancock and Ashok Kumar

\section{DATES COVERED (From - To)}

5a. CONTRACT NUMBER

5b. GRANT NUMBER

5c. PROGRAM ELEMENT NUMBER

PE 0604055D8Z

5d. PROJECT NUMBER

P2 5D390F

5e. TASK NUMBER

5f. WORK UNIT NUMBER

8. PERFORMING ORGANIZATION REPORT NUMBER

ERDC/CERL TR-15-13

Construction Engineering Research Laboratory

P.O. Box 9005

Champaign, IL 61826-9005

\section{SPONSORING I MONITORING AGENCY NAME(S) AND ADDRESS(ES)}

Office of the Assistant Secretary of Defense

3700 Defense Pentagon

Washington, DC 20301-3700

\section{DISTRIBUTION / AVAILABILITY STATEMENT}

Approved for public release; distribution is unlimited.

\section{SUPPLEMENTARY NOTES}

\section{ABSTRACT}

Two soft-wall tactical shelters, Airbeam Series 32 and Utilis TM 60, were set up at an outdoor test facility in Champaign, IL. Each was instrumented to record energy-loss measurements during a heating and cooling season, and a standard tracer-gas technique was used to measure infiltration. These data, and thermal load assumptions for a command-operations shelter, were used as inputs to develop and calibrate shelter simulation models using the Department of Energy's EnergyPlus modeling platform. Simulations were run to validate the calibrated models, and then a series of other simulations was run using climate data from eight U.S. climate zones and a locale in Kuwait. These simulations included the application of energy-conservation accessories such as shade flies and radiant heat barriers materials.

Simulation results indicate that using either type of radiant barrier provided the best performance in cold climates; and the combination of both barriers provided the best performance in the hot climates. The shade fly provided the least savings in all simulated climates except for Panama City, FL, where it provided the highest savings. With limitations explained in the report, the models provide a useful technology for identifying energy performance trends and making comparisons between the two modeled shelters.

\section{SUBJECT TERMS}

simulation modeling, energy conservation, soft-wall tactical shelters, performance testing, thermal management, EnergyPlus

\begin{tabular}{|c|c|c|c|c|c|}
\hline \multicolumn{3}{|c|}{ 16. SECURITY CLASSIFICATION OF: } & \multirow{2}{*}{$\begin{array}{l}\text { 17. LIMITATION } \\
\text { OF ABSTRACT }\end{array}$} & \multirow{2}{*}{$\begin{array}{l}\text { 18. NUMBER } \\
\text { OF PAGES }\end{array}$} & \multirow{2}{*}{$\begin{array}{l}\text { 19a. NAME OF RESPONSIBLE PERSON } \\
\begin{array}{l}\text { 19b. TELEPHONE NUMBER } \\
\text { (include area code) }\end{array}\end{array}$} \\
\hline $\begin{array}{l}\text { a. REPORT } \\
\text { Unclassified }\end{array}$ & $\begin{array}{l}\text { b. ABSTRACT } \\
\text { Unclassified }\end{array}$ & $\begin{array}{l}\text { c. THIS PAGE } \\
\text { Unclassified }\end{array}$ & & & \\
\hline
\end{tabular}

